\author{
WALDEN \\ UNIVERSITY \\ A higher degree. A higher purpose.
}

Walden University ScholarWorks

Walden Dissertations and Doctoral Studies

2015

\title{
Challenges of a Novice Nurse Educator's Transition From Practice to Classroom
}

Tori Brown

Walden University

Follow this and additional works at: https://scholarworks.waldenu.edu/dissertations

Part of the Higher Education Administration Commons, Higher Education and Teaching Commons, and the Nursing Commons

This Dissertation is brought to you for free and open access by the Walden Dissertations and Doctoral Studies Collection at ScholarWorks. It has been accepted for inclusion in Walden Dissertations and Doctoral Studies by an authorized administrator of ScholarWorks. For more information, please contact ScholarWorks@waldenu.edu. 


\title{
Walden University
}

\author{
COLLEGE OF EDUCATION
}

This is to certify that the doctoral study by

\section{Tori Brown}

has been found to be complete and satisfactory in all respects, and that any and all revisions required by the review committee have been made.

Review Committee

Dr. Jean Sorrell, Committee Chairperson, Education Faculty

Dr. Sheilia Goodwin, Committee Member, Education Faculty Dr. Bonita Wilcox, University Reviewer, Education Faculty

\section{Chief Academic Officer}

Eric Riedel, Ph.D.

Walden University

2015 


\begin{abstract}
Challenges of a Novice Nurse Educator's Transition From Practice to Classroom by
\end{abstract}

Tori Brown

MSN, Winston Salem State University, 2010

BSN, Winston Salem State University, 2006

Doctoral Study Submitted in Partial Fulfillment

of the Requirements for the Degree of

Doctor of Education

Walden University

May 2015 


\begin{abstract}
This project study addressed the lack of formal preparation encountered by novice nurse educators within a nursing program located in the southeastern region of North Carolina. This problem is significant at both the local and national levels because expert clinicians are needed to fill nurse educator vacancies that have led to qualified students being denied admission to nursing programs. A qualitative case study research design was employed to explore the perceptions of novice nurse educators in one nursing program transitioning from clinical nursing practice to the nurse educator role. The theoretical framework to guide this study was Benner's novice to expert model that outlines the journey of how novice nurse educators transition into an educator role. Guiding research questions focused on understanding the motives, challenges, positives experiences, and perceptions of support that novice nurse educators encountered during transition from clinical practice to academia. Purposeful sampling was used to recruit 7 novice nurse educators within an associate degree nursing program. Data collection included interviews with novice nurse educators, review of a 2012 self-study report, and demographic characteristics of participants. Interviews were transcribed verbatim, coded, and analyzed to identify themes. Five themes were identified: (a) work is always with you, (b) teaching in the dark, (c) making a difference, (d) a shoulder to lean on, and (e) more structure/mentoring. Findings indicated the need for a mentorship/orientation program, which was developed to assist in role transition for novice nurse educators. Implications could contribute to a positive social change by helping clinicians to transition effectively to meet society's need for qualified nurse educators.
\end{abstract}


Challenges of a Novice Nurse Educator's Transition From Practice to Classroom by

Tori Brown

MSN, Winston Salem State University, 2010

BSN, Winston Salem State University, 2006

Doctoral Study Submitted in Partial Fulfillment

of the Requirements for the Degree of

Doctor of Education

Walden University

May 2015 


\section{Acknowledgments}

First, I would like to give all the glory and honor to God the Almighty.

Throughout this journey, He has given me the strength to persevere even when I didn't think I could do it.

To my wonderful, loving husband, Kenneth Brown Jr., I would like to say thank you for your continuous love and support that you gave me during this journey. With you by my side, I was able to achieve an important educational goal of my life. I thank you for your encouragement, understanding, and love as we journeyed this unique life experience together.

To my wonderful, dedicated, and supportive committee chair members, Dr. Jean Sorrell (chair), Dr. Sheilia Goodwin (second chair), and Dr. Bonita Wilcox (university research reviewer). Your expertise and support helped guide me in earning this doctoral degree. I want to specially thank Dr. Sorrell. Words cannot express how thankful I am for you. Your words of encouragement helped me strive and push forward during challenging and trying times. Your dedication in helping others succeed is admirable. You have impacted my life tremendously. It is my wish that I grow into an educator and mimic your qualities someday.

I want to give a special acknowledgement to the "Three Musketeers" (Jennifer Buffenbarger, Cathy Daniels, and myself). You two ladies welcomed me with open arms when I entered into your group. Your supportive words motivated me to push forward and strive for my best. We developed a sisterhood that cannot be broken, I will never forget you two. 
Last but not least, I want to give a special acknowledgement to Dr. Dennis Sherrod. You have been my mentor since 2008. Throughout my MSN and EdD programs, your advice has been immensely valued. I will be forever thankful. 
Table of Contents

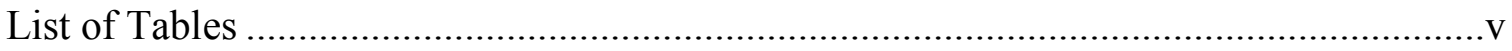

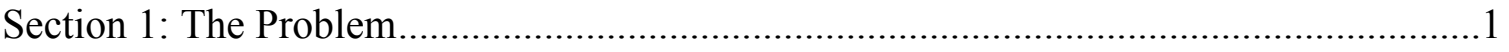

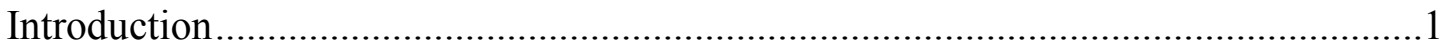

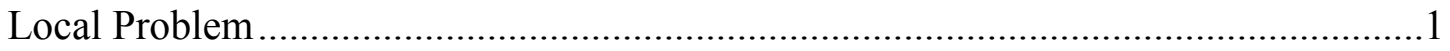

Evidence of the Problem at the Local Level ............................................................ 3

Evidence of the Problem From Professional Literature...................................... 8

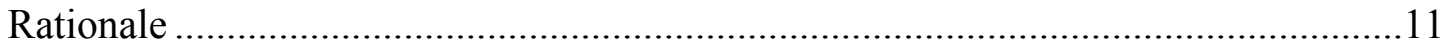

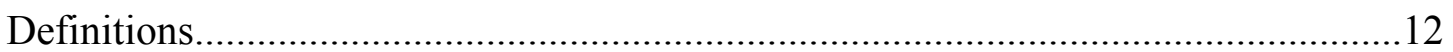

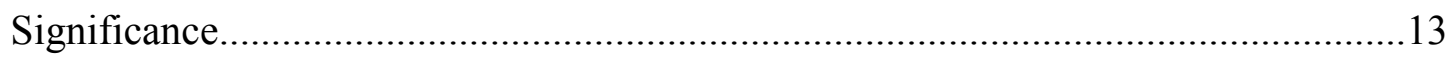

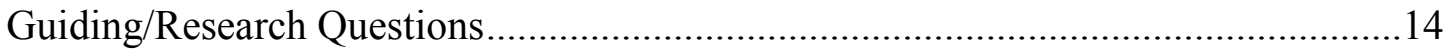

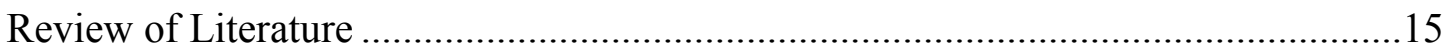

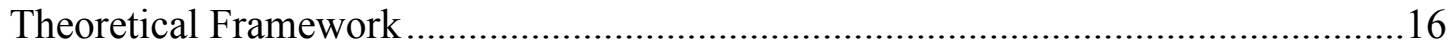

Factors That Contribute to Novice Educators' Challenges............................... 20

Differences Between the Clinical and Academic Environments ........................ 22

Mentorship for Novice Nurse Educators ......................................................... 24

Resources Needed by Novice Nurse Educators............................................. 27

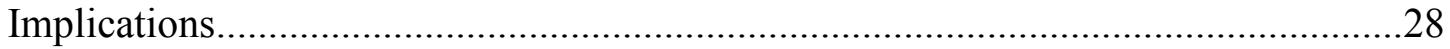

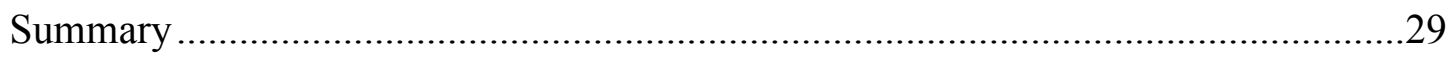

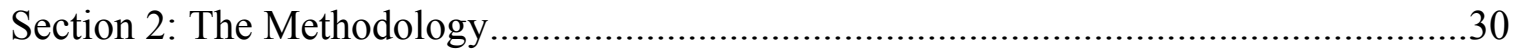

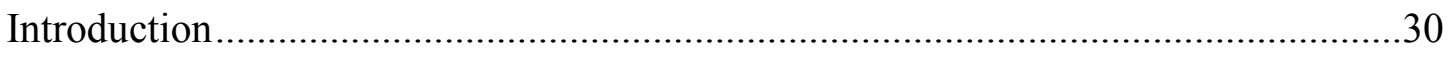

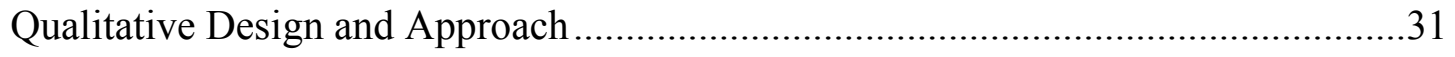


Description of Qualitative Research Design...................................................... 31

Justification of Research Design....................................................................... 32

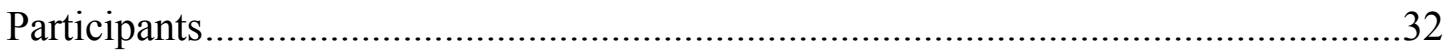

Criteria, Justification, and Gaining Access to Participants................................... 32

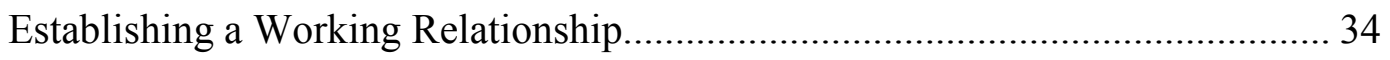

Ethical Considerations and Protection ............................................................... 34

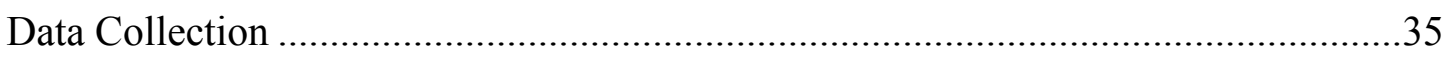

Types of Data Collected and Justification ......................................................... 35

Process and Plan of Data Collection and Recording/Gaining Access to

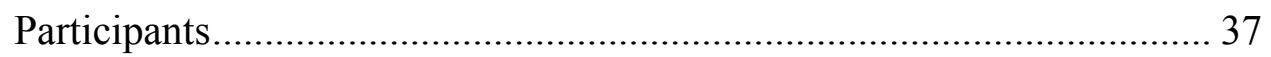

System for Keeping Track of Data ................................................................... 39

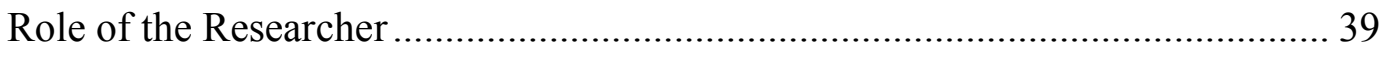

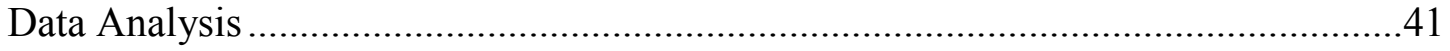

How Data Were Analyzed and Coded ................................................................ 41

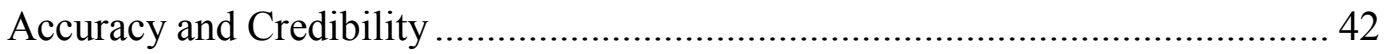

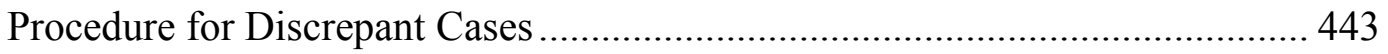

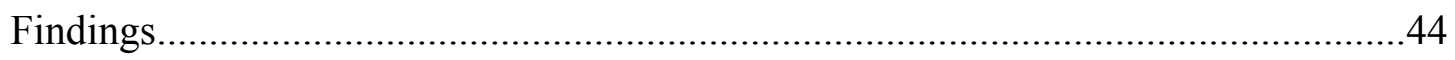

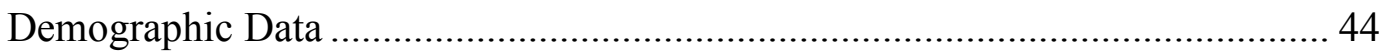

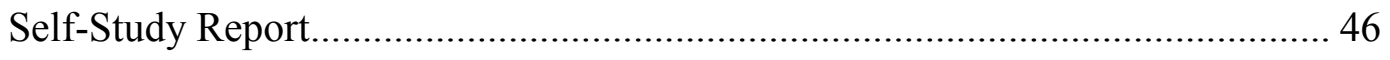

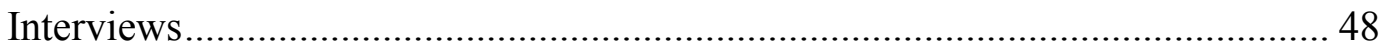

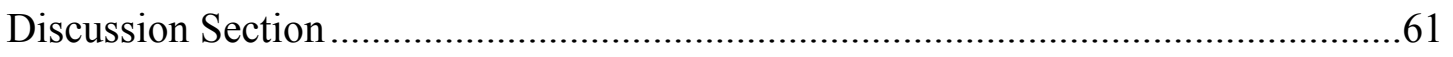

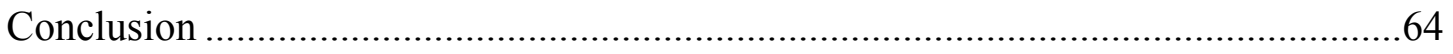




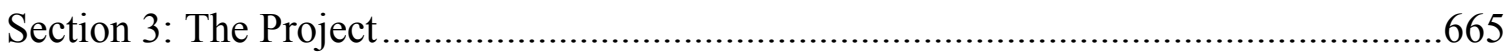

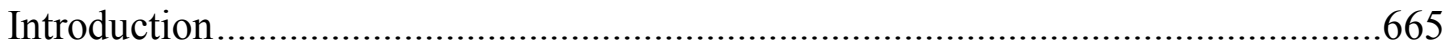

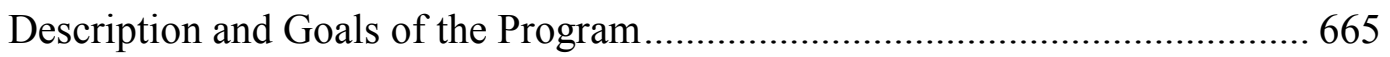

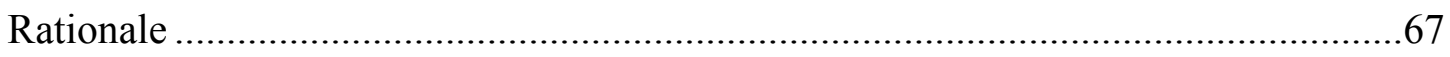

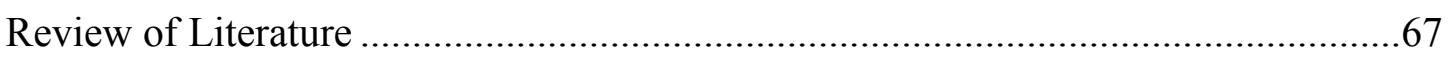

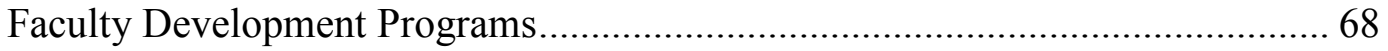

Components of a Mentorship/Orientation Program.............................................. 71

Layout of Mentorship/Orientation Programs....................................................... 73

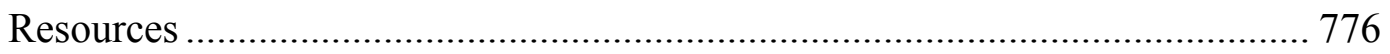

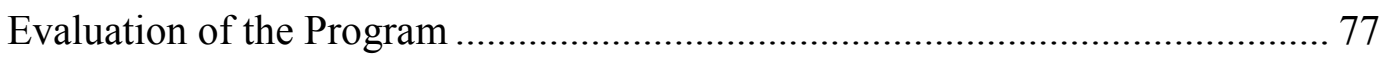

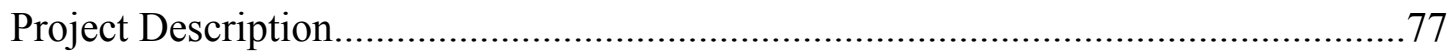

Purpose

Resources and Existing Supports................................................................... 79

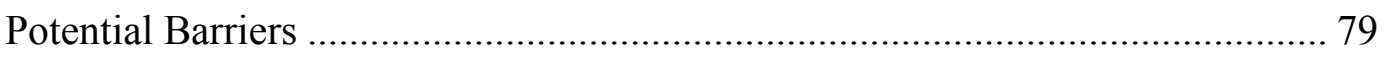

Proposal Implementation and Timetable ......................................................... 80

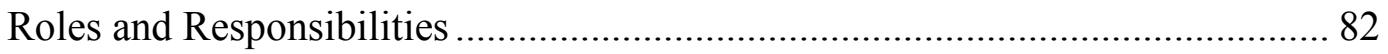

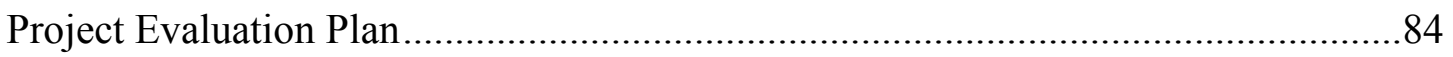

Project Implication and Potential Social Change......................................................887

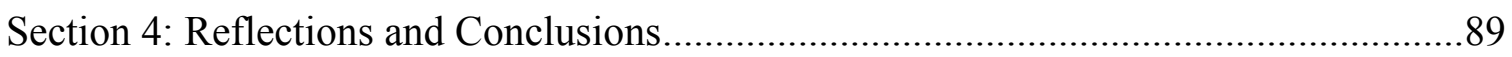

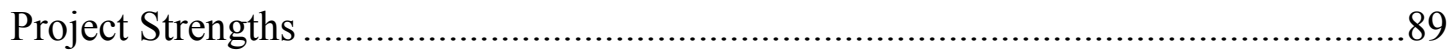

Project Weaknesses and Alternate Recommendations ……………….......................90

Scholarship, Project Development, and Leadership and Change .................................91 
Scholar, Practitioner, and Project Developer ...........................................................92

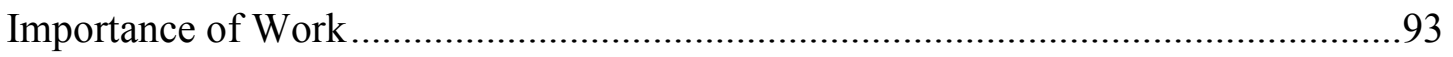

Implications, Applications, and Directions for Future Research .................................94

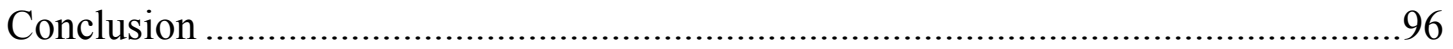

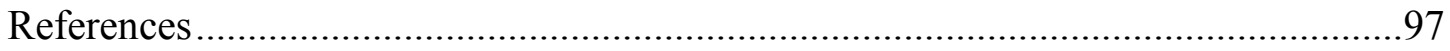

Appendix A:The Mentorship/Orientation Program for ADN Nursing Faculty...............109

Mentorship/Orientation Program Timeline.............................................................110

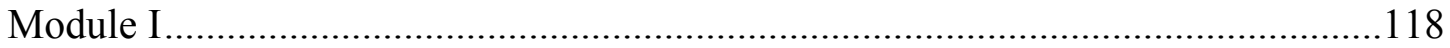

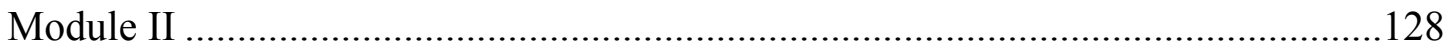

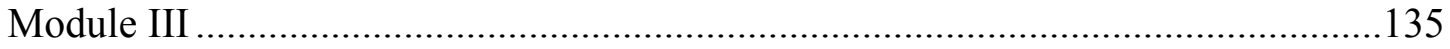

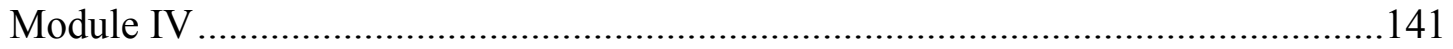

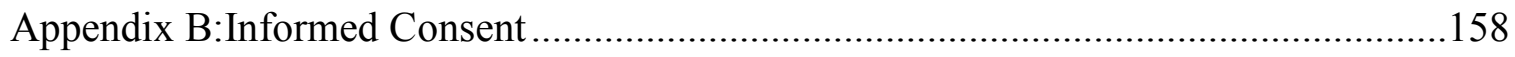

Appendix C:Demographic Sheet for Participants .........................................................1600

Appendix D: Permission to Gain Access to Participants...................................................162

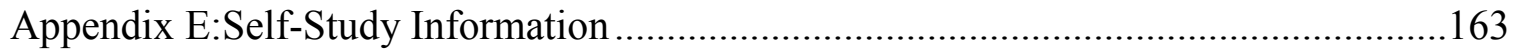

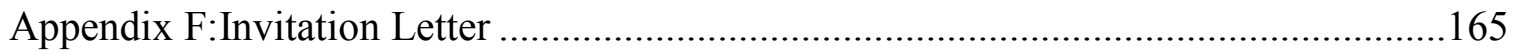

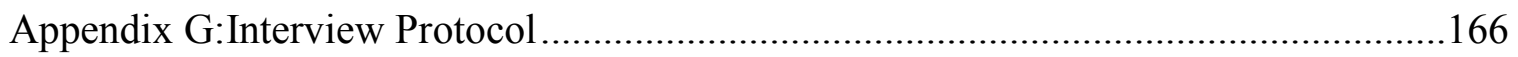

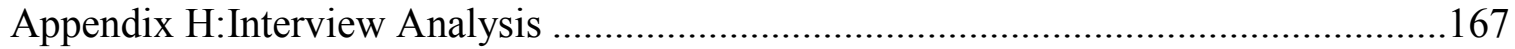

Appendix I:Research Site IRB Approval................................................................170

Appendix J:National Institute of Health Certificate of Completion ..................................171 


\section{List of Tables}

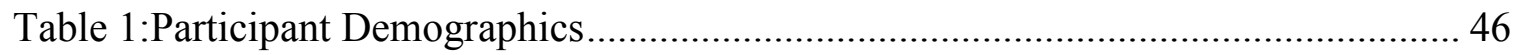

Table 2:Mentorship/Orientation Program Timetable................................................. 82

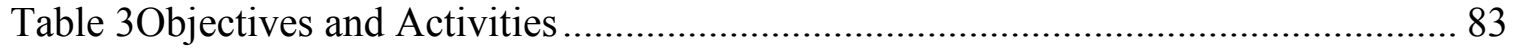

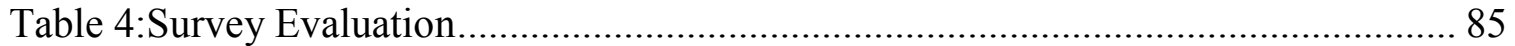

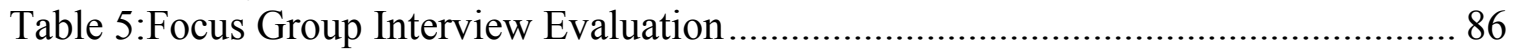


Section 1: The Problem

\section{Introduction}

The growing demands of society have led to an increase in college enrollment. However, the influx of students enrolling in nursing programs has created a nursing faculty shortage (Billings \& Halstead, 2009). This has created a problem of students being denied admission in one associate degree nursing program at a suburban community college nursing program located in the southeastern region of North Carolina. With the increased need of healthcare services, many students are seeking entry into nursing programs. However, student denial into nursing programs is a result of not having an adequate number of faculty members available to teach them. In this section, I provide evidence of the problem at a local and professional level, commonly used definitions, review of literature, theoretical framework, and implications for a possible project direction.

\section{Local Problem}

The southeastern community college that serves as the local setting for this project study was founded in 1958. Today, this college has become one of the largest technical colleges in the southeastern region, offering 93 degree programs, 26 diplomas, and 78 certificates in a variety of disciplines. One of the largest degree programs this community college offers is nursing. After completion of the nursing program, students earn an Associate Degree of Nursing (ADN). Acceptance into the ADN program is contingent upon several factors including acceptable scores/grades on the Scholastic Assessment Test and American College Tests (SAT/ACT), all science based courses, the 
Test of Essential Academic Skills (TEAS), attendance at an information session, and documentation of being a certified nursing assistant (CNA; L.A.S., personal communication, January 23, 2014). The curriculum at this North Carolina community college focuses on health promotion, disease prevention, and providing care to the community. While the faculty focus on educating the students on critical content, they also help learners form positive relationships with community agencies, hospitals, and other health care providers that align with the mission statement. The role of being a nurse educator is complex. Therefore, the novice educators who join the faculty for this nursing program have encountered many challenges due to the lack of formal preparation.

After graduating from nursing school, nurses gain clinical preparation as clinicians through experience. Many nurses who accept an educator position have expert clinical experience; however, as Schoening (2013) stated, these clinicians struggle with becoming acclimated to the academic setting and skills that are parallel to the educator role. Although these nurses are considered expert nurse clinicians, obtaining a new role as an educator makes them a novice nurse educator. A nurse educator requires a different set of skills than a registered nurse acquires. Therefore, it is imperative that novice nurse educators are equipped with the proper training in order to meet the high demands of the nurse educator role (Jacobson \& Sherrod, 2012).

Within this local research setting, lack of preparedness has posed the biggest challenge among the novice nurse educators. Specifically, the challenges that are commonly seen within this nursing program are managing the classroom, learning 
policies and procedures, applying a wide range of teaching approaches, and engaging students (L.A.S., personal communication, September 20, 2013). As Brady (2007) and Anderson (2009) stated, the factors contributing to the challenges of novice educators are multifaceted in nature. The diversity of ages, cultures, and life experiences among the students in this nursing program also has caused an increase in expectations for educators. Varying student populations enroll into this particular nursing program and they present with different educational learning styles. Skiba, Connors, and Jeffries (2008) described two distinct populations of students: nontraditional learners and the "digital natives, or millennials" (p. 226). These two groups differ in learning styles and educational demands. Creating a classroom to accommodate and mesh each learning style is difficult for novice nurse educators at this local research setting because of the lack of proper educational preparation.

\section{Evidence of the Problem at the Local Level}

In North Carolina, there are 64 nursing programs, representing different credentialing entry levels in the nursing profession, such as diploma (18-32 month program), associate's degree (ADN; 2-year program), and bachelor's degree (BSN; 4year program). Each of the three nursing program entries requires students to pass the National Council Licensure Examination (NCLEX) in order to practice as a registered nurse. According to the nursing program coordinator at the local research setting, there is a deficit of full time faculty (L.A.S., personal communication, January 23, 2014). Currently, $60 \%$ of the faculty members are full time, while the other $40 \%$ are part time employees. There are two full time unfilled positions available for this particular nursing 
program at this present time. However, there have not been any qualified applicants to apply for the available positions. The chair of the nursing program stated that the requirements for teaching have created challenges in filling those positions (K.P., personal communication, March 19, 2014). Faculty vacancies affect primarily the full time educators because they often are required to acquire additional workload assignments in order to meet the teaching needs for all students. Within the last 3 years, only three full time nurse educators have been hired. Over half of the full time faculty members are exceeding the student contact hours, which is 18 to 21 hours/week. Currently, 202 students are enrolled into the nursing program. There are two full and three part time male instructors and 18 full and 15 part time female instructors. The youngest full time educator is 27 years old, while the oldest full time educator is 62 years old. Additionally, the youngest part time instructor is 26 years old and the oldest part time nursing instructor is 64 years old. The median age of the nurse educators employed at this local research setting is around 50 years old.

The extreme workload these nurse educators face limits their ability to address student needs or to assist other faculty members with tasks. In addition to preparing lectures and tests, faculty members are also required to teach in the clinical setting, provide academic advisement for students, and participate in professional development activities. Brady (2007) stated that ADN nurse educators face a greater teaching workload because they are not required to perform research or publish literature. Usually the student to educator ratio for class is 20:1 but can fluctuate (L.A.S., personal communication, January 23, 2014). Clinical groups can range from six to eight students 
per educator; however, the North Carolina Board of Nursing says a clinic instructor can have up to 10 students per group (L.A.S., personal communication, January 23, 2014). As the students advance in their clinic courses, their patient loads increase as well. Therefore, if a clinic instructor has six to eight students and each student has responsibility for two patients, ultimately the instructor is responsible for 12 to 16 patients, in addition to the students. Each nurse educator at this local setting can advise up to eight students for academic guidance (L.A.S., personal communication, January, 23, 2014). In 2010-2011, there were 17 male students, 93 female students, including three Asian students, 23 African American/Black students, two Hispanic students, and 76 Caucasian students. The ages of each student ranged from early 20 s to 50 to 60 years old (Match College, 2014).

This nursing school has faced a decline in scores on the National Council Licensure Examination for Registered Nurses-RN (NCLEX-RN). This may be related to the persistent shortage of nursing faculty. NCLEX-RN is a required comprehensive exam that all nursing students must pass in order to practice as a registered nurse. During the past 3 years, the average NCLEX-RN score for this nursing program was $88 \%$. However, in May of 2013, the average passing score was 74\% for first time test takers (L.A.S., personal communication, January 23,2014$)$. The $14 \%$ decline could be a result of the recently hired educators or the workload fatigue experienced by the educators. According to North Carolina's Board of Nursing (2013), the overall NCLEX-RN scores for the state was $87 \%$ for first time test takers. 
Challenges in filling both full and part time nursing faculty positions have been a struggle. As a result, many of the North Carolina nursing programs have not accepted all students who have satisfied the admission requirements. According to AACN (2014), financial restraints and adequate clinical availability are the primary reasons for denying acceptance of qualified students. In an interview with the nursing program coordinator at the local setting, budget cuts by the state was the primary factor in many decisions made within their nursing program (L.A.S., personal communication, January 23, 2014). More than 5,400 students were denied acceptance in North Carolina nursing programs due to the lack of adequate classroom space and the necessary number of nurse educators to accommodate the influx in student enrollment (North Carolina Nursing Workforce Report, 2007). Additionally, the AACN stated that in 2005-2006, students seeking enrollment into an entry level nursing program increased by $13 \%$. This dramatic increase resulted in 40,000 qualified students being denied acceptance (Dunham-Taylor, Lynn, Moore, McDaniel, \& Walker, 2008). The lack of qualified nurse educators impacts the future of potential healthcare providers.

Without the necessary number of nurse educators, nursing programs will continue to place limitations upon student acceptance, consequently adding to the local healthcare issue. In the local research setting, there is a day and evening/weekend program designed to fit the needs of adult learners. The admissions department receives thousands of applications from students seeking entry into the nursing program. Annually, 70 to 80 students are accepted into the day program, while 50 students gain entry into the evening program (L.A.S., personal communication, January 23, 2014). Typically, after all the 
seats are filled, there are still 20 to 25 students, equaling $35 \%$, who are placed on the alternative list. These students do not have a guaranteed seat in the nursing program for the upcoming year, so another application is necessary. However, only less than $10 \%$ of the students on the waiting list gain entry into the nursing program (L.A.S., personal communication, January 23, 2014).

For novice nurse educators at this local setting, the plethora of challenges and responsibilities are difficult to handle during the initial phases of transition from clinical practice to academia. Many of these educators enter into the education profession minimally prepared. Therefore, the overall context of the academic environment is hard to grasp for novice nurse educators. If the novice educators do not feel secure in their position, they may leave the role, thereby increasing the faculty turnover. Although this problem is not new, there is a gap in practice identifying what the specific challenges novice nurse educators encounter and what resources they use to find solutions to their answers. Given the growing faculty shortage, it is important for novice educators to be fully prepared in every aspect related to educating our future healthcare providers.

This section was dependent upon personal communication from the chair and coordinator of the local research setting. An internet search of the newspaper, local board of nursing website, and other reliable sources were performed to aid in the documentation of evidence. However, after searching extensively no public documents were found that were specific to this local research setting. Therefore, relying on the chair and coordinator's expertise, experience, and history of this nursing program's faculty issues provided with me with foundational evidence in which I was able to link to supplemental 
verification (NCLEX scores, faculty hiring complications, current vacant nursing positions) of the problem being addressed in this study.

\section{Evidence of the Problem From Professional Literature}

The demand for increased numbers of registered nurses has been an ongoing for quite some time. The North Carolina Nursing Workforce Report (2007) estimated that between the years 2015 to 2020 , there will be a shortage of 9,000 to 18,000 registered nurses. The retirement of seasoned nurses and advancing of age are contributing factors in the shortage of clinical practicing nurses. The Nursing Management Aging Workforce surveyed 1,000 nurses and revealed that $55 \%$ of them plan to retire between the years of 2011 and 2020 (Dunham-Taylor et al., 2008). Ultimately, the advancing age of the general population will result in increased healthcare needs (North Carolina Nursing Workforce Report, 2007). In order to resolve the loss of nurses the healthcare profession will face, nursing schools must continue to produce proficiently educated registered nurses. The contribution of competent and knowledgeable clinically practicing registered nurses is contingent upon the supply of nurse educators. Duphily (2011) expressed the necessity of seasoned nurse educators in helping to cultivate and empower the novice generation of educators, which can assist in alleviating the nursing shortage. However, the National League for Nursing NLN (2010) stated that currently there are less than an adequate number of nurse educators to teach in the academic setting. More specifically, the AACN (2012) stated there is a 12\% shortfall of nurse educators to adequately educate potential healthcare professionals. Therefore, as Spencer (2013) stated, the supply and demand within the nursing profession continues to be a battle. 
Dattilo, Brewer, and Streit (2009) stated that many nursing educators are placed in "precarious positions" in learning how to be educators (p. 368). The new pool of nurse educators entering into academia often has a vast history of clinical expertise but lack adequate preparation for an academic role. Spencer (2013) stated that although many of the candidates are qualified to teach because of their vast clinical experience, it is impracticable to expect these individuals to be an expert in the academic role. The North Carolina Board of Nursing (NCBON; 2011) stated that full and part faculty who teach in a nursing program must obtain the appropriate training within 3 years of hire to teach adult learners. This required educational preparation includes curriculum development, implementation, and evaluation. The educational preparation may be achieved by one of the following: (a) completion of 45 contact hours of continuing education, (b) completion of a certificate program in nursing education, (c) nine semester hours of education coursework, (d) national certification in nursing education, or (e) documentation of successful completion of structured, individualized development activities of at least 45 contact hours approved by the Board (NCBON, 2011).

Inadequate educational preparation of nurse educators may lead to poor teaching outcomes (Billings \& Halstead, 2009). Many educational organizations do not assist educators in funding their educational preparation, thereby causing novice educators to rely on their basic education, experience, and minimal orientation to begin their new positions (Clark, Houten, \& Perea-Ryan, 2010). Hence, organizational support is necessary so that novice educators receive confidence, encouragement, and the proper preparation during their role transition into academia (Kapustin \& Murphy, 2008). 
However, a vast number of part time faculty members are hired to instruct clinical groups even though they are not given many opportunities to view the full picture of academia (West et al., 2009). Lack of preparation can produce stress and create doubt upon their teaching abilities, which can hinder them in furthering their career in academia full time. According to the North Carolina Nursing Workforce Report (2007), the lack of retention and recruitment of nurse faculty members greatly affects efforts to adequately educate the students attempting to become registered nurses. In 2010, the Affordable Care Act passed, which will enable 32 million Americans to gain access to healthcare services. Thus, it is vital that nursing programs are able to produce an adequate supply of registered nurses in order to not only meet the demands of North Carolina but all of the United States. Additionally, the retirement rate of seasoned faculty correlates to the shortage of nursing faculty. According to the AACN (2014) the median age of nurse educators is 53.5 years, which will result in a wave of retirement. With the experienced faculty members retiring, the novice educators are left unfamiliar with the educator role. Therefore, it is important to explore the challenges novice educators face during their transition to academia. The lack of preparedness for novice educators may negatively impact the future of the nation's healthcare providers. Duphily (2011) conducted a study related to the experiences of novice nursing faculty. The participants within this study stated their previous experience and training did not prepare them for the high expectations that are integrated into a nurse educator position, thus making these educators feeling unprepared (Duphily, 2011). Hence, there is a gap in practice for 
identifying the specific challenges that novice educators encounter and the resources that are used.

\section{Rationale}

The concern that many novice nurse educators have a lack of formal preparation and an appropriate orientation stems from my personal experience. In addition, prestigious nursing organizations such as the NLN and AACN have also expressed concern. As a part time novice nurse educator, I can remember having a group of students for the first time. During my teaching experiences, I encountered obstacles, trial and error situations, and mistakes. The National League for Nursing Board of Governors (2006) stated that new faculty often sense a lack of support from colleagues. I also felt alone in learning the appropriate methods to solve problems with students. Dattilo et al. (2009) concluded that the need for a mentor was necessary for novice educators in order to become successful in the academic profession. The NLN (2013) suggested the senior faculty, who are considered experts, should mentor the novice educators.

In a previous discussion with a full time nurse educator at the local research setting, she stated she had been employed at the school for a couple years and still learns about academia every day (L.M., personal communication, January 23, 2014). During this conversation, the educator also indicated that at times, teaching is overwhelming. McDonald (2010) conducted a study related to the lessons learned from nurses who transition into education. Not only do educators need to prepare for classroom, they must also familiarize themselves with the clinical aspects of nursing education. Looking back upon my first year of teaching clinical, I was solely responsible for scheduling an 
orientation, learning the charting system, and following the policies at a local hospital that I was not familiar with. Learning the nursing program's and the hospital's policies was exhausting. The National League for Nursing Board of Governors (2006) indicated that being a nurse educator is multidimensional, including tasks such as teaching, maintaining clinical competence, and engaging in professional development. These tasks are especially challenging for novice educators. Nurse educators are the first step in producing proficient registered nurses that will serve as the forefront of healthcare. Therefore, it is vital to examine the transition of clinical practicing nurses into academia so that the necessary interventions can be put into place to help the growth and success of novice educators. Thus, the purpose of this qualitative case study is to explore the challenges that novice educators face upon hire in a nursing program.

\section{Definitions}

Within this study, there are various terms used to describe the individuals who assist students in receiving their education. Each role differs; however, they all play a significant part in the advancement of our future healthcare providers.

Clinical practicing nurse: A licensed or registered nurse who provides direct patient care in an acute and/or long term care facilities (North Carolina Nursing Workforce Report, 2007).

Novice: An individual with less than 3 years of experience in their desired profession (Kumi-Yeboah \& James, 2012).

Nurse educator: Individual with a combined experience in the clinical and the academic settings. They "anticipate the increasing complexity of the healthcare system and prepare 
graduates who can think, make decisions in uncertainty, take risks, facilitate change, and communicate effectively" (National League for Nursing Board of Governors, 2006, p. 2). Seasoned faculty: Educators who have experience and knowledge within an academic setting and often assume the role of being mentors (National League for Nursing Board of Governors, 2006).

\section{Significance}

Nurse educators are essential in educating future healthcare professionals to meet the societal demands of the aging population. The NLN has expressed a concern regarding the lack of qualified nurse educators available to fill vacant positions in nursing programs. In 2002, the NLN identified that to close the gap on the nursing shortage, it will take a one third of an increase of student enrollment to accommodate the shrinking numbers of nurses. However, with lack of qualified nurse educators and vacant positions, students are being denied acceptance into nursing programs.

The NLN (2010) stated there were 1,900 vacant nurse educator positions nationwide. Nursing programs nationally attempted to fill these positions, but they found recruitment was a challenge. However, of the candidates that applied, $46 \%$ of nursing programs reported that many were educationally unqualified (NLN, 2010). The deficit of nurse educators will only intensify as present nursing faculty members reach retirement. Therefore, the dearth of nursing faculty directly relates to the gap of clinically practicing nurses. Examining the challenges novice educators encounter in the local research setting will shed light onto this phenomenon and help to unveil the root of the problem. Hearing the lived experiences of novice nurse educators, researchers can began to understand their 
thoughts and feelings related to the transition phase. Clinical practice and academia are different aspects of nursing; therefore, novice nurse educators deserve quality training in order to meet the high demands of academia and healthcare. This study may provide an avenue for identifying and implementing interventions that will assist the novice educators at this community college to have an easier transition process from clinical practice to academia. In addition, this study will provide direct insight into the lived experiences that novice nurse educators encounter.

\section{Guiding/Research Questions}

Academia is a profession with different expectations, responsibilities, and requirements than clinical nursing practice. Thus, the transition from practice to academia can be daunting for novice nurse educators. Previous literature has suggested the implementation of a mentorship program to facilitate the transition process. Programs as such include an extensive orientation and an assigned mentor to assist the novice nurse educator in becoming successful within his or her new role. To achieve this goal, guiding questions that are related to Benner's novice to expert model are needed to help researchers understand the specific challenges novice nurse educators encounter. To assist in this process, I determined that a qualitative study would be most appropriate.

Guiding questions are a fundamental query that offers direction for the search of a phenomenon of interest. The guiding questions below were designed to provide focus and understanding of the challenges novice nurse educators encounter during transition from clinical practice to academia. The following questions were the frame to the overall objective of the study. The following questions guided the research for this project study: 
1. How do novice educators describe their motives in wanting to become a nurse educator?

2. What are novice nurse educators' perceptions of challenges they faced in transition from clinician to nurse educator?

3. How do novice nurse educators describe positive experiences that they encountered in their first year of teaching?

4. What are novice nurse educators' perceptions of support offered by the nursing department in their first year of teaching that helped them overcome challenges in the transition process?

\section{Review of Literature}

An extensive review of the literature was conducted using CINHAL and MEDLINE Simultaneous Search and Education Research Complete online library databases. These databases were searched for journals and articles between the years of 2000 and 2014. The search terms included novice nurse educator, novice educator, challenges of a nurse educator, nurse educator, and nurse educator transition. Combining all search terms together, the two online databases generated 5,466 articles.

Developing confidence and expertise as a nurse educator is reflective upon the environment, support from experienced colleagues, and the experiences gained. In nursing education, the NLN (2005) requires each educator to become knowledgeable and proficient in eight core competencies. The eight competencies are as follows: (a) facilitate learning, (b) facilitate learner development and socialization, (c) use assessment and evaluation strategies, (d) participate in curriculum design and evaluation of program 
outcomes, (e) function as a change agent and leader, (f) pursue continuous quality improvement in the nurse educator role, $(\mathrm{g})$ engage in scholarship, and (h) function within the educational environment (NLN, 2005). Although expert nurse clinicians pursue careers in nursing education, these individuals lack full development of many of these core competencies, thereby making them novice educators (McDonald, 2010). Transition into a new role can create apprehension and stress based upon the skills that nurse educators must achieve. Therefore, enhancement of the particular competencies can be accomplished with proper guidance, support, and encouragement.

\section{Theoretical Framework}

The process of role transition can be supported from Benner's nursing model novice to expert (1982). The novice to expert (1982) conceptual framework was derived from the Dreyfus model of skill acquisition (1980) that was created by professors $\mathrm{H}$. Dreyfus and S. Dreyfus. This model demonstrates the progress an individual exhibits through personal growth and experiences (Pena, 2010). The Dreyfus model of skill acquisition was created on the foundation that humans know how to perform a task from repetitive practice or experience (Pena, 2010). However, this model describes the various phases one must advance through in order to become an expert at the task. Dreyfus and Dreyfus (1980) constructed five phases that identify the individual's growth. The five phases consist of novice, advanced beginner, competent, proficient, and expert (Pena, 2010). To use this model, Benner (1982) described five stages one must advance through in order to become an expert nurse clinician. The Dreyfus model was expanded into 
clinical nursing practice to understand the differences between experienced and novice nurses and their knowledge development (Benner, 1982).

\section{Novice}

Coming into a new position, the novice is confronted with a large variety of situations that he or she is encountering for the first time. Initially, these individuals feel uncertain of their decision making skills and acquire emotions of disappointment when they make mistakes (Dracup \& Bryan-Brown, 2004). Applying Benner's novice to expert model (1982), novice educators are taught to follow certain policies and procedures. Novices over time learn how to reason things through analytical evaluation (Tanner, 2006). Due to lack of experience, Benner stated that the novice should be taught in terms of objective attributes. Anderson (2008) described the novice educators as mermaids in the sea of academia. Learning new responsibilities and work roles, the novices frequently found themselves attempting to escape the rough waters that often lay ahead of them (Anderson, 2008). Therefore, providing objective thinking and rationale to novice educators will give them direction and support in their new role. In addition, the novice develops practical knowledge that is redefined from familiar textbook knowledge (Tanner, 2006). If adequate support is given during this initial phase, the novice can quickly begin to transition forward into the advanced beginner stage.

\section{Advanced Beginner}

During the advanced beginner stage, the clinician has encountered enough situations so that "marginally acceptable performance" is demonstrated (Benner, 1982, p. 403). Given that objective attributes were given throughout the previous stage, the nurse 
educator has gained some experience and has started to connect reoccurring components or issues. Additionally, Benner (1982) stated that mentors can construct specific guidelines for the advanced beginner in order to guide practice. Priority setting becomes a focus among advanced beginners. However, like novice educators, advanced beginners only perceive a little of the situations they are dealing with because things are still new and unfamiliar (Benner, 1982).

\section{Competent}

At this stage, the individual begins to see his or her actions in a long term range. Typically, the individual has been employed for at least 2 to 3 years before competency begins to develop. Moving from objective thinking, the individual establishes an abstract perspective of the problem (Benner, 1982). Although the speed of completing tasks is lacking in the competency stage, the ability to master skills, cope with situations, and manage situations appropriately is developing (Benner, 1982). Planning is an essential component that helps the competent performer stay organized with tasks and accomplishes them with no guidance from a supervisor. Anderson (2009) examined expert clinicians transitioning to academia. A common theme within this study was beginning strokes. Under this theme, characteristics emerged such as identifying and initiating change, reaching out, recognizing rewards, developing vision, finding balance, and regaining comfort and confidence (Anderson, 2009). The findings of Anderson supported those of Benner's work with clinicians, in that the 2-year educators were fully grounded within the listed subcategories of the theme beginning strokes. As a competent educator, perception begins to shift from self to the surrounding environment. 


\section{Proficient}

Deeper analytical thinking guides the proficient individual's practice. As Benner (1982) stated, proficiency is viewed as comprehending the entire situation as a whole. In addition to understanding long term goals, the proficient performer views situations or problems holistically. As a result of practice being guided by holistic views, long term goals, and deeper understanding within the position, the proficient clinician can improve their decision making skills (Benner, 1982). The difference between the competent performer and the proficient individual is that the proficient one considers fewer options when problems arise. Certain aspects of a situation can be more or less important to the proficient educator because maxims are utilized to guide practice (Benner, 1982). Typically, it takes 3 to 5 years to accomplish this phase.

\section{Expert}

Expertise is gathered through a long history of different experiences. Experts do not require maxims to guide their practice because they rely on their intuition (Benner, 1982). Unlike the previous phases, the expert performer has the ability to pinpoint and integrate various aspects of a situation together (Dracup \& Bryan-Brown, 2004). Experts have gained wisdom and knowledge relating to their profession, so certain decisions or choices are based upon an intuitive response. With extensive knowledge, understanding, and experience, expert performers are often used as mentors or preceptors for novices within their professions. Experts/mentors are a valuable resource to novices. However, as Benner (1982) stated, expertise takes a long time to achieve. During this stage, the expert understands the right questions to ask and the appropriate solutions to implement. 
Therefore, as the National League for Nursing Board of Governors (2006) asserted, it is essential that experts perform as mentors in order to share their knowledge, wisdom, and experiences to cultivate the novice educator's contribution in nursing education.

Nursing programs are encouraging seasoned clinical practicing nurses to assist in educating nursing students. The expert clinical nurses who transition into academia from bedside nursing often spiral through a whirl wind of feelings during their transition period. Although these nurses enter into academia with expert clinical skills, the educational arena requires different competencies that many nurses do not initially obtain. Regardless of these nurses' clinical expertise, they are categorized as novice in the educational department. Kumi-Yeboah and James (2012) stated that the novice educator is considered an individual who has less than 3 years of experience within the educational environment. While novice educators focus on surviving, they encounter challenges of managing the classroom, using technological devices, and implementing different pedagogical styles. Kumi-Yeboah and James indicated that hard work, dedication, learning, and experience assist novice educators in their journeys in becoming an expert educator. However, there are varying factors that contribute to the challenges novice educators experience.

\section{Factors That Contribute to Novice Educators' Challenges}

The diverse role of nursing educators affects recruitment, retention, and career satisfaction among nursing educators. One of the immediate issues that contribute to the shortage of nursing faculty is the increased workload (Bittner \& O’Connor, 2010). When working in the hospital or clinical area, nurses tend to specialize and develop expertise 
within a specific patient population. Consequently entering into academia, where there is a shortage, can often result in educators teaching additional courses or a course where content is unfamiliar. This leads to an increase in workload as described by Bittner and O'Connor (2010). Asking a novice nurse educator to teach outside of his or her comfort zone can produce stress or discomfort. For example, McDonald (2009) organized a study that explored the transition process of novice nursing instructors in which knowledge deficit was a common theme within the findings. One participant described the inadequate feelings they had teaching in courses that did not relate to their previous bedside nursing background. Cangelosi, Crocker, and Sorrell (2009) concluded that teaching is not derived from clinical experience. Teaching is an art that involves special skills and knowledge obtained through educational courses. In addition, teaching in a classroom setting requires educators to use and implement specific educational competencies such as socialization, assessment, evaluation, curriculum design, and outcomes (McDonald, 2009). However, deficiency of academia knowledge among the novice educators can hinder the competencies from being fully executed.

Lack of educational preparedness has also played a factor in the retention of nurse educators. Siler and Kleiner (2001) explored the experiences of novice educators. Unfamiliarity was one of the first themes generated within this study. Many of those participants acknowledged that teaching in higher education is not for everyone. Nursing education requires more skill than just lecturing about disease processes and caring for patients; educators have to understand how to create syllabi, tests, and class assignments; how to evaluate student progress; and how to implement different learning styles (Siler \& 
Kleiner, 2001). Dattilo et al. (2009) also emphasized the importance of nurse educators having formal education courses about curriculum development, assessment techniques, and evaluation processes. Obtaining formal education can assist educators in understanding the guidelines and procedures for working with students in academia. However, many associate degree community colleges do not require nurse educators to have prior nursing educational courses upon hire. Schoening's (2013) study illustrated the disorientation phase began after the nurse educators started working. The lack of education and the orientation process left nurse educators in this study feeling "thrown in or flying by the seat of my pants" (Schoening, 2013, p. 169).

\section{Differences Between the Clinical and Academic Environments}

Anderson (2008) stated that there are many distinct differences between clinical and academia and the roles nurses play in each setting. Nursing education warrants a different skill set for faculty in order to be effective in educating the students. As a result, many emotions and feelings are combated within the first few years of teaching. For example, Anderson (2009) conducted a study that aimed to describe the process that nurses experience during their transition from clinical practice to academia. The participants compared the early transitions phase to the metaphor of water, such as sitting

on the shore, splashing in the shallow, drowning, and others (Anderson, 2009). Similarly, in another study, Anderson (2008) explored the work role of a nurse educator in a baccalaureate nursing program. Within this study, Anderson referred to the participants as mermaids. This visual metaphor was parallel to a water theme. Findings of both studies demonstrated overwhelming feelings related to learning new information, 
responsibilities, and regaining comfort. In addition, Duffy's (2012) findings demonstrated the difficulty of shifting into a higher educational role from a nurse clinician role. The feeling of doubt and uncertainty was acknowledged by the participants in regards to curriculum content and teaching confidence. Gaining an educational philosophy that best suits an individual's personality can assist the novice educator in acclimating through a smoother transition period.

Work role balance (role conflict and role ambiguity) differs between the academic and clinical setting and is a factor that predicts the retention rates of nursing instructors. Gormley and Kennerly (2010) investigated the influence of the work role and the perceptions of the climate. Nurse educators are expected to perform research and service in addition to teaching inside the classroom. Institutions of higher education stress the importance for educators to be involved with research and service, which may detract from teaching responsibilities.

Juggling responsibilities can lead to burnout, which has currently impacted the shortage of nursing educators. Cash, Daines, Doyle, Tettenborn, and Reid (2009) conducted a study that highlighted the critical issues nurse educators find important in the work environment. Results determined that support and guidance in difficult situations with students, advocating for faculty, and the creation of mentoring programs were deemed most significant (Cash et al., 2009). While research and service are important in the advancement of nursing education, understanding the qualities nurse educators think are valuable to their work environment is a starting point in reconstructing the nurse educator profession (Cash, Doyle, Tettenborn, Daines, \& Faria, 2011). Additionally, 
Cash et al. (2011) examined the implication for recruitment and retention and concluded if nurse educators' work environment is not considered, then many nursing programs will deteriorate, which could negatively affect healthcare.

\section{Mentorship for Novice Nurse Educators}

In order to attack the challenges novice educators encounter, mentorship/orientation programs have been introduced in the majority of nursing programs. These programs assist novice educators in their transition from clinical practice to academia. Mentorship of novice educators can be compared to Mezirow's (1997) Transformative learning: Theory to practice, which is built upon the frames of references habit of mind and point of view. These frames of references assist the learner to understand his or her experiences through individual development and critical reflections. Since transitioning into a new role can be related to transformative learning, it is pertinent that the educator (mentor) guides the learner (novice) in becoming aware of their own assumptions. As Mezirow described, the main idea in transformative learning is to actively facilitate the learner in connecting concepts and to assess the rationalization of new knowledge. Based upon Mezirow's four main components which include experience, critical reflection, reflective discourse, and action, these components assist the learner in obtaining new knowledge as well as strengthen their skills, which adds to their competence. As West et al. (2009) stated, learning is a process that involves filtering through past experiences in order to expand on new concepts.

Jacobson and Sherrod (2012) reported that the evolution mentorship programs has benefitted novice educators in a number of ways, such as improved knowledge, skill, 
competency, and performance as well as professional development. Dattilo et al. (2009) offered a strategy for advanced educators and nursing administration that helps distinguish between orientation and mentorship. Novice educators need an intense outline of responsibilities, policies and procedures, and teaching expectations, which is considered an orientation. Mentorship requires the seasoned educators to assist novice faculty in accomplishing scholarly interests, which occurs after confidence and experience has settled into the novice educator's transition (Dattilo et al., 2009). Nonetheless, the pairing of mentee to mentor needs careful consideration in order for the mentee to receive maximum support. As White, Brannan, and Wilson (2010) stated, the mentoring process thrives off of three main factors: reciprocal relationships among mentee and mentor that help foster open communication, novice educators who require encouragement and guidance in order to overcome their challenges, and preplanned activities in a formal atmosphere that enrich development among the novice educators.

Comparably, Manning and Neville (2009) studied nurses' experiences transitioning from staff nurse to the role of clinical nurse educator. These participants found the new role to be challenging and difficult. Manning and Neville highlighted the importance of orientation, mentorship, and networking with seasoned clinicians. As Bolton and Ray (2004) and Corning (2002) stated, mentorship and networking must be acknowledged as a valid and appropriate method with any role transition (as cited in Manning \& Neville, 2009). To become proficient in nursing education, the individual must understand the role and responsibilities that are included. If role confusion is present, then ultimately the student's academic success can be hindered. 
There has been documented success with orientation/mentoring programs. Blauvelt and Spath (2008) described a mentoring program established within a nursing program. The participants were given guidance in the following areas: classroom and testing, clinical, curriculum, and student advisement. Many novice educators acquire feelings of uncertainty and doubt related to their new role as educator; however, these participants expressed positive feedback because of the support and guidance that were supplied from a mentor (Blauvelt \& Spath, 2008).

To help establish the roles and responsibilities of the mentee and mentor, mentorship models have been developed. Yoder (1990) created a framework that was constructed upon the "interaction of environment, people, and events" (Jacobson \& Sherrod, 2012, p. 280). In addition, Thrope and Kalischuk (2003) designed the collegial mentoring model that fosters personal and professional development. The transformational and transcending model was recently developed with the intention that both mentee and mentor are influenced by each other. Jacobson and Sherrod (2012) explained that the model signifies the constant changes both parties experience during the mentoring process. Congruency is a vital component in the transformational and transcending model. Consequently, if the congruency between mentee and mentor is not compatible, then constraints will arise creating an uncomfortable relationship (Jacobson \& Sherrod, 2012).

Effective mentorship is built upon the concept of collaboration between the mentee and mentor. It is essential that mentors provide guidance and support because the novice educators will become the seasoned faculty of tomorrow (Kapustin \& Murphy, 
2008). Thus, mentors involved in an orientation/mentorship must possess certain characteristics such as being approachable, having interpersonal skills, providing support, and having excellent professional development abilities (Smith \& Zsohar, 2007). Equally important, the mentee should manifest the ability to be open, take initiative and risks, and integrate decision making (Jacobson \& Sherrod, 2012). The mentee and mentor relationship thrives on particular elements in order to create a successful mentoring phase. Smith and Zsohar (2007) described these elements as trust, respect, and professionalism, coaching the mentee as necessary to help him or her develop his or her professional and teaching skills and providing guidance to the mentee in developing his or her own approaches to teaching. Clark and Byrnes (2012) stated that providing the fundamental components within the mentorship program can support and socialize novice educators into the field of higher education. Becoming familiar in a new role requires support, guidance, and dedication that entail the assistance of a mentor. The wisdom and intelligence a mentor can offer regarding the complex issues in academia can ease the transition phase for novice educators. Therefore, as Jacobson and Sherrod (2012) stated, novice educators should participate in an orientation program to accommodate the unique needs that arise within this profession.

\section{Resources Needed by Novice Nurse Educators}

Transitioning into academia can be difficult for most novice educators. However, with the necessary resources, the transition phase for novice nurse educators can become easier. As previous literature has indicated, effective mentoring is beneficial in order for novices to become acclimated to their new role. Clark (2013) examined new clinical 
faculty's experiences in academia. Clark's participants indicated that socialization into the faculty role can assist novice educators in understanding their responsibilities. More specifically, these participants recommended that nursing programs offer an introduction into the course, provide a shadow experience, and assign a mentor/contact person for new faculty members if questions should arise. Additionally, Clark and Byrnes's (2012) participants stated that in addition to mentoring and socialization, self-reflection or selfevaluation and observation are vital components in their novice years in academia.

Moreover, nurses who move from clinical practice into academia undergo an identity transformation. Murray, Stanley, and Wright (2013) examined the experiences of individuals who transition from clinical practice into academia in order to provide essential information and advice. Adjusting to a new role and responsibilities takes time in which some universities are not sensitive too (Murray et al., 2013). Therefore, collegial support for novice educators is also fundamental for a successful transition.

\section{Implications}

The demand of fully qualified nurse educators is apparent based upon the statistics provided by the NLN. However, maturing into a knowledgeable, successful, and proficient nurse educator requires support and guidance of the expert faculty. Nursing education is a profession that poses many challenges among the novice educators. Nonetheless, there is a gap in practice addressing specific challenges novice educators encounter. Engaging in a dialogue with novice educators may provide insightful data that will target the challenges and obstacles these participants encounter during their first few years in nursing education. The findings of this study may provide helpful information to 
facilitate the transition of nurses to the nurse educator role. This may include the implementation of formal and informal mentoring activities, development of peer support groups, and enhancement of a formal orientation. The data collection and analyses of these participants' experiences as educators may also support the necessity of a formal mentorship/orientation program. This study will contribute to the nursing profession by gaining a better understanding of the novice educator's challenges and possible methods to overcome them.

\section{Summary}

For many nurse educators, the transition period from clinical to academia can be frightening in itself. Having the accountability of educating society's future healthcare providers can create apprehension and fear. A review of current literature supported that the transition period of expert clinicians to novice nurse educators is a challenging and stressful situation. Therefore, proper support from seasoned faculty is required. The AACN stated if support from colleagues is lacking, exasperation can easily build, eventually leading to high faculty turnover rates (as cited Baker, 2010). Although the current literature supported mentorship/orientation programs, very few researchers discussed specific challenges novice educators encounter during their transition from expert clinician to novice educator. The purpose of this qualitative study was to explore particular challenges that novice educators face during their first 3 years in a nursing program. 
Section 2: The Methodology

Introduction

The purpose of this study was to understand the challenges novice nurse educators experience during their transition from clinical practice to the classroom in an associate degree nursing program located in a southeastern state. Previous research indicated that many novice educators transition from clinical practice to academia with a lack of formal preparation. Curry, Nembhard, and Bradley (2009) as well as Anthony and Jack (2009) stated that qualitative research is becoming more commonly used in the health sciences professions. Therefore, to achieve a better understanding of the specific challenges novice nurse educators endure, a qualitative case study was the most suitable study design to implement.

Qualitative studies support the researcher in understanding how participants comprehend or interpret an experience, situation, or incident. Furthermore, a qualitative case study is an analysis of a particular location, topic, or event. Anthony and Jack (2009) stated that researchers use case studies when examining a group of participants within their natural setting. Additionally, Anthony and Jack concluded that qualitative case studies are often used in nursing education to assist in identifying objective verb statements such as describe, explore, understand, and evaluate. Qualitative research provides attributes that differ from quantitative research. Prion and Adamson (2014) stated there are three distinct characteristics in qualitative research, which include having an emic perspective, having a holistic approach to the participants, and becoming inductive and interactive. This study addressed the challenges novice nurse educators 
encountered during their transition into an associate degree nursing program located within a southeastern region of United States.

\section{Qualitative Design and Approach}

\section{Description of Qualitative Research Design}

A qualitative research design is used to understand and make sense of a phenomenon by studying it naturally. Qualitative researchers are interested in how people perceive or interpret their feelings towards certain experiences (Merriam, 2009). Curry et al. (2009) stated that qualitative research should be considered when the researcher needs to examine multifaceted phenomena, to generate data that assist in the comprehension of an issue, to gain awareness of potential causal mechanisms, or to explore specific populations of individuals. To capture the true essence of the participants' feelings, openended questions were used. An open-ended question allows the researcher to gain thick rich verbal descriptions from the participants regarding their viewpoint (Curry et al., 2009).

Moreover, qualitative research enables the participant's perspectives to be the focal point of the study, whereas quantitative research often focuses upon the relationship of independent and dependent variables. Additionally, quantitative researchers use statistical information to assist in the data analysis and conclusion, thereby a quantitative approach is inappropriate for this particular study. Likewise, an ethnographic study observes the participants within a cultural group, and a grounded theory research design requires researchers to collect information throughout an extended period of time in the eagerness to generalize the data (Lodico, Spaulding, \& Voegtle, 2010). Although both of 
these designs are considered qualitative, these methods would be unsuitable for the research question because ethnographic studies collect data of the interactions within a cultural group to assess their influence upon society and grounded theory studies gather data to develop a theoretical framework.

\section{Justification of Research Design}

Merriam (2009) stated that often qualitative researchers choose to investigate a certain phenomenon because of the absence of a theory that effectively justifies the phenomenon. Therefore, to help build concepts, theories, or hypotheses, qualitative researchers use inductive reasoning throughout the duration of their study. Inductive reasoning can derive from collecting and analyzing data from interviews, observations, or document analysis (Lodico et al., 2010). Once all the data are collected and summarized, categories, concepts, and/or themes are constructed, which helps the researcher interpret and seek clarification regarding the phenomenon being studied.

\section{Participants}

\section{Criteria, Justification, and Gaining Access to Participants}

The participants for this study were nurse educators in an ADN nursing program at a community college in a southeastern state. A sample size of 10 to 15 participants was anticipated for this study. The inclusion criteria for selection of participants included both of the following:

- Nurse educator with less than 3 years of teaching experience.

- Nurse educator teaching in both academic and clinical settings. 
Bogdan and Biklen (2010) stated that ideally in a qualitative study, the sample should be a relatively small number. Using a small number of participants allows the researcher to obtain data with an in-depth inquiry method (Creswell, 2007). Small samples allow an efficient time frame spent with the participants and data that are filled with rich evidence related to the phenomenon (Curry et al., 2009).

I obtained a list of potential participants by requesting permission from the chair of the nursing program to review the faculty informational database. Therefore, after I filtered throughout the employee information, I selected 11 nurse educators who met the inclusion criteria. Out of the 11 participants, seven replied back and were willing to participate in the study. Demographics of the participants included five full time faculty members (two males, three females) and two part time faculty members (one female and one male).

Merriam (2009) expressed that generalizing data is not the primary focus in qualitative research as it is in quantitative research. Therefore, a purposeful sampling procedure was used. According to Merriam, researchers should construct a criteria list that incorporates features or necessary attributes the participants need to obtain when using purposeful sampling procedures. Furthermore, Curry et al. (2009) stated the purpose in purposeful sampling is to identify "information-rich" participants (p. 1445). Purposeful sampling for this project study was aimed for diversity in gender, ethnicity, age, and full/part time nurse educators. 


\section{Establishing a Working Relationship}

I described to all participants the nature of the study in full detail, obtained informed consent from each participant, and assured confidentiality of the data that were gathered. Because some participants may be hesitant to discuss particular topics with the researcher, I established a friendly, professional rapport with all of the participants during the beginning of the research process. Several recommendations researchers may follow in order to cultivate a healthy respectful researcher-participant relationship are outlined (Bogdan \& Biklen, 2007). The steps I took included introducing myself, remaining welcoming, blending in with the setting, and retaining inoffensive notes. Creating a healthy relationship between researcher and participant can aid researchers in acquiring essential information (Bogdan \& Biklen, 2007). A healthy relationship assists the participants in trusting the researcher, thereby making the participants more inclined in sharing their true feelings.

\section{Ethical Considerations and Protection}

The proposal for the study was approved by the Institutional Review Board (IRB) from Walden University (reference number 08-20-14-0285351) and the local research setting. When a human serves as a primary subject in a research study, researchers must take precautionary measures in order to comply by the regulations implemented by the IRB (Bogdan \& Biklen, 2007). These regulations were established to protect all study subjects from any potential danger associated with a research study. Each participant needs to be provided with an informed consent form. The informed consent discloses the researcher's contact information, confidentiality procedures, and protection of the 
participant's rights (Creswell, 2012). Before any data were collected, the letter of consent was signed by each participant and returned to me (Appendix B). In addition, to comply with the guidelines of the IRB, I carried out the following protocols: avoided coercion, honored the participant's privacy, protected the identity of each participant, treated each participant respectfully, and analyzed the data with honesty and integrity (Lodico et al., 2010). Furthemore, I informed each participant that they have a right to withdraw from the study without consequences at any time. If at any time a participant had a concern, I addressed the issue(s) promptly and respectfully. Written notes gathered during the data collection phase were safe guarded by placing them in a file that was locked and could only be accessed by me. In addition, electronic files were stored in a password protected file.

\section{Data Collection}

\section{Types of Data Collected and Justification}

Qualitative data collection differs from quantitative data collection. In qualitative research, Merriam (2009) stated that the researcher becomes the primary instrument for data collection as well as data analysis. In order to collect rich and thick information from the study sample, I performed semistructured interviews with novice nurse educators. As Bogdan and Biklen (2007) stated, semistructured interviews allow for some flexibility on the researcher's behalf. Semistructured interviews have a set of questions generated prior to the interview; however, as Curry et al. (2009) asserted, to help clarify certain aspects, the researcher can use prompts or probes for more detail of the concept. 
In order to provide authenticity, Anthony and Jack (2009) suggested the use of multiple sources to gather data. Another source of data collection I used was the SelfStudy Report that was constructed for the Board of Nursing review of the nursing program in 2012. This document is not a public record but is accessible to faculty within the school. Reviewing the Self-Study prior to interviewing the participants assisted me in seeing a clear picture of how this nursing program functions as an organization. From this data source, I collected descriptive information about the nursing program, such as the faculty roles, courses each faculty member taught, and number of full and part time employees during that specific year. Information from the review of the Self-Study also provided additional evidence for understanding any problems that have been identified in the nursing program related to use of novice faculty.

A third source of data related to demographic characteristics of participants. To help capture a full understanding of the novice educators and experiences, a data demographic form was created (Appendix C). Demographic data included personal characteristics such as age and gender as well as years of nursing experience, educational background, and prior teaching experiences. These data methods are important in order to validate that purposeful sampling was carried out appropriately. These data enhanced understanding of the participants' diversity and characteristics that might influence their responses to the interview questions.

The triangulation data collection technique provides the researcher with further insight into the phenomenon (Lodico et al., 2010). When researchers triangulate multiple sources of data, it gives the study a more accurate reflection through more than one lens 
that helps reveal multiple aspects of the phenomenon being examined (Baxter \& Jack, 2008).

\section{Process and Plan of Data Collection and Recording/Gaining Access to Participants}

The data collection process began after IRB approval from Walden University and the local research setting. In order to obtain access to data, I requested permission from the chair of the nursing department through a written letter to review the Self-Study and employee database (Appendix D).

After I obtained permission to access data, I reviewed the Self-Study to gain an overall understanding of characteristics of the nursing faculty and any documentation of specific information related to novice faculty. To retrieve the data, I used a tool that I had designed in collaboration with two expert nurse educators (Appendix E). Collecting this information prior to interviewing participants allowed me to be more knowledgeable about the nursing program in order to enhance understanding of participants' responses and initiate appropriate probes during the participant interviews.

After I obtained a list of potential participants who met inclusion criteria, I sent an email invitation letter to those nurse educators; the letter described the nature of the study and asked for their participation (Appendix F). An instruction for a reply that states either yes or no for their participation was included within the email. Once all participants responded, the participants who elected to participate in the study were provided with a consent letter upon initiation of the interview session. Although the invitation letter described the nature of the study and asked for the participant's permission, an informed consent was also needed. Creswell (2012) stated an informed consent should include the 
signature of the participant that signifies acknowledgment of their rights. Prior to conducting the interview, each participant was asked to sign the consent form. Providing the participants with the consent letter personally allowed me to verify their signature as authentic.

Interview questions were prepared to elicit responses from participants who related to each of the research questions for this project study (Appendix G). I designed the interview protocol with four open ended interview questions and two probing questions to guide me in exploring the experiences, thoughts, and perceptions of the participants. Prior to conducting the interviews, two experts in nursing education reviewed each question for clarity, terminology, and depth. Minor revisions were made, such as rewording in order to clarify the questions.

Interviews were audio-recorded. Recording interview sessions are a convenient and generic procedure in qualitative research (Merriam, 2009). Audio-recording the interviews permitted me to be more attentive to nonverbal clues of the participants during the interview. In addition, audio-recording allowed data to be accurately maintained, which makes transcription easier. However, to protect my participants' privacy, I followed recommendations from Merriam (2009) and obtained authorization prior to recording the interview. Directly after the interview session was over, I asked each participant if they could fill out the demographic data form that provided background information. The demographic form did not contain any identifying information such as names or birthdates. Therefore, their privacy was still protected. 


\section{System for Keeping Track of Data}

Upon gathering the data from the Self-Study document, a table was constructed that allowed me to input data in the appropriate category column that relates to Appendix E. Likewise, the demographic form was organized in the same manner. To keep track of the data collected during the interviews, a number was assigned in sequential order to each participant's interview protocol form. This tracking system allowed me an opportunity to revisit the data collected and identify if any recurring themes were emerging. The number assigned to the interview form correlated with the demographic sheet. This also assisted me in identifying the demographic data that correlated with each participant.

\section{Role of the Researcher}

A concern that may arise during the data collection phase is the researcherparticipant relationship. Currently, I am employed part time at the local research setting as a clinical instructor and have been there for 4.5 years. Therefore, I have developed relationships with many of the educators at this particular nursing program. However, I do not work alongside the participants because my position entails me being off campus with my assigned students. Hence, I did not feel my relationship with participants posed a threat to the gathering of my data.

My journey in higher education and adult learning began in 2010 when I graduated with my Master degree in Nursing (MSN) with a nursing education concentration. Since I am fairly new to academia, I can relate to many of the emotions that novice educators experience. During my data collection, I took my current and past 
nurse educator roles into consideration knowing many nursing programs have different protocols for novice nurse educators.

Although my working relationship with the potential participants was minimal, caution was taken to guard the data collection against bias. In qualitative research, the researcher becomes the primary instrument. Merriam (2009) explained that in order for qualitative research to be credible, investigators "need to explain their biases, dispositions, and assumptions," which is called the researcher's position or reflexivity (p. 219). Prior to gathering data, explaining my feelings related to the phenomenon and interview questions could help the reader to understand the interpretation of the researcher (Merriam, 2009). This method does not eliminate the variances, but rather helps to clarify the researcher's values and conclusions of the study. Therefore, my role was to gather data using triangulation and analyze each piece of evidence with the highest integrity.

Bogdan and Biklen (20007) stated privacy can be accomplished by using pseudonyms when statements from the participants are inserted within the study. Therefore, I used pseudonyms in place of the participants name or assigned number. In addition, participants could feel reluctant in discussing certain viewpoints with the researcher. However, I reinforced to each participant that the data and the findings provided insight and will assist in developing resources that promote a smoother transition for novice nurse educators into academia. A concern with qualitative research is researcher bias. Qualitative researchers must evaluate their own feelings towards the phenomenon and maintain objectivity so that the reality of the participant's experience 
can be captured. Being objective during the data collection and analysis processes assisted in the rigor and the accurate representation of the participant's experiences.

\section{Data Analysis}

\section{How Data Were Analyzed and Coded}

The first step to analyzing data is to gather and organize all the information obtained during the data collection phase. Demographic data were summarized and presented in a table format. Specific information was taken from the Self-Study report prior to the interviews (Appendix E). These data were necessary to help me become more aware of the nursing faculty characteristics and related facts regarding this nursing program. Data that were abstracted enlightened me of the nurse educators within my local research setting.

All audio-recorded interviews were transcribed verbatim using a voice recognition computer software program called Dragon Naturally Speaking Premium 13. Bogdan and Biklen (2007) stated dictation software allows the individual to transcribe using a microphone and converts it into text via computer. This method can save the researcher valuable time. The computer that was used in the data analysis process was secured with a password. While listening to and transcribing the data, I was constantly assessing for codes in order to identify potential themes. Bogdan and Biklen (2007) stated codes are patterns or schemes identified in the collected data such as specific words that were used or distinct actions the researcher observed throughout the collection phase. After each interview session, the data were transcribed. Each transcription was assigned a 
number that was linked to the participant in order to help keep data appropriately organized. Each page of the transcriptions was numbered in the right hand upper corner. After each interview was transcribed, a table (Appendix H) was constructed which assisted me in keeping the pertinent information organized that specifically related to the research questions. Participant quotes were extracted and placed appropriately under each research question. In addition, each research question was given a specific color. As I removed the relevant statements from the transcriptions, I highlighted the data according to the research question color. This method also helped me stay systematic and locate the data quickly if needed. Tentative themes and codes were also written within the table.

Themes are general classifications in which the researchers place the identified codes. Collecting data can be a long process; therefore, developing themes can assist the researchers to locate and recall significant data from several months before. Since the study focused upon novice nurse educators and their experiences, I focused on the novice aspects described by Benner. Such aspects could include no experience, skill development, follow the rules, and context free learning (Pena, 2010).

\section{Accuracy and Credibility}

To ensure accuracy and credibility, I utilized member checking. Merriam (2009) stated member checking is a common method to ensure validity of the findings. After the data were transcribed into a document, I allowed my participants to review the documents to confirm the accuracy of the transcription. After I completed each of the seven tables, I emailed each participant their table and asked if he or she could review the document for 
the correct interpretation. I anticipated that I would collect data over a 1 to 2 month period. Merriam (2009) suggested researchers should allow for member checks to occur through the duration of data collection to verify that analyses are valid. As a method of member checks, I sent each completed table to the participants for them to review for accuracy and correct interpretation. Participants sent back their approval of the data collected and granted consent for me to move forward with writing up the findings.

Triangulation is another method that was incorporated during the duration of my study. Merriam (2009) expressed that triangulation cross checks data by comparing information using multiple sources of data collection. As expressed previously, interviewing and examining a Self-Study report were the primary means of data collection. Furthermore, Creswell (2012) stated that triangulation enhances the accuracy of a study. Gathering data from multiple sources assists in supporting the themes that will be constructed.

Researcher bias could be an issue due to my familiarity with some of the participants and my current position at this particular local research setting. Therefore following each interview, I used reflective analysis in order to evaluate my feelings, thoughts, or opinions. Creswell (2007) stated that reflective analysis is useful for researchers to be accurate in their data collection so that the true essence of the participants is portrayed.

\section{Procedure for Discrepant Cases}

Adequate time should be spent evaluating each interview, observation, or historical document. In some instances, a discrepant case or alternate explanation 
emerges within the data (Merriam, 2009). Discrepant cases are data that challenge or disconfirm the study's expectations. Although these cases may not coincide with the expected data, researchers still should include the data within the study's outcome. This process is similar to an outlier. If the study has multiple discrepant cases, then that may indicate there is a need for more research relate to the topic.

\section{Findings}

Data collection occurred primarily through individual participant interview sessions. However, review of individual participant demographics and review of a composite Self-Study report also generated data. Originally 11 participant invitations were sent out, but of the 11 participants two declined and two did not respond back. Therefore, this study had a sample size of seven. Individual face-to-face semistructured interviews were held with the participants in a small private room. Interviews lasted between 20 to 40 minutes. During the interviewing process, I asked some probing questions to obtain a deeper understanding into the participant's feelings, opinions, and experiences.

\section{Demographic Data}

The demographic form generated descriptive data that related to each participant's background of their nursing, education, and teaching experiences. Collectively, the average number of years as an $\mathrm{RN}$ for the seven participants was 16 years. Participants ranged in age from 28 to 57 years, with an average age of 42.7 years. There was an array of areas in which these nurse educators were or are still employed, such as medical-surgical, emergency/intensive care, hospice/palliative care, and surgery. 
Out of the seven participants, five of them had a master's degree in nursing (MSN). One of these seven participants had a master's degree in nursing administration. The other two participants had a bachelor of science in nursing degree (BSN). Before teaching ADN students, two of the participants had some previous teaching experience as a nurse educator for endoscopy and teaching LPN students for 2 years.

Benner's (1982) novice to expert scale (novice, advanced beginner, competent, proficient, and expert) was used on the demographic form to assess the participant's perception of the level of competency related to teaching. Although none of the participants had any previous positions related directly to teaching ADN nursing students, two of the participants rated themselves as advanced beginners, one participant rated herself between an advanced beginner and competent, three of the participants rated themselves as being competent, and one participant considered herself as proficient. Uniquely, none of the participants labeled themselves as novice educators. The participants were also asked to rate themselves as nurse clinicians. Four years of nursing experience was the least amount and 30 years was the greatest amount of nursing experience among all of the participants. There were two participants who rated themselves as competent, three rated themselves as proficient, and two participants rated themselves as an expert in relation to being a clinician. 
Table 1

Participant Demographics

\begin{tabular}{ccccccccc}
\hline Participant & Gender & Age & $\begin{array}{c}\text { Employment } \\
\text { status }\end{array}$ & $\begin{array}{c}\text { Years } \\
\text { as an } \\
\text { RN }\end{array}$ & $\begin{array}{c}\text { Years } \\
\text { teaching } \\
\text { in ADN } \\
\text { program }\end{array}$ & $\begin{array}{c}\text { Education } \\
\text { al level }\end{array}$ & $\begin{array}{c}\text { Rank as } \\
\text { nurse } \\
\text { clinician } \\
\text { (Benner } \\
\text { Scale) }\end{array}$ & $\begin{array}{c}\text { Rank as } \\
\text { nurse } \\
\text { educator } \\
\text { (Benner } \\
\text { Scale) }\end{array}$ \\
Mary & F & 42 & Full & 20 & 2 & MSN & Competent & Competent \\
John & M & 36 & Full & 4 & 3 & MSN & Proficient & Competent \\
Ellen & F & 57 & Full & 29 & 1 & MSN & Expert & $\begin{array}{c}\text { Advanced } \\
\text { Beginner }\end{array}$ \\
Mark & M & 35 & Part & 7 & 0.5 & BSN & Expert & Competent \\
Suzanne & F & 54 & Full & 30 & 3 & MSN & Competent & Proficient \\
Cindy & F & 47 & Full & 18 & 1 & MSN & Proficient & $\begin{array}{c}\text { Advanced } \\
\text { Beginner/ } \\
\text { Competent }\end{array}$ \\
\hline Ashley & F & 28 & Part & 4 & 0.5 & BSN & Proficient & $\begin{array}{c}\text { Advanced } \\
\text { Beginner }\end{array}$ \\
\hline
\end{tabular}

\section{Self-Study Report}

Data that were abstracted from the Self-Study report provided a context for the study of nursing faculty characteristics and related facts regarding the local nursing program. These data included collective information of the entire full and part time faculty during the year of 2012. In that year, there were a total of 16 full time and 14 part time faculty members (30 educators total) for 220 students. Out of the 30 nurse educators, 24 had an MSN, while the remaining six had a BSN. Although, the Self-study stated that 
the majority of the nurse educators had a master's degree, the length of time since their degree was not specified. However, all except five faculty members met the North Carolina Board of Nursing preparation in teaching and learning. The teaching and preparation components are educational training courses or activities nurse educators must complete within a specific timeframe in order to be qualified to teach nursing students. These faculty members had planned to complete this requirement within the allotted time frame. The Self-Study did not specify how many of either the full or part time nurse educators were novice or experienced.

The Self-Study review showed that the full time faculty teaches between 18 to 21 student contact hours per semester, along with five office hours. In addition, faculty members are to have 30 hours per week related to teaching/college activities. Faculty workload was evident during 2012 within two courses, NUR 111 and NUR 213. The course NUR 111 (Introduction to Health Concepts) is the first course nursing students take upon entering into the program, it is eight credit hours. This course provides fundamental information in order for students to be successful in the upcoming nursing courses. The course NUR 213 (Complex Health Concepts) is the last nursing course students take upon graduation and it is ten credit hours. This course helps students put all the nursing concepts together and is also a preparation for NCLEX. In 2012, there were three faculty members with two clinic groups in NUR 111 and one faculty member with two clinic groups in NUR 213. The workload for students and faculty members can be extensive in addition to the clinical hours. This evidence of the faculty workload that was collected from the previous 2 years with no changes made. 
No information was included in the Self-Study regarding the number of years each faculty member worked as a Registered Nurse with direct patient care, nor the patient population in which the faculty members worked while providing direct patient care.

\section{Interviews}

Invitational emails were sent to all potential participants. After a reply was send back, I provided the participants with at least three potential interview days and times. Interviews were held at the local research setting within a small, locked room which provided privacy for the participants. Permission was granted from the chair of the nursing department to use the rooms for interviewing purposes. First, I introduced myself to the participants and then proceeded to explain the interview process. Each interview lasted approximately 20 to 40 minutes. I took brief notes during the interviews to document nonverbal cues, such as body language, if the participants smiled, of if the participant's hesitated to answer any question, but I was careful to maintain eye contact with each participant. Participants were smiling during the interview and appeared comfortable in responding to questions.

Findings from analysis of interview data are presented here in relation to the four research questions.

Research Question 1: How do novice educators describe their motives in wanting to become a nurse educator?

In order to gain a full understanding of the participants' background, I asked about what motivated them to want to become a nurse educator. Specific instances that 
sparked the nurse educator's interest in wanting to become a nurse educator were described. The theme identified related to this research question was Wanting to give back by helping others succeed.

Participants talked about instructors who had made a difference during their own education and how they wanted to give back and help others succeed. Ashley shared an aspiration to want to help nursing students because of her academic experience:

When I became a nurse on a med-surg floor, we had nursing students there and I always kind of felt like I needed to take them under my wing. Because I remember how difficult nursing school was and how stressful it was. That pretty much made me love nursing students and then because I had not been out long when I had my first nursing student in that setting, I just really thought it would be nice to be able to give them a good experience.

Cindy also revealed her motivating factor, wanting to share her knowledge, is why she wanted to become a nurse educator. She thought back to the time when she first worked on the floor at the bedside:

The students would be on the floor and I hoped I would be one the one selected to work with one of the students. Just to be able to share what I have learned so far to help them with that and, when I would see people that I knew who had moved into the positions I thought, 'Yeah I think I might like to do that too.'

Cindy also described the desire to leave something behind: 
I wanted to be able to have something to leave behind. I was thinking I will not always be able to physically to work at the bedside you know 40 hours per week but still be able to carry on what I know.

Ellen struggled with the decision whether to move from clinical nursing to education, especially since it would be "about a $\$ 15,000$ pay cut," but decided education was where she should be:

It is that teaching mentoring that I love so...I'm pretty faith driven and I felt and perhaps this is where I should be and that I was going back to my roots and I was going back to what I loved -- I'd be teaching again and the other would get me out of management and maybe this is what I was supposed to do, so I kind of came back to what I originally thought I wanted to do back in the $90 \mathrm{~s} .$.

A part of "giving back" for participants appeared to be the enjoyment that came from sharing knowledge with students and helping them succeed. Mary stated:

I realized, wow, I really like working with students. ..I really liked teaching students who didn't know very much and getting them excited about nursing. Mark shared a similar feeling about wanting to help students succeed:

I think I enjoy teaching or helping others more than I actually enjoy the patient care side of nursing. You know anything that I have done in life I always find myself learning how to do something and trying to share that or help others do the same thing whether it be something small or large.

Suzanne described her feelings of helping students this way: 
I really enjoyed seeing them succeed and seeing them later on telling, 'I'm in the nursing program'...I think that since I'm teaching first year students, first semester students, the newbies as I call them, what stands out in my mind as a positive is when I get to see them when they graduate or I see them in the workforce. They remember me as a teacher, they have something positive to say, something that I spoke into their life, or something that I did that they remember, so that really gives me confirmation that I'm in the right place.

In summary, when the participants described their motives for wanting to be a nurse educator, it was clear that they had great intentions in wanting to give back to the healthcare profession by educating nursing students and helping them succeed. As Ashley stated, she understood how difficult nursing school can be; her motivator was to soften the challenging aspects by creating a good clinical experience.

Research Question 2: What are novice nurse educators' perceptions of challenges they faced in transition from clinician to nurse educator?

With every career change, challenges are likely to arise for the individual. To address Research Question 2, I asked each participant to think back on the challenges he or she has faced in transitioning from clinical practice to teaching and to describe an incident when they wondered whether they made the right decision to move into teaching instead of clinical practice. The nonverbal cues most participants had upon answering this question was a slight pause and the appearance of thinking. All seven participants discussed the situations and issues that surrounded a challenging experience related to their transition into the teaching role. 
One theme that was identified in the data related to this research question was Work is always with you.

John shared his personal thoughts related to specific challenges about outside work that he encountered as a novice nurse educator:

There is a lot of outside work that is involved. As when you're in clinical practice, you clock out at the end your shift and you are done, you go home and know my day is over. Where here...teaching, there's always grading to be done, and lessons plans to think of, what do I need to do or prepare for next course, so there is a lot outside your eight to five scheduled hours that you do that takes up a lot.

In addition, Mary also described the outside work that she found a challenge and added that she found the changes in assignments troublesome, feeling that she was "low man on the totem pole." She shared some personal reflections of her challenges that she encountered upon entering into a nurse educator position:

And there was once a change in my class assignment and I wasn't real happy about that, it wasn't what I wanted; it was basically low man on the totem pole. I was told you have to do this...I did not enjoy that situation. It was more work than I expected. I'm a nine-month employee and I came back from the summer and it was like boom...here you go and it just took so much time to prepare and grade... I could be in the hospital right now and I could leave my job at the door go home and have family time and come back. 
Similarly, John described outside work that he has encountered since being a nurse educator:

My background is all (specific area) so now I had focus on generalized nursing again, so it has forced me to reeducate myself. I have to go back, and I have to read, and I have to study, prepared just as if I was a student again.

Ellen also stated she spends "a lot of time grading papers." When embarking upon a new position, the transition process can be daunting just learning the role itself. Cindy had the opportunity to discuss her thoughts which include:

There are challenges all the time that come up when working with students. You know being able to step back and watch them, evaluate what they are doing, and then providing the feedback... Being able to step in in time before they do make a mistake, if they are going to make a mistake, or knowing if they are going to make a mistake before it takes me by surprise and wondering why didn't I see that.

Cindy also mentioned her classroom skills and that her comfort level was her biggest challenge:

I do not have as much experience up in front of the classroom....Every class is different. So our classes go by so quickly, so by the time I start getting used to one class we flip to another class.

In addition, having students in the clinical setting can be challenging. Mark described the challenges experienced in the clinical setting with students: 
Being a clinic adjunct instructor, you don't know the students except for the first day you see them....You get very limited time with them, so you don't have a great deal of background with anybody. It's kind of like a body of work, one day a week for 10 to 12 weeks and you had to figure out where they are, and what a class dictates they should be, and how to get them there.

Likewise, being in the clinical setting, there is work involved such as grading care plans. Mark discussed this aspect which he feels is inconsistent with other faculty:

I feel ill prepared, I'm kind of learning to grade their stuff while going and I don't know if my grading is going to be consistent with the other instructors out there so......

Furthermore, Ashley described her clinical experience and having patience was her biggest challenge:

And sometimes they'll ask questions and you're like oh my gosh... I'm not sure of that answer... That makes you doubt....Am I ready for this or whatever.... I think that's been the biggest thing is learning that patience with them and they're very... what's the word....Hesitate I guess, especially with new things and so just walking them through that and trying to put them at as much ease as I can. You know again it just takes patience.

A second theme related to Research Question 2 was Teaching in the dark. Participants stated that they felt unprepared for their new role and needed more structure in the transition process to help them feel more competent. Mary discussed a specific situation that related to this theme: 
I started orientation, nursing orientation, and then literally a week later I was in the classroom teaching so I felt unprepared. I didn't know where I was teaching, what I was teaching, I didn't have a textbook so all of that was very nerveracking.

Ellen also talked about her experience with a particular situation that related to this theme:

I was presenting in the dark and the lead teacher came to me and said you presented things that were not in their curriculum. Well I had the concepts but I do not have access to anything but a textbook.... which I'd have to read all those pages so that was very very difficult.... think there was some on purpose lack of inclusion.... So I really had to learn on my own that first semester I really didn't get much assistance.... I just said okay be quiet and figure out on your own. So I've did a lot of figuring it out on my own.

John also has struggled with questioning if he is effective his teaching skills:

I think just seeing when you are done providing information and teaching students, you don't get the... or see the knowledge stick. One in particular was that I had taught this course previous course on fluid and electrolytes balance, and took them into the next course, and ask them in a neurology section about fluids and electrolytes, and they could not answer the question... They acted like they have never heard it before, I was like did I really teach them anything, am I my really good at you know....am I effective in what I'm doing, is this really where I should to be this, or am I making progress. 
In summary, when the participants described their challenges in the nurse educator role it was clear these educators had some struggles and challenging situations occur during their transition into academia. As John stated "There is a lot of outside work that is involved." Although the struggles and challenges among each participant was unique, it was evident that being a novice nurse educator is not always an easy role.

Research Question 3: How do novice nurse educators describe positive experiences that they encountered in their first year of teaching?

The theme, Making a difference, emerged from Research Question 3: This question seemed to bring smiles to the faces of the participants as they reminisced about previous situations that related to the positive aspects of being a nurse educator. An excerpt from Ellen disclosed a very touching moment which was really special to her:

So, I was the new kid, I was the one in their senior class who they had never met, I came at the end of October and they met me in January for the first time. The senior group, the 59 students chose me to be the person to pin them so I think that stunned the group, but I think it was....it stunned me....because I felt that we had a good relationship and I could see that I was reaching them. They were coming to me with issues, and I felt that I was making a difference.

Also, Mark discussed a positive situation that made him realize teaching nursing students can bring joy to the lives of nurse educators:

One of the students that I had in that clinic rotation is now going through the (hospital orientation class). When I bump into her I still receive great feedback 
from her and she stopped by to see the group of students that I'm with now and she stated very kind things about the experience that they'll get working with me. With a smile, Mary discussed her first semester in the clinical setting with her group of students:

I would say my first semester of course...the first semester is always the special moment...but the clinical group I had they just ended up bonding very well. And it was a good group, we worked together and whatnot, and I think what I realized, I really enjoyed looking forward to clinic days because the students in the ADN program, they're not just the traditional 18-year-olds who are young, these are older students who really desire to learn, really desire to be a nurse... So I think that whole semester was special I think that one thing that really clicked it for me was at the end of the semester...we were celebrating not only being done, but this group of students was graduating, they surprised me with a gift...it was just just.... I don't know it was just really special to hear words like you made a difference, you made this semester the best semester I've had in my program. Likewise, Ashley verbalized what special feelings she received from the students: I also get a lot of fulfilment from students that we have had instances where they have gotten to do new things... Inserting catheters and starting IVs. They get so excited when they get to do new things like that and so to see them light up because they get these opportunities there hands on opportunities had been.....You know that's just fulfilling. 
Cindy also mentioned her positive moments such as "when I get positive feedback from the students and therefore I know something has worked, and I felt like it helped them to push forward."

In summary, when the participants reminisced about their positive experiences, they recalled many satisfying experiences, such as Mark's memory of a previous student who stated "very kind things about the experience that they'll get working" with him. While discussing the positive experiences, many of the educators felt they were making a difference in their students' lives, which brought a smile upon their faces.

Research Question 4: What are novice nurse educators' perceptions of support offered by the nursing department in their first year of teaching that helped them overcome challenges in the transition process?

The last research question was specific to faculty support. The participants were clear that faculty support was present upon request only. This was one concern for the majority of the participants. The common theme that was generated from the data was $A$ shoulder to lean on. Suzanne described her thoughts, feelings, and perceptions regarding faculty support:

Just having that right support is the biggest thing whether it's one person or a group of people I think that is the most important for a new faculty coming in. In comparison, Cindy laughingly expressed positive feelings when she requested permission to observe her colleagues teachings styles:

I just kind of talked with the other instructors and asked was it is okay if I observed their teaching so I could kind of see different teaching styles.....other 
faculty are my "go to people" that I would go to, probably all of them, they were helpful, I could ask questions and nobody ever made me feel like why she asking that question.

Mary discussed how stressed she was to have had orientation and the next week started teaching. She went further to state the experience:

It was made softer knowing that the teammates that I had for that class were very understanding. We shared the teaching, so my teaching was later in the semester. I could always ask them questions, they were always checking on me.

In addition, John stated "having other faculty that I can take materials to look at this before I teach, to ensure is this appropriate, just any questions, and having resources up and down the hall of people of who you can go ask."

Furthermore, Ellen expressed her feelings:

I think that actually just sitting in on the classes and I followed a couple people in clinical doing that was helpful, I think that is a resource. I met one of the instructors that was extremely....like come see me and I'll help you... That was a good way to segue into meeting people.

Mark also described the support he received from faculty: My lead instructor last semester realized that and she provided me with a lot of the resources in formats that would easily and accessible to me so I would have all the tools that I needed.

Although many of the participants stated faculty support was present, it was by request. Due to the uncertainty, novice educators may feel become fearful of not having all the 
correct answers for the students. Therefore, an occurring theme that emerged during the participant interviews was More structure/mentoring. This theme was derived from the concerns that this nursing program does not offer any official, defined, or structured mentorship/orientation program for novice faculty. The participants expressed their thoughts and experiences related to the lack of mentorship offered during their transition phase as a novice nurse educator. Ashley verbalized her feelings:

I do feel like being a brand new clinical instructor, there could have been better support from the full time faculty end or them assign me a mentor....There has been kind of a lack of communication that has been frustrating. I kind of like had it not been for many of the emails I have sent or questions I've asked that I would have completely been blind.

Similarly, Ellen voiced her thoughts regarding the structure of this local research setting's orientation process for new faculty:

What needs to be in place is a pathway, that when someone new comes, you have an organization... as to how to train them, and you say okay they need to know this and this and this is how we are going to structure it.

Likewise, Mary described her orientation process as a novice nurse educator: I wish maybe because of my personality it was more official, defined, organized; the mentoring I'm talking about was my teammates saying hey do you need any help this is how we do this and different things like that. And I wish I would have had a little bit of that before I jumped into actually teaching. 
Difficult clinical situations often arise and Mark shared his thoughts related to a complex situation he encountered with a student, he struggled on how to deal with the situation:

There was no training offered to me in regards to how to deal with a situation like that. You know that was a complete total curveball that was not expected from my first time in teaching students.

In summary, the participants felt that a more structured plan or path to guide the novice faculty should have been present. As Ellen stated "What needs to be in place is a pathway, that when someone new comes, you have an organization... as to how to train them." Nursing education is not an easy role to transition into, so the participants felt having support and guidance was needed to help novice educators smooth their transition into academia.

Out of the seven participant interviews, no discrepant cases or outlying information were identified. All statements aligned with each research question.

\section{Discussion Section}

Support and assistance from the seasoned nursing faculty will help novice nurse educators to mature into proficient and successful educators. Parallel to the novice to expert model by Benner (1982), the seasoned faculty are considered the experts. Despite the literature surrounding mentorship and novice nurse educators, this nursing program does not offer any more guidance than a general faculty orientation held for all new faculty entering into each discipline of the college (personal communication, K.P, January 23, 2014). Jewell (2013) expressed the connection between the novice to expert model by Benner and novice nurse's appropriate transitional time frame. An appropriate 
transitional period for novice nurses is roughly 1 year. The long period of time allows their skills and knowledge to be developed (Morrow, 2009). Similarly, this idea can be related to novice nurse educators (Durham-Taylor et al, 2008). Healthcare, more specifically nursing education, is an academic environment that poses many challenging aspects among novice educators. Therefore, a transition period is highly recommended for novice nurse educators (Anderson, 2009).

Based upon the interviews, the participants felt as though an official faculty support role was lacking from their orientation into the nurse educator role. As Schoening (2013) stated, mentorship should be an essential pathway for any new faculty member. The idea surrounding a novice nurse educator and a mentor directly relates to Benner's (1982) model. Although none of the participants categorized themselves as novice educators, Kumi-Yeboah and James (2012) define novices as individuals with less the 3 years of experience. Collectively, these participants had an average of 1.5 years of teaching experience. Novices rely on direct rules to guide their practice whether the person is a nurse or faculty member. Experts are reliant on their intuition because of their experience within a plethora of situations (Blum 2010). Most often, experts are used as mentors for novices. A mentorship assists in building confidence and effective skills that will produce competent nurse educators (Schoening, 2013). Being involved in nursing education is an avenue that can help other aspiring individuals grow and become successful (Schoening, 2013). Therefore, it is imperative nurse educators are equipped with the proper tools and skills to help flourish our future healthcare providers. 
Hessler and Ritchie (2006) stated it is helpful to allow novice nurse educators to gain confidence while teaching in subject areas that are comfortable to them. As stated by one of the participants, their course assignment changed unexpectedly. When changes as such occur, it can create uncertainty among novice nurse educators. In addition DurhamTaylor et al. (2008) stated along with the cascade of responsibilities, novice nurse educators must also learn to juggle the workload such as extensive hours of class and clinical preparation. Often, the workload is not mentioned, it is just experienced, which can create anxiety or doubt if the proper support is lacking. Durham-Taylor et al. (2008) stated it is unrealistic to expect new faculty to figure these tasks and roles out on their own, as this creates isolation, frustration, and a lack of satisfaction. As described in the Self-study report, the full time faculty members have an extensive workload which includes four educators having more than one clinical group in addition to teaching class. Weidman (2013) stated how overwhelming it is for new faculty to jump right in and learn everything. Having the appropriate time frame to become accustomed to the new role is beneficial.

Disorientation often results from an individual moving into an unfamiliar role (Schoening (2013). These participants felt a lack of structure was in place. Hence, their transitional period was less smooth than intended. Singh, Pilkington, and Patrick (2014) expressed how valuable support was from experienced faculty in tasks such as navigating through issues. Therefore, it is vital mentors construct learning tasks for the novice nurse educators which can lead to an easier transitional period. Novice and expert nurse educators working together will also foster collegial affiliations within their place of 
employment (Schoening, 2013). Novice nurses educators require an appropriate course load and a strong mentor to assist in a smoother transitional phase which is parallel to Benner's novice to expert model (1982).

\section{Conclusion}

Although, the participants described many positive experiences, several challenges were also identified in the findings as well. One challenge which really stood out as being a difficult barrier for the novice faculty was the lack of a mentorship/orientation program.

Having a lack of mentorship/orientation can hinder the success of novice educators despite their extensive nursing background. Therefore, I found it appropriate to design a mentorship/orientation program within this local research setting. Benner's novice to expert model focuses upon an individual's experience of migrating through the phases before becoming an expert in the field. This model will enhance the project study by illuminating the concepts surrounding the novice (mentee) and the expert (mentor) and the relationship each has towards one another. This program was designed to better serve future novice nurse educators who desire to give back to the community by assisting in producing competent and proficient future healthcare providers. 
Section 3: The Project

\section{Introduction}

The data collected during this study provided evidence that a

mentorship/orientation program was needed at this local research setting. Nurse educators are responsible for ensuring the educational preparation of the healthcare workforce. Therefore, implementing this type of program is critical to the success of the students. In Benner's novice to expert conceptual framework (1982), the main focus of the individual is to progress through the different phases of personal growth and experiences that relate to their career. The final stage of progression is the expert. Participants in the study made it evident that a mentor would have been highly beneficial during their transition phase into academia. Benner's framework supports the in-depth participant descriptions of their experiences transitioning from clinical practice to academia.

\section{Description and Goals of the Program}

Participants in the study stated that a mentorship/orientation program would have been an essential component to their transition process. They expressed that the anxiety they felt was due to the lack of support and necessary information. Therefore, the objective of the mentorship/orientation program would be to provide the novice educator with a pathway in order to grow successfully in the nursing education arena. Upon hire, the novice nurse educators will be required to review four learning modules. Each module will end with a posttest that will assess their competency with the information. A $75 \%$ pass rate on the posttest is required before the educator can advance to the next section. The content of the learning modules relate to the NLN (2005) core competencies 
that reflect the skills, knowledge, and attitude that nurse educators should acquire in order to adequately prepare our future healthcare providers. The learning modules will provide a framework for the educational process in helping students succeed. Completion of the learning modules and posttests are required within the first month of hire.

Instituting this type of program is the first step in preparing these educators of their roles and responsibilities. More specifically, the mentorship/orientation will facilitate the novice educators in acquiring the appropriate skills, resources, confidence, and necessary tools in order to become an efficient educator. Essentially, the mentorship/orientation program will offer developmental services in the areas of knowledge and skills that all nurse educators should be equipped with. The program will be in the genre of professional development with a formative and summative evaluation process at the end to assess for competency and participants' satisfaction of the learning modules. Novice nurse educators will become aware of the resources that are often used among the nursing faculty. Some of the resources consist of but are not limited to accreditation process and expectations, policies and procedures, curriculum design, technology implementation, and professional expectations.

Even though many novice nurse educators are educationally prepared with an MSN or doctorate degree, transitioning into academia can often produce anxiety and feelings of apprehension. Although skills take time to develop, the experienced faculty should assist the novice educators in creating syllabi, lesson strategies/plans, and lectures (Zajac, 2011). In addition, offering assistance in exam planning, test analysis, and the ability to connect classroom theoretical knowledge to practice during clinical should be 
contemplated while working with novice nurse educators. The critical aspects of being a nurse educator will be addressed during the content and explanation of the proposed project.

\section{Rationale}

Embarking into a new role can induce uncertainty among novice educators. Weidman (2013) stated novice educators expressed difficulty when having to learn new skills related to nursing education such as teaching styles, lecture preparation, and evaluation of students. The participants' responses indicated the need to implement a mentorship/orientation program in order for novice educators to grasp the full understanding and responsibilities of adult learners. By implementing this mentorship/orientation program, it will not only help retain nursing faculty but can produce a relaxed and conductive atmosphere for the students.

\section{Review of Literature}

The purpose of this literature review was to explore research articles and studies that were relevant to the development of the mentorship/orientation program. The search was conducted using CINHAL and MEDLINE Simultaneous Search and Education Research Complete online library databases. The keywords that were used included novice nurse educators and mentorship, mentor programs, orientation programs, and novice nurse educators/mentors. These terms yielded a total of 350 articles that focused upon the criteria and recommendations of mentorship/orientations programs and the elements they should acquire for novice educators. The articles selected for this literature review are within the 5-year required timeframe. During the literature search, the need for 
more academic training was a recurrent pattern illustrated within many of the research studies. Training for novice educators included informal and formal activities in order to transition appropriately and smoothly. Administrators should provide sufficient professional developmental opportunities to their novice educators. Professional development allows novice educators to learn and become comfortable within their new role.

\section{Faculty Development Programs}

Teaching preparation programs are designed to facilitate the learning needs of novice educators. More commonly, nursing programs are adopting the idea with the novice nurse educators to ensure their transition process is at ease. In addition, Poindexter (2013) stated that when educators are competent and integrate evidence based practices, student outcomes are strengthened. Handwerker (2012) discussed the complexity and responsibility of the nurse educator role. It is up to the educator to move past the "teacher centered behavioral pedagogies" and encourage critical thinking among the students so that the knowledge can be applied when in the clinical setting (Handwerker, 2012). This responsibility can be challenging for novice nurse educators; therefore, a mentor is strongly needed in the initial transition process. Although nursing administrators do not expect novice educators to be fully proficient in every aspect within academia, Poindexter reported that novice nurse educators felt the need to be better prepared in the areas of assessment, evaluation, and curriculum design.

Novice faculty can be compared to the students they teach in the sense that both parties are adult learners. Eddy (2010) stated that those faculty members learn to teach by 
various methods such as observation, trial and error, and reading material. Novice educators who teach on the community college level attempt to figure out their requirements for teaching in order to be successful. Easing the transition of novice faculty can be accomplished by the use of supporting faculty, mentoring, establishing learning communities, or knowing where to find resources (Eddy, 2010). Galbraith (2004) expressed that the aim of a mentorship is to promote and assist in the development of the learner. Mentors are important aspects to novice educators; they are considered “interpreters of the environment" (Galbraith, 2004, p. 453). Therefore, mentors can help the novices to understand their new role in a logical manner by gently mixing support and challenges.

A thorough mentorship/orientation program supports the new faculty, which helps increase the effectiveness of the nursing program. In addition, Wilson, Brannan, and White (2010) expressed that these types of programs also increase retention rates among faculty. Gardner (2014) stated that the novice faculty who did not receive mentoring or support felt they were "falling through the cracks" and felt lost (p. 108). The overall objective of mentorship programs is to support the novice faculty, which is accomplished through the relationship of an established mentor and mentee, in which the pair work together through a viable plan (Jackevicius et al., 2014). The plan consists of the progression of competencies through Benner's novice to expert model and model of skill acquisition. Some of the competencies required of novice nurse educators include facilitating student learning, learning development and socialization, assessment and 
evaluation, curriculum design, leadership and collaboration, and scholar roles (NLN, 2005).

Another innovation strategy that novice nurse educators should familiarize themselves with is technological advances. Jackevicius et al. (2014) also believed that another objective in mentorships programs is for mentors to provide guidance to the mentee on time management, prioritization, and work-life balance, all of which novice educators seem to struggle with initially. As Suplee and Gardner (2009) stated, mentors provide an "insider's view" of responsibilities within that role; therefore, mentors can assist in solving problems, provide the direction to informational sources, and encourage networking.

Moreover, many nursing programs are transitioning into an online teaching format. Therefore, mentorship/orientation programs can also be beneficial to educators in this capacity. Woolforde, Lopez-Zang, and Lumley (2012) surveyed 114 educators, and $77 \%$ replied with an interest in learning more about technology in nursing education. Vitale (2010) stated that novice nurse educators should pair with a mentor at the start of the course. Necessary tools for novice nurse educators to understand prior to teaching online is learning the course design, implementing active student learning techniques, and understanding evaluation strategies (Vitale, 2010). Online courses can allow students to feel isolated, so it is imperative novice educators fully grasp how to implement strategies that can be learned through mentorship and faculty development. 


\section{Components of a Mentorship/Orientation Program}

Mentorship/orientation programs can include many components that are essential for novice nurse educators. Davidson and Rourke (2012) conducted a study of the learning needs identified by clinical nursing instructors (CNIs). Robinson (2009) stated that clinical educators often feel insecure related to their teaching ability. Most often, clinical nurse educators feel threatened to exemplify a near perfect teaching performance for the students (Robinson, 2009).

The purpose of the Davidson and Rourke (2012) study was to identify neglected needs of clinical instructors that can hinder their success in their role. There were 44 CNIs who participated in the study; the results included the percentage of how important each CNI thought the selected categories were: $84 \%$--new employee information, $50 \%$-being introduced to faculty members, more than $80 \%$--curriculum content and objectives, more than 90\%--simulation technology, and 80\%--evaluation practices (Davidson \& Rourke, 2012). Likewise, DeWolfe, Laschinger, and Perkins (2010) highlighted that in order to be effective preceptors, it is vital the preceptors have an understanding of the course content and evaluation requirements. Gaining an understanding in the evaluation processes and forms that are used by the nursing program is a crucial component in the orientation process for preceptors, clinical nurse educators, and adjunct faculty.

In order to develop a strong mentorship/orientation program, certain criteria and aspects should be initially instituted. One of the key components in making a mentorship successful is obtaining dedicated mentors (experts) to facilitate learning among the mentee (novices). As Carey and Weissman (2010) pointed out, mentors are individuals 
who have established creditability, trustworthiness, reliability, and generosity. Another characteristic of a mentor is they are able to separate their own agenda from the mentee's learning needs, always keeping the mentee's needs a priority. Mentors have certain roles to maintain in order to help the mentee flourish into a successful educator such as being a guide. Carey and Weissman believed that mentors should not necessarily direct the mentee's actions, yet they should work with the mentee to enhance their ability of existing possibilities. Additionally, mentors should offer support in every aspect of challenges and opportunities so the mentees can learn, grow, and reflect in their transition into academia. Daley (n.d) concluded her study by stating novices learn in a dependent fashion, which is a natural process linked directly to their career and development status. Therefore, novices require mentors to be flexible and understanding during their transition process.

Hadidi, Lindquist, and Buckwalter (2013) stated that there were four significant concepts in a successful mentoring relationship that include clear communication, departmental support, mentors sharing interest and compatibility, and additional resources (outside mentors and expertise of faculty from other departments). Likewise, Martin and Hodge (2011) established the same four components in order to establish a successful mentor relationship. Furthermore, Hadidi et al. (2013) also concluded that essential elements in a mentor-mentee relationship are the mutual investment of time, engagement, energy, personal support, and encouragement of the mentee.

However, Eifler and Veltri (2010) alleged that mentors do not have to be from the same discipline as the mentee. In their study, a nurse educator with 20 years of nursing 
experience with no previous teaching experience was paired with an educator who had 20 years of professional practice but no nursing experience. It was found that nurse educators can gain assistance in refining their pedagogy approaches by seeking the advice from education faculty. During Eifler and Veltir's study, the experienced educator gained a new appreciation and depth of understanding of her own teaching skills as a result of assisting the novice nurse educator, for whom education was a fresh aspect. As Caffarella (2010) stated, during program planning, it is essential to involve contributors who can offer diversity in many capacities, a plethora of experiences, and high enthusiastic levels in order to achieve a magnitude within the learning process.

Singh and Patrick (2014) examined the empowerment and mentoring in nursing education. Online surveys and interviews were both used to generate the necessary data. A total of 74 nursing educators responded to participate. Although the necessity for a mentorship was apparent, only $44 \%$ of the participants were actively engaged in a mentorship program. Traditionally, mentorships are a one-on one partnership integrated with informal and formal learning tools. Weidman (2013) indicated that transitioning into academia is stressful; however, with a mentor, the transition can be a positive experience.

\section{Layout of Mentorship/Orientation Programs}

Previous research by Schoening (2013) demonstrated that novice nurse educators experience difficulty as they transition into academia. Schoening developed four distinct phases the novice nurses experience. These phases include anticipation/expectation, disorientation, information seeking, and identity formation. Collectively, the four phases depicted the nurse educator transition model. Understanding the phases that novice nurse 
educators encounter will help nursing administrators in formulating strategies that will support the novice faculty during their transition. Thus, as Schoening believed that designing the proper supportive activities will help to eliminate the disorientation phase that many novice nurse educator encounter.

There are many methods in which to implement a mentorship/orientation programs. Wilson et al. (2010) developed a formal mentor program that was responsive to a series of events that occurred over a 3-year period. This particular program consisted of formal faculty development workshops over a 6-day period. Two of the days were oncampus retreats and the other 4 days were all-day workshops. Program topics that were incorporated were teaching and learning strategies, curriculum development, clinical teaching, assessing and evaluating learning outcomes, and tenure/promotions issues. In addition to the workshops, the mentor and mentee pair was expected to meet biweekly and to use journaling. The nursing department also purchased education textbooks and journals for the participating faculty members. Ultimately, the findings revealed that open lines of communication are necessary to foster a relationship; however, there were challenges including balancing the relationship while sharing necessary knowledge within a busy work schedule. When the lines of communication were discussed, Wilson et al. (2010) stated the participants valued the face-to-face discussions more so than journaling. The mentors found it enlightening to work with the mentees because it gave them an opportunity to reflect on their own teaching practices. However, the workload of the mentor should be taken into consideration when asked to provide mentorship to the novice educators (Wilson et al., 2010). 
Comparably, Gilbert and Womack (2012) described a nursing orientation program they implemented and received excellent feedback from the participants. This program consisted of a 2-day intensive workshop followed by monthly 1.5 hours of on-going orientation during their first academic year. Day 1 was content focused including teaching in the clinical area and evaluation. Additionally, teaching behaviors, attitudes, practices, education principles, and legal/ethical issues were also topics of discussion. However, because many adult learners are hands-on and want to apply what they have learned, participants were given the opportunity to work together within their learning activities. Day 2 of the intensive workshop was focused upon classroom teaching and evaluation. Specifically, topics included developing and using lesson plans, lecturing effectively, using creativity in the classroom, and participating in an examination analysis. Again, a hands-on activity that consisted of the participants preparing a lesson plan was allotted for the novice nurse educators. In addition to preparing the teaching plan, participants were also asked to write two exam questions based upon the content. These skills provided a real-life outlook into nursing education. At the end of each workshop day, evaluations related to each learning objective were conducted. Novice nurse educators require more than two days to fully become equipped with the fundamental skills needed to be proficient, therefore, informal time during their first year for topics such as advisement, preparation of annual review, time management, teaching strategies, and evaluation of core competencies was allotted (Gilbert \& Womack, 2012). Additionally, Gagliardi, Webster, Perrier, Bell, and Straus (2014) concluded a mentor program that consists of preliminary workshops with combined individual 
mentoring sessions was beneficial. Mentoring sessions should be offered at least one hour over the course of 6 months in order to be effective. However, Gagliardi et al. (2014) stated further research is needed to evaluate the effectiveness.

\section{Resources}

In order to implement a new program, all faculty members and administrators need to collectively come together to discuss the roles each individual will have during the process. Caffarella (2010) stated there are many program planning models that consist of ideas of how to develop a successful program. Whichever model the program planner chooses to use, it is advised to follow the model from start to end so that all steps of developing the program are covered. However, the most essential part of having a successful program is support from the stakeholders and participants. As Caffarella (2010) stated, support is seen both in commitment and action. Schoening (2013) stated to help promote the most effective mentorship program; all mentors should receive training in the essential elements of mentorship. Mentors may serve in multiple roles such as teacher, supporter, or coach (Jacobson \& Sherrod, 2012). As a result, the role of the mentor is the foundation within the orientation/mentorship program. Therefore, mentors should be acknowledged for their commitment in the process of assisting novice nurse educators. Alsever (2008) suggested providing a luncheon or giving a small gift to the mentors as a means of saying thanks for the hard work and dedication. Another important part of developing a successful program is answering the "why, what, who, where, and how" aspects. It is crucial that the program goals are defined. Alsever (2008) stated many mentor programs fail due to fuzzy program goals. 


\section{Evaluation of the Program}

Recommendations of the novice faculty are highly beneficial to the development and continuation of mentorship/orientation programs. Suplee and Gardner (2009) stated that evaluation of faculty orientation programs can be completed in a two-part process. The first phase is allowing the novice faculty to evaluate at the finish of the orientation. The second evaluation phase takes after the novice has worked alongside the mentor in their role for several months (Suplee \& Gardner, 2009). Anderson, Silet, and Fleming (2012) stated that programs that have implemented mentors can use surveys as a means to perform evaluations. The surveys can be open or closed ended and address the following topics: frequency of meetings, quality and satisfaction, availability, expectations, and professional development (Anderson et al., 2012). Formal and informal evaluations can also be gathered as feedback from the mentees to ensure goals were met (Hadidi et al., 2013). Periodically, performance evaluations can be implemented which can generate new developmental and renewal processes during the relationship. Another form of evaluation as mentioned by Evans, Razia, and Cook (2013) is formative participatory evaluations. Participants were asked to fill in a questionnaire and group discussions were also held in order to thoroughly explore the participant's view of the program.

Evaluations should always be kept in a locked and safe location to protect the mentee and mentors.

\section{Project Description}

The review of literature helped to develop the mentorship/orientation program by providing program development information and resources. Developing a program from 
the beginning can be daunting. However, gathering current evidence-based research assisted me in developing the mentorship/orientation program. It is imperative that mentorship/orientation programs are established since many seasoned, experienced nurse educators are now currently eligible for retirement. This leaves the nursing education profession open for novice educators who will be responsible for fully educating our future healthcare providers. With the complexity of nursing education, it is essential that novice nurse educators are guided on how to function within the role. The literature offered different innovative methods that could be appealing to the next generation of nurse educators. In addition, the literature provided different components of a mentorship program, resources, and evaluation processes.

\section{Purpose}

The purpose of the mentorship/orientation program is to provide novice nurse educators the information and resources in order to successfully transition from clinical practice into academia. This program is outlined to assist novice nurse educators in developing fundamental aspects that nurse educators are responsible for within academic courses and the clinical practice setting. During the program, novice educators will gain essential and effective teaching skills which will create a conductive learning environment for the students. In addition, the mentoring program will offer continual support to the novice nurse educators as they transition and become familiar with important resources and proficiencies that are parallel to the educational process. 


\section{Resources and Existing Supports}

To fully execute the mission statement within this nursing program, the implementation of a mentorship/orientation program for novice faculty will support the complex expectations of faculty and administrators of this nursing department. Billings and Halstead (2009) further stated that mentoring programs can assist novice faculty in molding and strengthening their skills in an unfamiliar nursing institution. These programs are designed to assist faculty members in reaching their highest potential as nurse educators in order to educate nursing students to be efficient, knowledgeable, and professional nurses for the community. The participants from this study had experienced challenging circumstances and experiences of not having full faculty support during their transition into academia. Thus, the participants were all in favor of a more extensive, structured, and defined mentorship/orientation program for novice nurse educators. In addition, the nursing administrators were also on board with the idea. The faculty and administration are considered as key stakeholders of this nursing program. Therefore, these participants are an essential component in the existing issue, as they are the forefront in resolving the issue. Developing a program based upon faculty issues/concerns directly involves their input or opinion.

\section{Potential Barriers}

The average cost of implementing the mentorship/orientation program would require a financial plan. Federal grant money is available to help fund supplies and professional development activities in order to support novice faculty. However, most learning activities will take place via online modules and during scheduled work hours; 
therefore, the budget will be mainly for professional development support. In order to maintain a viable and productive program for the novice educators, the nursing department may need to consider containing a portion of the federal grant money received each year specifically for the program.

\section{Proposal Implementation and Timetable}

As described in Appendix A, the mentorship/orientation program was designed in the format of one academic semester in length (Fall or Spring semester). Initially, the novice nurse educator will need to complete the online modules that discuss the critical aspects of the core competencies as outlined by the NLN (NLN, 2005). Next, the mentee will be assigned or paired with an experienced or seasoned faculty. Upon hire, nursing administrators will pair the two parties together (mentee and mentor) based upon criteria such as personal interests, experiences in clinical practice (area worked), and the mentor's workload. During the initial meeting, the mentor and mentee will sit together and collaborate to establish the goals and desired objectives needed during the mentorship/orientation program. Regular meeting times will also need to be established during the first meeting together.

Although investment of time is a big requirement within a mentoring relationship, there are many advantages that occur during the mentorship process. Therefore, both parties can collectively gain benefits from this partnership. Jacobson and Sherrod (2012) stated during the mentoring relationship, the mentee will be able to share new ideas and techniques that were learned during their academic programs. Additionally, the mentor can share their educational experiences, skills, and perceptions related to teaching. 
Kapustin and Murphy (2008) outlined an approach entitled TEAM (Take on, Engagement, Achievement, and Maintenance) that mentors can use to maintain an effective relationship with their mentees. The TEAM approach can establish a foundation of mutual trust between the two parties. In the first month, the novice educator will have required meetings to attend that are established by the college. At first, mentees will observe their assigned mentors conduct lectures and take a group of students to the clinical setting. Slowly, mentees will start preparing for a course by establishing a syllabus, formatting a lecture, preparing an exam, and taking a group to the clinical setting on their own. In addition, professional development activities will be integrated into the mentee's transitional period. Below is a timetable of the mentorship/orientation program (months are based upon an academic year): 


\section{Table 2}

Mentorship/Orientation Program Timeline

\begin{tabular}{|c|c|}
\hline - Month one & $\begin{array}{l}\text { Mentee will: } \\
\text { - } \\
\text { Attend general orientation provided by } \\
\text { the college. } \\
\text { Complete all four of the learning } \\
\text { modules located online. } \\
\text { Meet their assigned mentor } \\
\text { (introductory period). They will } \\
\text { establish meeting times (weekly, bi- } \\
\text { weekly, monthly). } \\
\text { Receive a notebook that contains core } \\
\text { concepts that are essential to a novice } \\
\text { educator such as faculty roles; } \\
\text { classroom, testing, and, clinical } \\
\text { expectations; curriculum building; } \\
\text { advising; and additional resources. }\end{array}$ \\
\hline - Month two & $\begin{array}{l}\text { - Begin observation of the mentor in the } \\
\text { class and clinical settings. }\end{array}$ \\
\hline - Month three-four & $\begin{array}{l}\text { Will have hands on experiences such as } \\
\text { assisting with administrating, grading, and } \\
\text { analyzing of tests; designing own lectures } \\
\text { plans; and lecturing to a class. Mentee will } \\
\text { be asked to evaluate the effectiveness of } \\
\text { the program. }\end{array}$ \\
\hline
\end{tabular}

\section{Roles and Responsibilities}

An important aspect of the mentorship/orientation program is the actual mentor processes/methods. Mentoring directly involves the seasoned faculty and the novice educator working together and collaborating to ensure the needs of the novice are met (Jacobson \& Sherrod, 2012). However, the chair of the nursing department and the nursing coordinator will be responsible for initiating and ensuring the program is successful, such as paring the mentor and mentee together and gathering the formative and summative evaluations. Initially, support for the mentor will also be offered by administration. Also, because of the time investment required by the mentor, this role is 
also considered a part of their teaching workload. Kapustin and Murphy (2008) stated the mentors can be orientated into their role by formal or informal processes. Topics the mentors should review include the mission statement, teaching-learning models, classroom management, and faculty resources (Kapustin \& Murphy, 2008). The seasoned faculty members are responsible for ensuring the novice educator has all necessary resources. In addition, the seasoned faculty will guide the novice educator in their transition; collaborate with nursing administration to establish program outcomes, be welcoming and respectful of the novice educators, and establish an encouraging environment that supports novice educator to the nursing institution. In comparison, the novice educator will have responsibilities of learning the role of a nurse educator. The responsibilities include but are not limited to:

\section{Table 3}

\section{Objectives and Activities}

\begin{tabular}{ll}
\hline $\begin{array}{l}\text { Objectives } \\
\text { - The novice educator will be exposed to } \\
\text { diverse teaching strategies. }\end{array}$ & $\begin{array}{c}\text { Activities } \\
\text { - }\end{array}$ \\
$\begin{array}{l}\text { Observe the seasoned faculty during } \\
\text { lecture of a disease process or nursing } \\
\text { concept. }\end{array}$ \\
$\begin{array}{l}\text { The novice educator will identify test taking } \\
\text { procedures. }\end{array}$ & $\begin{array}{l}\text { Assist in administrating and analyzing a } \\
\text { test alongside with the seasoned faculty. }\end{array}$ \\
$\begin{array}{l}\text { The novice educator will be able to } \\
\text { demonstrate how to effectively manage a } \\
\text { nursing course independently. }\end{array}$ & $\begin{array}{l}\text { Create lesson plans on course content, } \\
\text { lecture the material using diverse } \\
\text { techniques, and create and administer an } \\
\text { exam. }\end{array}$ \\
\hline
\end{tabular}




\section{Project Evaluation Plan}

A formative and summative evaluation will be used to measure the program outcomes. Theoretically, formative evaluations occur while the program is taking place and summative evaluations are implemented at the end of the program to gain a clear understanding of the overall effectiveness and worth the program holds. Therefore, since the mentorship/orientation program will be new to this nursing program, both formative and summative evaluation process would be highly beneficial to assess the effectiveness of the program. The overall outcome of this program is to produce highly qualitied, satisfied, and more confident educators for the nursing program. Formative evaluations can be reported through the use of memos, presentations, or phone calls (Lodico et al., 2010). During summative evaluations, Lodico et al. suggested the use of surveys and qualitative methods as a means of gathering appropriate data. Surveys and interviews will elicit a deeper response from the participants so that the perceptions and experiences can be collected. Therefore, this information will help assist in any changes (if any) that need to be made to the program in order to enhance the quality. There will be two different data collection strategies to elicit data from the participants, which are a survey and a focus group interview. Gathering constructive feedback and evaluations will assist the nursing administration in making the proper adjustments so the program will continue to be successful in the future. In addition, it will provide follow-up opportunities for mentees to assess and expand their own learning. 


\section{Table 4}

\section{Survey Evaluation}

\begin{tabular}{|c|c|}
\hline Purpose & $\begin{array}{l}\text { The purpose of this data collection method is to } \\
\text { assess the effectiveness of the program as perceived } \\
\text { by the novice educators. This survey will be given } \\
\text { before the start of the program and after the program } \\
\text { is complete. It is important that the stakeholders } \\
\text { assess to see if the program was successful and } \\
\text { valued by the novice nurse educators. Therefore, } \\
\text { performing an assessment survey would be a } \\
\text { relevant method to assess effectiveness (pre and post } \\
\text { the program) of the novice educator. }\end{array}$ \\
\hline Guiding Questions & $\begin{array}{l}\text { These questions are geared towards the novice } \\
\text { educator to assess their view of their competency } \\
\text { skills. Please rate the following statements to the } \\
\text { scale provided } \\
\text { A. Not Competent } \\
\text { B. Somewhat competent } \\
\text { C. Competent } \\
\text { D. Very competent } \\
\text { 1. Developing a syllabus } \\
\text { 2. Creating lectures and learning outcomes that are } \\
\text { associated to the curriculum } \\
\text { 3. Integrating the use of technology into the lecture } \\
\text { 4. Creating appropriate tests and analyzing the scores } \\
\text { 5. Verbalizing appropriate methods in handling } \\
\text { student situations (Appendix A). }\end{array}$ \\
\hline Implementation & $\begin{array}{l}\text { This assessment technique will be conducted during } \\
\text { month one and month four of the program. } \\
\text { Assessment surveys can be taken online via survey } \\
\text { monkey. Survey monkey will allow easy analysis } \\
\text { and visualization of scores. }\end{array}$ \\
\hline Reporting Strategy & $\begin{array}{l}\text { Stakeholders: } \\
\text { First line: Chair of the nursing department- The chair } \\
\text { is responsible for all faculty performance. Therefore, } \\
\text { it is pertinent for this stakeholder to review results of } \\
\text { the survey. }\end{array}$ \\
\hline
\end{tabular}


Rationale: Understanding weak areas of the novice faculty can assist in improving the program for future participants.

Second line: Instructors of GTCC- This information is essential for them to understand.

Rationale: Many of the seasoned faculty members are mentors to the novice educators. Weak areas are essential to understand, so that they can focus on that content area for the next novice educator they may encounter.

\section{Table 5}

Focus Group Interview Evaluation

\begin{tabular}{|c|c|}
\hline Purpose & $\begin{array}{l}\text { The purpose of the focused group interview is to } \\
\text { gather insights of the nursing faculty. }\end{array}$ \\
\hline Guiding Questions & $\begin{array}{l}\text { These questions will be asked to the seasoned } \\
\text { nursing faculty (mentors) } \\
\text { 1. What are your feelings toward novice educators' } \\
\text { competency levels? } \\
\text { 2. What were some challenges and positive aspects } \\
\text { of the mentorship/ orientation program? } \\
\text { 3. Do you feel novice nurse educators should be } \\
\text { supported by the seasoned faculty during their first } \\
\text { year of teaching? Why or why not? } \\
\text { These questions will be asked to the novice nurse } \\
\text { educators } \\
\text { 1. Describe your competency levels now compared to } \\
\text { month one regarding curriculum development, } \\
\text { learning objectives, lectures/ planning, and testing } \\
\text { procedures. } \\
\text { 2. What is your perception related to being involved } \\
\text { in a mentorship/orientation program? }\end{array}$ \\
\hline Implementation & $\begin{array}{l}\text { This interview will take place during month four of } \\
\text { the program among the experienced faculty and the } \\
\text { novice faculty. The chair and nursing coordinator } \\
\text { will conduct the two focused group interviews and } \\
\text { will analyze the data. }\end{array}$ \\
\hline
\end{tabular}




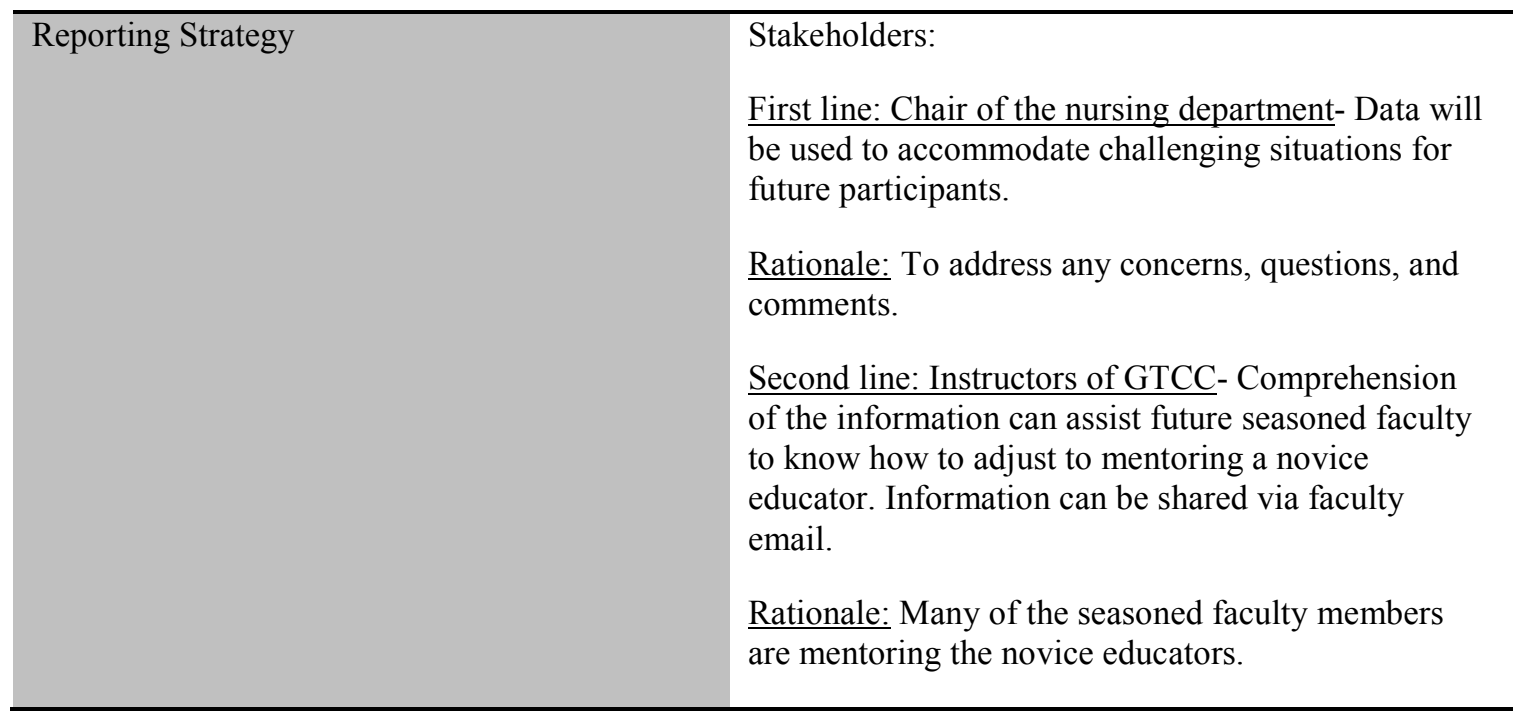

\section{Project Implication and Potential Social Change}

The mentorship/orientation program is a valuable resource for educators who are transitioning into academia. Suplee and Gardner (2009) stated these types of programs help set the stage for novice educators' journey into their careers. Developing a formal mentorship/orientation program will assist novice educators in building relationships, developing pertinent skills, and adapting to the new environment. Novice nurse educators need a safe learning environment in order to transition through Benner's model.

Supporting the novice nurse educators is not only a personal benefit, but it will also help the academic success of students. The growing demands of the healthcare system have placed complex requirements on nurse educators to adequately teach the widely diverse student population. Therefore, in order to sustain this program, it will take collaboration and an initiative effort amongst all stakeholders to provide an environment of nurture for the novice nurse educators. In addition, a collaborative effort between the seasoned 
faculty and the novice educators is needed to build a trusting, nurturing, and fulfilling relationship.

Collaboration can enhance the culture of excellence and productivity among nurse educators (Suplee \& Gardner, 2009). In addition, collaborating can essentially produce highly qualified and skilled healthcare providers. Nurse educators are key factors in ensuring quality education is provided within the nursing profession. Therefore, it is imperative that the novice nurse educators who strongly desire to explore a career in academia are equipped with the proper tools and guidance. Overall, the mentorship/orientation program can ease the transition of highly skilled clinicians into academia. As a result, enrollment can increase and students can gain an education in the nursing profession. Improving the transition of nurses to nurse educators will promote a positive social change by helping to produce more qualified nurses to provide care to the general population of America. 
Section 4: Reflections and Conclusions

\section{Project Strengths}

Mentorship/orientations programs are designed to meet the learning needs of the participants. Benner (1984) suggested that individuals will transition through phases of personal and professional development, which often require support from the experienced peers. Ultimately, by providing a better foundational support, novice educators will be able to provide excellence in practice. Therefore, this program provides a wide range of supporting elements for novice educators. Schoening (2013) stated that peer mentoring and networking serves as a means to increase productivity within the workplace.

Offering support amongst the novice nurse educators will assist them to integrate successfully within the new environment. The integration of mentorship/orientation programs is the gold standard in nursing education and will assist novice educators in reaching their full potential (Billings \& Halstead, 2009). For that reason, the implementation of an array of supporting elements is essential to novice nurse educators.

Mentoring is a type of supportive role that is multidimensional and is highly individualized to each mentee. The program activities were designed to give the participants an opportunity to gain the proper knowledge in order to be effective in teaching and delivering content. Additionally, working collaboratively with expert faculty members will allow novice educators to gain the skill acquisition through experience. 


\section{Project Weaknesses and Alternate Recommendations}

The duration of this program can be identified as a weakness. This program was designed to meet the leaning needs of nurse educators in important aspects related to nursing education. The mentorship/orientation program is set to be 1 academic semester in length with a mentor. The mentor would take a lighter workload to accommodate and be fully effective and available to the mentee. Nursing education is already experiencing a faculty shortage. As Kapustin and Murphy (2008) stated, many faculty members are involved in a multiple responsibilities. Therefore, the long duration takes away the novice and expert educator's ability to function independently as a faculty member who can create a heavier workload for their fellow colleagues. A solution to this issue is to integrate more realistic experiences as a nurse educator within graduate programs. Many graduate programs provide students with the fundamentals of being a nurse educator; however, the hands-on experiences are lacking. The AACN (2005) stated that a crucial element in graduate programs is the learner and their learning, rather than teaching.

Nurse educator programs should incorporate more opportunities for future educators to implement their skills prior to graduation, such as teaching for a full semester alongside the nursing instructor for that course. Nurse educator students can benefit from such hands-on activities as participating in all aspects of lecturing, preparing an exam, analyzing the exam results, and understanding clinical expectations. Gaining the experience of how to be an educator during the graduate program can alleviate the stress of the role post graduation. This strategy can help decrease the length of time a novice nurse educator may need with a mentor. 
Another strategy to help decrease the mentoring process length of novice nurse educators is to start orienting graduate students who have expressed interest in becoming nurse educators. Starting the process of mentoring can never be too early. Conveying information related to the full and part-time teaching roles can give students a clearer outlook of the responsibilities within nursing education. This task can also be offered through professional development activities or programs. Graduate students can gain much insight from professional development opportunities such as new educational research and innovative techniques in teaching and engaging students (AACN, 2005). Professional development can also help accelerate a nurse educator's career.

\section{Scholarship, Project Development, and Leadership and Change}

Faculty members are responsible for encompassing knowledge through scholarship among their learners. Educators are mentors who guide learners through programs that are individualized in order to master the skills appropriate to their students or mentees (Billings \& Halstead, 2009). Boyer (1990) described four areas of scholarship that faculty must engage that include discovery, integration, application, and teaching. Through these four areas of scholarship, educators are able to implement new information and evaluate the effectiveness of their teaching.

Throughout this process, I gained a new appreciation for educators and the role of faculty as a central core to scholarship. By thoroughly reading through the literature, I gained more awareness of how to devise multiple teaching techniques in order to engage the mentees during the mentorship/orientation program. This technique helped me understand the aspect of scholarship of teaching. I designed the mentorship/orientation 
program so that an interactive learning environment was created for the mentees, including voiceover PowerPoint instruction and posttests for participants to evaluate their own learning. An interactive learning environment will provide an opportunity for mentees to discover new knowledge related to their roles as nurse educators.

Developing the mentorship/orientation program was a scholarly endeavor that I extended to the scholarship of discovery and application. This program was developed to provide novice educators with a pathway that will assist their transition phase into academia. Ensuring the alignment of each area and the evaluation processes within the program was a challenge. Initially as I began building this program, I quickly realized that project developments require a lot of planning and collaborating with faculty to ensure each piece will be effective. Additionally, to ensure efficacy of a program, project developers must have the proper evaluations techniques in place. As I began looking at my evaluation processes, I had to be certain that the evaluation techniques were consistent in what I wanted evaluated. However, it was through collaboration with stakeholders that helped me strengthen my project development skills as well as my leadership techniques that will enhance my professional career.

\section{Scholar, Practitioner, and Project Developer}

As a scholar, I realized this mentorship/orientation program was necessary for future novice nurse educators in order to feel more comfortable and prepared with teaching students. I learned that I can make a difference in my community by implementing the mentorship/orientation program to enhance novice nurse educators in their transition. Therefore, during my planning process, I had to research works of other 
scholars to assure that the content I wanted to implement would be valuable and warranted for novice nurse educators. Thoroughly researching current literature helped me to locate the best evidence-based practices for developing an appropriate program for novice nurse educators. Thus, advancing my knowledge in nursing education has made me a stronger scholar.

As I reflect back on the development of this program and the research that was conducted, I recognized that leaders in nursing education have broad perspectives that rely on creativity and uniqueness to accommodate each individual. Although I was presented with challenging situations as a project developer, I was able to persevere through the difficulties by collaborating and relating to the various perspectives of the stakeholders. This program development allowed me to not only sharpen my project development skills but also to reflect and deepen my understanding and role as a practitioner.

\section{Importance of Work}

As the experienced nurse educators prepare for retirement, implementing a mentorship/orientation program is essential to prepare the next generation of nurse educators. Through this research process, I learned that many of the associate degree nursing programs do not have a mentoring/orientation program in place for novice educators. Being an adjunct faculty for an associate degree nursing program, I can concur with the feelings expressed by the participants of this study. I did not expect that the participants would have welcomed the idea of wanting and needing the guidance of a mentor. From my perception, the participants understood the value of mentorship. It is 
through faculty mentoring that helps steer a school towards excellence (Kapustin \& Murphy, 2008).

The nursing education profession has an obligation to the nation to ensure we are preparing our future healthcare providers with skills and knowledge needed to effectively care for those who seek medical attention. However, this process first begins with competent nurse educators. Through educational preparation and effective mentoring, nurse educators can provide high quality learning amongst their students. This experience has allowed me to gain self-awareness and to become an agent of change for my community.

\section{Implications, Applications, and Directions for Future Research}

Based upon the findings, novice nurse educators are faced with challenging situations upon entering into nursing education. Although many nurse educators come with an array of clinical experiences, nursing academia has different expectations and responsibilities. Therefore, these individuals should be provided with the fundamental tools that will enhance their teaching ability. With technology at a peak, there are numerous methods to provide novice educators with teaching competencies that will be necessary for their career. In addition, orientation programs provide a means for novice nurse educators to become acclimated into their new role.

Nurse clinicians who are transitioning to the nurse educator role enter a complex environment for which they may have received little preparation, Most of these individuals have had little experience in formal teaching or evaluation of students. Benner's novice to expert model (1982) emphasizes that since novices have little or no 
experience in the situations they face, they must be provided with structure and rules to guide their performance. Once they have more experience, they gain an understanding of the context in which they are implementing their role and learn how to adjust rules to meet the needs of specific situations. Without proper guidance, however, novice educators may not move on to the competent stage. They may not learn the teaching and evaluation skills that they need to educate students as competent nurses. They also may become frustrated as novice educators and decide to leave academia and return to clinical practice. This could leave nursing programs with inadequate numbers of faculty, resulting in the denial of admission for qualified students and fewer registered nurses to meet societal health care needs.

The structured mentorship/orientation program presented in Section 3 was based upon the study findings. The program consisted of educational modules with interactive posttests to assess the effectiveness and delivery of the content. However, future research is recommended to evaluate the effectiveness of the mentorship/orientation program post completion. In addition, future research is needed to evaluate the perceptions of nurse educators as they move through competent, proficient, and expert skill levels. Phenomenological research could provide valuable insights into what these nurses experience as they transition through the educator skill levels. In addition, quantitative research with larger samples would enhance understanding of specific learning needs of novice nurse educators. 


\section{Conclusion}

The results of this study revealed a need to implement a program designed to fit the transitional needs of novice nurse educators. Supporting novice nurse educators through the use of a mentorship/orientation program can alleviate some of the stress encountered within this new role. Along with collaborating with key stakeholders, nursing administrators and faculty should continually assess the learning needs that are essential to the novice educator's development. It is the duty of the nursing education profession to ensure proficient and knowledgeable healthcare providers are produced to care for the sick and to promote health and wellness. Therefore, nurse educators have to be fully equipped with the fundamental skills and knowledge in order to properly educate students.

Although funding in nursing education seems to be a concern, there are various innovative ways in developing programs for novice nurse educators to expand their skills and knowledge. Implementing a well-structured program that fully describes the learning objectives, learning activities, and the evaluation processes can ease the transitional phase for expert nurse clinicians into the role of a novice nurse educator. 


\section{References}

American Association of College of Nursing. (2005). Faculty shortages in baccalaureate and graduate nursing programs: Scope of the problem and strategies for expanding the supply. Retrieved from http://www.aacn.nche.edu/publications/white-papers/faculty-shortages American Association of Colleges of Nursing. (2010). Nursing shortage. Retrieved from http://www.aacn.nche.edu/media-relations/fact-sheets/nursing-shortage

American Association of College of Nursing. (2014). Nursing faculty shortage. Retrieved from http://www.aacn.nche.edu/media-relations/fact-sheets/nursing-facultyshortage

American Association of College of Nursing. (2014). Student enrollment expands at U.S. nursing colleges and universities for the 9th year despite financial challenges and capacity restraints. Retrieved from http://www.aacn.nche.edu/news/articles/2009/09enrolldata

Anderson, J. (2008). An academic fairy tale: A metaphor of the work-role transition from clinician to academician. Nurse Educator, 33(2), 79-82.

doi:10.1097/01.NNE.0000299511.70646.ab

Anderson, J. (2009). The work role transition of expert clinician to novice academic educator. Journal of Nursing Education, 48(4), 203-208. doi:10.3928/0148483420090401-02 
Anderson, L., Silet, M., \& Fleming, M. (2012). Evaluating and giving feedback to mentors: New evidence-based approaches. Clinical and Translational Science, 5(1), 71-77. doi:10.1111/j.1752-8062.2011.00361.x

Anthony, S., \& Jack. S. (2009). Qualitative case study methodology in nursing research: An integrative review. Journal of Advanced Nursing, 65(5), 1171-1181. doi:10.1111/j.1365-2648.2009.04998.x

Baker, S. (2010). Nurse educator orientation: Professional development that promotes retention. Journal of Continuing Education in Nursing, 41(9), 413-417. doi:10.3928/00220124-20100503-02

Baxter, P., \& Jack, S. (2008). Qualitative case study methodology: Study design and implementation for novice researchers. Qualitative Report, 13(4), 554-559. Retrieved from http:www.nova.edu/sss/QR/QR13-4baxter.pdf

Benner, P. (1982). From novice to expert. American Journal of Nursing, 82(3), 402-407. Retrieved from http://www.jstpr.org

Billings, D., \& Halstead, J. (2009). Teaching in nursing: A guide for faculty ( ${ }^{\text {rd }}$ ed.). St Louis, MO: Saunders.

Bittner, N., \& O’Connor, M. (2010). Focus on retention: Identifying barriers to nurse faculty satisfaction. Nursing Education Research, 33(4), 251-254. doi:10.5480/1536-5026-33.4.251

Blauvelt, M., \& Spath, M. (2008). Passing the torch: A faculty mentoring program at one school of nursing. Nursing Education Perspectives, 29(1), 29-33. doi:10.1043/1536-5026(2008)029[0029:PTTAFM]2.0.CO;2 
Bogdan, R. C., \& Biklen, S. K. (2007). Qualitative research for education: An introduction to theories and methods (5th ed.). Boston, MA: Allyn \& Bacon.

Boyer, E. (1990). Scholarship reconsidered: Priorities of the professorate. Princeton, NJ: The Carnegie Foundation for the Advancement of Teaching.

Brady, M. (2007). Recruitment and retention of associate degree nursing faculty. Journal of Nursing Education, 46(4), 190-192. Retrieved from http://web.ebscohost.com.ezp.waldenulibrary.org

Caffarella, R. (2002). Planning programs for adult learners: A practical guide for educators, trainers, and staff developers (2nd ed.). San Francisco, CA: JosseyBass.

Cangelosi, P., Crocker, S., \& Sorrell, J. (2009). Expert to novice: Clinicians learning new roles as clinical nurse educators. Nursing Education Research. 30(6), 367-371. doi: http://dx.doi.org/10.1043/1536-5026-30.6.367

Carey, E., \& Weissman, M. (2010). Understanding and finding mentorship: A review of junior faculty. Journal of Palliative Medicine, 13(11), 1373-1379. doi: 10.1089/jpm.2010.0091

Cash, P., Daines, D., Doyle, R., Tettenborn, L., \& Reid, R. (2009). Recruitment and retention of nurse educators: A pilot study of study what nurse educators consider important in their workplaces. Nursing Economics, 27(6), 384-389. Retrieved from http://web.a.ebscohost.com.ezp.waldenulibrary.org/ehost/pdfviewer/pdfviewer?vi 
$\mathrm{d}=3 \& \mathrm{sid}=\mathrm{e} 796 \mathrm{bd} 2 \mathrm{c}-\mathrm{d} 24 \mathrm{~d}-427 \mathrm{c}-9474-$

5ac1 ee8fa845\%40sessionmgr4002\&hid $=4214$

Cash, P., Doyle, R., Tettenborn, L., Daines, D., \& Faria, V. (2011). Working with nurse educators' collective wisdom: Implications for recruitment and retention. Nursing Economics, 29(5), 257-264. Retrieved from http://web.b.ebscohost.com.ezp.waldenulibrary.org/ehost/pdfviewer/pdfviewer?vi $\mathrm{d}=3 \& \operatorname{sid}=\mathrm{db} 31 \mathrm{c} 461-937 \mathrm{f}-4473-\mathrm{a} 2 \mathrm{cf}-\mathrm{f} 772 \mathrm{baa} 557 \mathrm{af} \% 40$ sessionmgr113\&hid=101

Clark, C. (2013). A mixed method study on the socialization process in clinical nursing faculty. Nursing Education Research, 34(2), 106-110. http://dx.doi.org/10.5480/1536-5026-34.2.106

Clark, N., Alcala-Van Houten, L., \& Perea-Ryan, M. (2010). Transitioning from clinical practice to academia: University expectations on the tenure track. Nurse Educator, 35(3), 105-109. http://dx.doi.org/10.1097/NNE.0b013e3181d95069

Clark, S., \& Byrnes, D. (2012). Through the eyes of the novice teacher: Perceptions of mentoring support. Teacher Development, 16(1), 43-54.

http://dx.doi.org/10.1080/13664530.2012.666935

Curry, L., Nembhard, I., \& Bradley, E. (2009). Qualitative and mixed methods provide unique contributions to outcomes research. Circulation, 119, 1442-1452. doi:10.1161/CIRCULATIONAHA.107.742775

Daley, B. (n.d.). Novice to expert: How do professionals learn? Retrieved from http://www.edst.educ.ubc.ca/aerc/1998/98.htm 
Dattilo, J., Brewer, K., \& Streit, L. (2009). Voices of experience: Reflections of nurse educators. Journal of Continuing Education in Nursing, 40(8), 367-370. doi:10.3928/00220124-20090732-02

Davidson, K., \& Rourke, L. (2012). Surveying the orientation learning needs of clinical nursing instructors. International Journal of Nursing Education Scholarship, 9(1), 1-11. doi: 10.1515/1548-923X.2314

DeWolfe, J., Laschinger, S., \& Perkin, C. (2010). Preceptors' perspectives on recruitment, support, and retention of preceptors. Journal of Nursing Education, 49(4), 198-206. doi:10.3928/01484834-20091217-06

Dracup, K., \& Bryan-Brown, C. (2004). From novice to expert to mentor: Shaping the future. American Journal of Critical Care, 13(6), 448-450. Retrieved from ajcc.aacnjournals.org

Duffy, R. (2013). Nurse to educator? Academic roles and the formation of personal academic identities. Nurse Education Today, 33, 620-624.

http://dx.doi.org/10.1016/j.nedt.2012.07.020

Dunham-Taylor, J., Lynn, C., Moore, P., McDaniel, S., \& Walker, J. (2008). What goes around comes around: Improving through more effective mentoring. Journal of Professional Nursing, 24(6), 337-346. doi:10.1016/j.profnurs.2007.10.013

Duphily, N. (2011). The experience of novice nurse faculty in an associate degree education program. Teaching and Learning in Nursing, 6(3), 124-130. doi:10.1016/j.teln.2011.01.002 
Eddy, P. (2010). New faculty issues: Fitting in and figuring it out. New Directions for Community Colleges, 152, 15-24. doi:10.1002/cc.423

Eifler, K., \& Veltri, L. (2010). Drawing from outside for support in teaching. Journal of Nursing Education, 49(11), 623-627. doi:10.3928/01484834-20100630-02

Evans, C., Razia, R., \& Cook, E. (2013). Building nurse education capacity in India: Insights form a faculty development programme in Andhra Pradesh. BioMed Central, 12(8), 18. Retrieved from http://www.biomedcentral.com/1472$6955 / 12 / 8$

Gagliardi, A., Webster, F., Perrier, L., Bell, M., \& Straus, S. (2014). Exploring mentorship as a strategy to build capacity for knowledge translation research and practice: A scoping systemic review. Implementation Science, 9,1-11. doi: 10.1186/s13012-014-0122-z

Galbraith, M. (2004). Adult learning methods: A guide for effective instruction ( $\left.{ }^{\text {rd }} \mathrm{ed}.\right)$. Malabar, Florida: Krieger Publishing Company.

Gardner, S. (2014). From learning to teach to teaching effectiveness: Nurse educators describe their experiences. Nursing Education Perspectives, 35(2), 106-111. doi: $10.5480 / 12-821.1$

Gilbert, C., \& Womack, B. (2012). Successful transition from expert nurse to novice educator? Expert educator: It's about you! Teaching and Learning in Nursing, 7, 100-102. doi:10.1016/j.teln.2012.01.004 
Gormley, D., \& Kennerly, S. (2010). Influence of work role and perceptions of climate on faculty organizational commitment. Journal of Professional Nursing, 26(2), 108-116. doi:10.1016/j.profnurs.2009.11.001

Hadidi, N., Lindquist, R., \& Buckwalter, K. (2013). Lighting the fire with mentoring relationships. Nurse Educator, 38(4), 17-163. doi:10.1097/NNE.0b013e318296dccc

Handwerker, S. (2012). Transforming nursing education: A review of current curricular practices in relation to Benner's last work. International Journal of Nursing Education Scholarship, 9(1), 1-16. doi:10.1515/1548-923X.2510

Hessler, K., \& Ritchie, H. (2006). Recruitment and retention of novice faculty. Journal of Nursing Education, 45(5), 150-154. Retrieved from http://web.b.ebscohost.com.ezp.waldenulibrary.org/ehost/pdfviewer/pdfviewer?vi $\mathrm{d}=3 \& \operatorname{sid}=58 \mathrm{a} 3 \mathrm{c} 828-0471-470 \mathrm{~b}-8 \mathrm{c} 2 \mathrm{e}-\mathrm{fb} 13 \mathrm{fd} 064248 \% 40$ sessionmgr111\&hid=101

Jackevicius, C., Le, J., Nazer, L., Hess, K., Wang, J., \& Law, A. (2014). A formal mentoring program for faculty development. American Journal of Pharmaceutical Education, 78(5), 1-7. doi:10.5688785100

Jacobson, S., \& Sherrod, D. (2012). Transformational mentorship models for nurse educators. Nursing Science Quarterly, 25(3), 279-284. doi: $10.1177 / 0894318412447565$

Jewell, A. (2013). Supporting the novice to nurse to fly: A literature review. Nurse Education in Practice, 13, 323-327. http//dx.doi.org/10.1016/j.nepr.2013.04.006 
Kapustin, J., \& Murphy, L. (2008). Faculty mentoring in nursing. Advanced Practice Nursing e-Journal, 8(4), 1-6. Retrieved from http://www.medscape.com/viewarticle/582904_print

Kumi-Yeboah, A., \& James, W. (2012). Transformational teaching experience of a novice teacher: A narrative of an award-winning teacher. Adult Learning, 23(4), 170-177. doi:10.1177/1045159512457354

Lodico, M., Spaulding, D., \& Voegtle, K. (2010). Methods in educational research: From theory to practice. San Francisco, CA: Jossey Bass.

Manning, L., \& Neville, S. (2009). Work-role transition: From staff nurse to clinical nurse educator. Nursing Praxis in New Zealand, 25(2), 41-53. Retrieved from http://web.b.ebscohost.com.ezp.waldenulibrary.org/ehost/pdfviewer/pdfviewer?vi $\mathrm{d}=5 \& \operatorname{sid}=58 \mathrm{a} 3 \mathrm{c} 828-0471-470 \mathrm{~b}-8 \mathrm{c} 2 \mathrm{e}-\mathrm{fb} 13 \mathrm{fd} 064248 \% 40$ sessionmgr111\&hid=101

Martin, C., \& Hodge, M. (2011). A nursing department faculty-mentored research project. Nurse Educator, 36(1), 35-39. doi:10.1097/NNE.0b013e3182001c39

Match College. (2014). Nursing Program at Guilford Technical Community College (GTCC). Retrieved from http://www.matchcollege.com/communitycolleges/guilford-technical-community-college/nursing McDonald, P. (2010). Transitioning from clinical practice to nursing faculty: Lessons learned. Journal of Nursing Education, 49(3), 126-131. doi:10.3928/0148483420090122-02

Merriam, S. (2009). Qualitative research: A guide to design and implementation. San Francisco, CA: Jossey-Bass. 
Mezirow, J. (1997). Transformative leaning: Theory to practice. New Directions for Adult and Continuing Education, 74, 5-12. Retrieved from http://www.ecolas.eu/content/images/Mezirow\%20Transformative\%20Learning.p df

Morrow, S. (2009). New graduate transitions: Leaving the nest, joining the flight. Journal of Nursing Management, 17(3), 278-287. doi:10.111/j.1365-2834.2008.00886

National League for Nursing. (2005). Core competencies of nurse educator with task statements. Retrieved from http://www.nln.org/profdev/corecompetencies.pdf

National League for Nursing. (2010). Nurse educator shortage fact sheet. Retrieved from http://www.nln.org/governmentaffairs/pdf/NurseFacultyShortage.pdf

National League for Nursing: Board of Governors. (2006). Position statement: Mentoring of nurse faculty. Retrieved from http://www.nln.org/aboutnln/PositionStatements/mentoring_3_21_06.pdf

North Carolina Board of Nursing. (2011). Board of nursing: General provisions.

Retrieved from http://www.ncbon.com/myfiles/downloads/administrative-coderules.pdf

North Carolina Board of Nursing. (2013). Summary of NCLEX-RN first time tested. Retrieved from https://apps.ncbon.com/LicensureStats/LicStat-CATRNWEB.asp North Carolina Institute of Medicine. (2007). Task force on the North Carolina nursing workforce report. Retrieved from www.nciom.org 
Pena, A. (2010). The Dreyfus model of clinical problem-solving skills acquisition: A critical perspective. Medical Education Online, 15, 1-11. doi:10.3402/meo.v15i0.4846

Poindexter, K. (2013). Novice nurse educator entry level competency to teach: A national study. Journal of Nursing Education, 52(10), 559-566. doi:10.3928/0148483420130913-04

Prion, S., \& Adamson, K. (2014). Making sense of methods and measurement: Rigor in qualitative research. Clinical Simulation in Nursing, 10(2), 107-108. http://dx.doi.org/10.1016j.ecns.2013.05.003

Robinson, C. (2009). Teaching and clinical educator competency: Bringing two worlds together. International Journal of Nursing Education Scholarship, 6(1), 1-14. doi:10.2202/1548-923X.1793

Schoening, A. (2013). From bedside to classroom: The nurse educator transition model. Nursing Education Perspectives, 34(3), 167-172. http://dx.doi.org/10.5480/15365026-34.3.167

Siler, B., \& Kleiner, C. (2001). Novice faculty: Encountering expectations in academia. Journal of Nursing Education, 40(9), 397-403. Retrieved from http://web.b.ebscohost.com.ezp.waldenulibrary.org/ehost/pdfviewer/pdfviewer?vi $\mathrm{d}=7 \& \mathrm{sid}=58 \mathrm{a} 3 \mathrm{c} 828-0471-470 \mathrm{~b}-8 \mathrm{c} 2 \mathrm{e}-\mathrm{fb} 13 \mathrm{fd} 064248 \% 40$ sessionmgr111\&hid=101

Singh, M., Pilkington, B., \& Patrick, L. (2014). Empowerment and mentoring in Nursing Academia. International Journal of Nursing Education Scholarship, 11(1), 1-11. doi:10.1515/ijnes-2013-0070 
Skiba, D., Connors, H., \& Jeffries, P. (2008). Information technologies and the transformation of nursing education. Nursing Outlook, 56(5), 225-230. doi: 10.1016/j.outlook.2008.06.012

Smith, J., \& Zsohar, H. (2007). Essentials of neophyte mentorship in relation to the faculty shortage. Journal of Nursing Education, 46(4), 184-186. Retrieved from http://web.b.ebscohost.com.ezp.waldenulibrary.org/ehost/pdfviewer/pdfviewer?vi $\mathrm{d}=9 \& \operatorname{sid}=58 \mathrm{a} 3 \mathrm{c} 828-0471-470 \mathrm{~b}-8 \mathrm{c} 2 \mathrm{e}-\mathrm{fb} 13 \mathrm{fd} 064248 \% 40$ sessionmgr111\&hid=101

Spencer, C. (2013). From bedside to classroom: From expert back to novice. Teaching and Learning in Nursing, 8(1), 13-16. doi:10.1016/j.teln.2012.10.004

Suplee, P. \& Gardner, M. (2009). Fostering a smooth transition to the faculty role. Journal of Continuing Education in Nursing, 40(11), 514-520. doi:10.3928/00220124-20091023-09

Tanner, C. (2006). Thinking like a nurse: A research-based model of clinical judgment in nursing. Journal of Nursing Education, 45(6), 204-211. Retrieved from http://web.b.ebscohost.com.ezp.waldenulibrary.org/ehost/pdfviewer/pdfviewer?vi $\mathrm{d}=11 \& \operatorname{sid}=58 \mathrm{a} 3 \mathrm{c} 828-0471-470 \mathrm{~b}-8 \mathrm{c} 2 \mathrm{e}-$ fb13fd064248\%40sessionmgr111\&hid=101

Thorpe, K., \& Kalischuk, R. (2003). A collegial mentoring model for nurse educators. Nursing Forum, 38(1), 5-15. http://dx.doi.org/10.1111/j.17446198.2003.tb01198.x 
Vitale, A. (2010). Faculty development and mentorship using selected online asynchronous teaching strategies. Journal of Continuing Education in Nursing, 41(12), 549-556. doi:10.3928/00220124-20100803-02

Weidman, N. (2013). The lived experience of the transition of the clinical nurse expert to the novice nurse educator. Teaching and Learning in Nursing, 8, 102-109. http://dx.doi.org.10.1016/jteln.2013.04.006

West, M., Borden, C., Bermudez, M., Hanson-Zalot, M., Amorim, F., \& Marmion, R. (2009). Enhancing the clinical adjunct role to benefit students. Journal of Continuing Education in Nursing, 40(7), 305-310.

http://dx.doi.org/10.3928/00220124-20090623-05

White, A., Brannan, J., \& Wilson, C. (2010). A mentoring-protégé program for new faculty, part 1: Stories of protégés. Journal of Nursing Education, 49(11), 601607. doi:10.3928/01484834-20100630-04.

Wilson, C., Brannan, J., \& White, A. (2010). A mentor-protégé program for new faculty, part II: Stories of mentors. Journal of Nursing Education, 49(12), 665-671. doi:10.3928/01484834-20100730-08

Woolforde, L., Lopez-Zang, D. \& Lumley, L. (2012). The nursing professional development series: Addressing the learning needs of nurse educators. Journal of Continuing Education in Nursing, 43(9), 391-392. doi:10.3928/0022012420120822-03 
Appendix A: The Mentorship/Orientation Program for the ADN Nursing Faculty

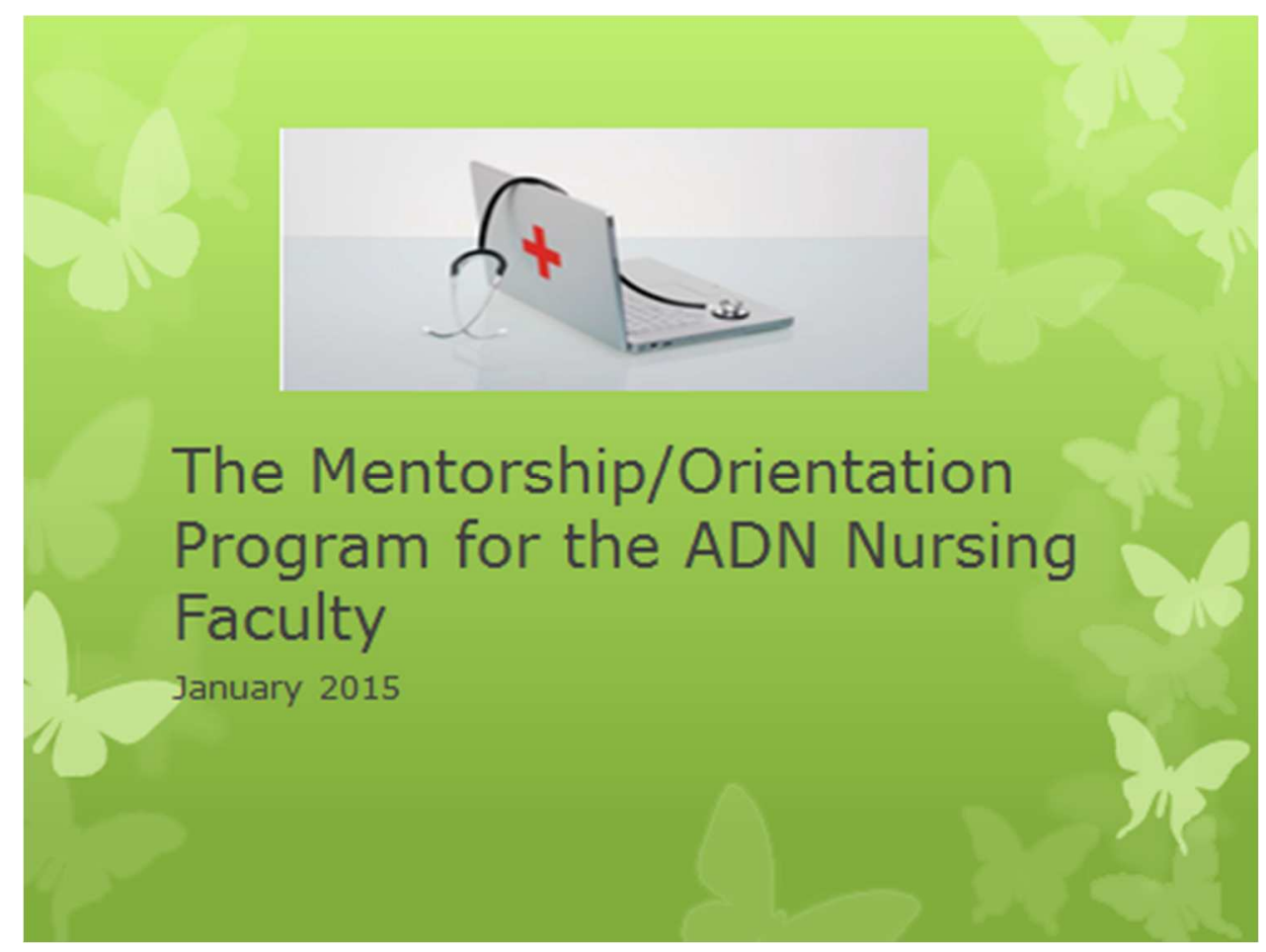




\section{Mentorship/Orientation Program Timeline}

Month 1 - The mentee will:

- Attend general college orientation

- Meet their assigned mentor/establish meeting times (weekly, bi-weekly, monthly)

- Review core concepts notebook

- Complete a Pre-novice educator competency survey

- Complete the four learning modules located in Moodle. Each module requires a passing score of at least $75 \%$. The modules contain information based on the NLN core competencies. These modules will give the educator an overview of the responsibilities of a nurse educator. Modules need to be completed no later than week 4.

- Complete the learning module evaluation

Month 2 - The mentee will:

- Begin observing their mentor in classroom and clinical settings

- Continue meeting times with mentor

Month - 3 - 4 The mentee will:

- Gain more hands on experience with classroom and clinical

- Evaluate the effectiveness of the program by completing the Post-novice educator competency survey

- Engage in a follow-up focus group interview to share their perceptions of being involved in a mentorship/orientation program

- Complete mentor evaluation form 


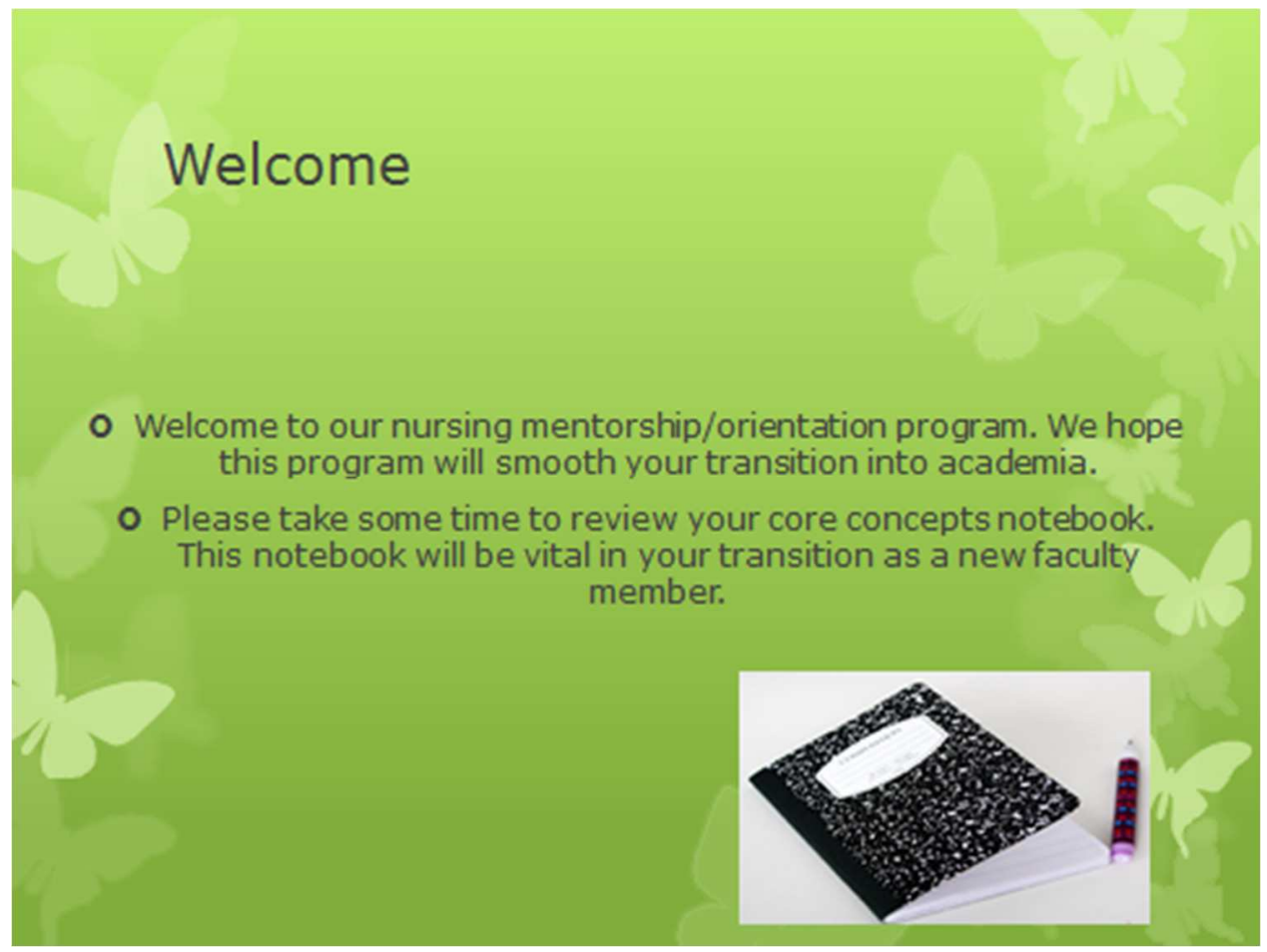

Welcome to our nursing program. We are pleased you decided to start your nurse educator journey with us. This program was designed to assist novice nurse educators to fully understand the aspects that go along with teaching students. The notebook that was provided to you will list the contact information of other department located on campus. In addition, the core concepts notebook also discusses faculty roles; classroom, testing, and, clinical expectations; and advising. 
First Things First
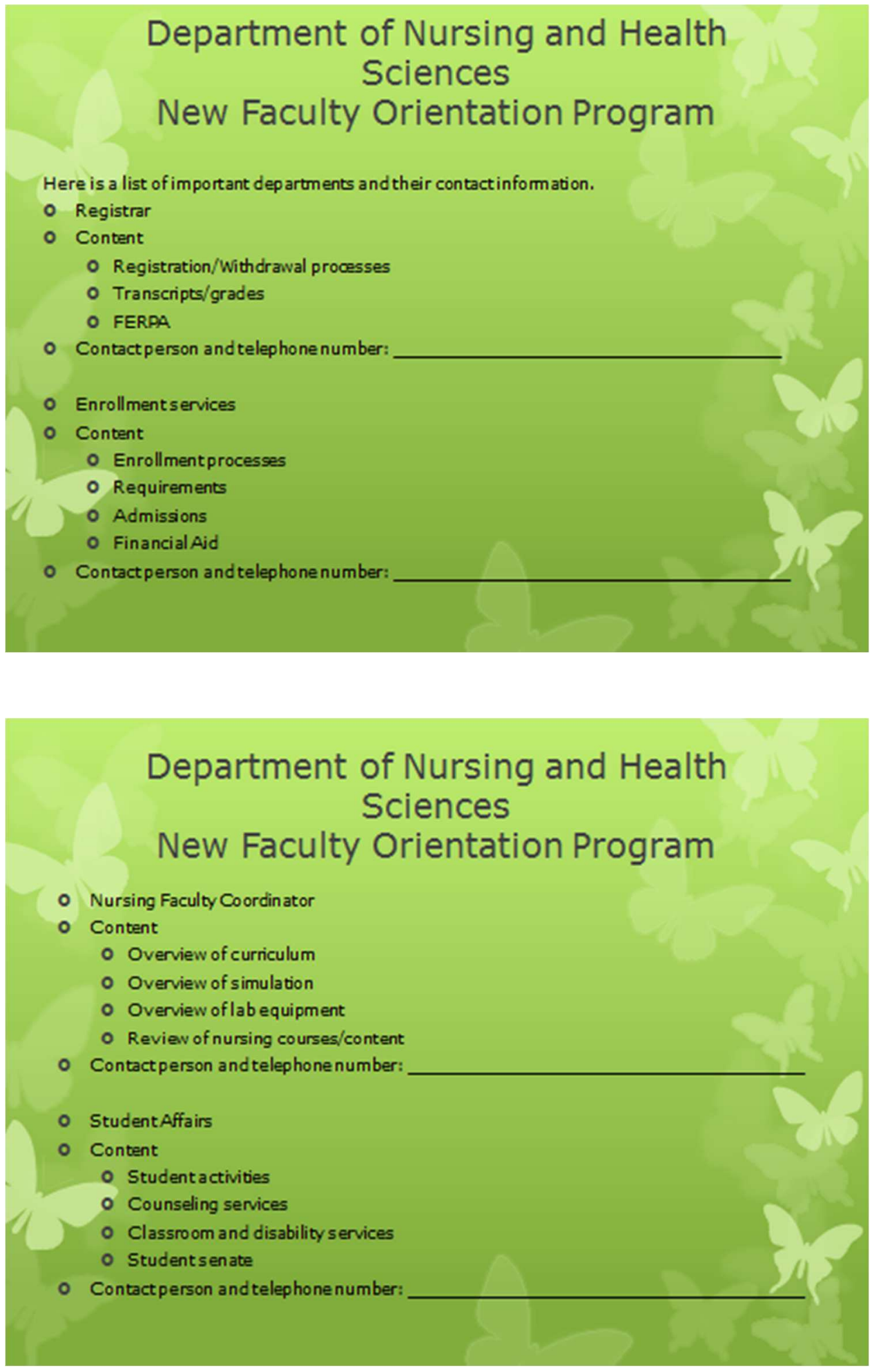


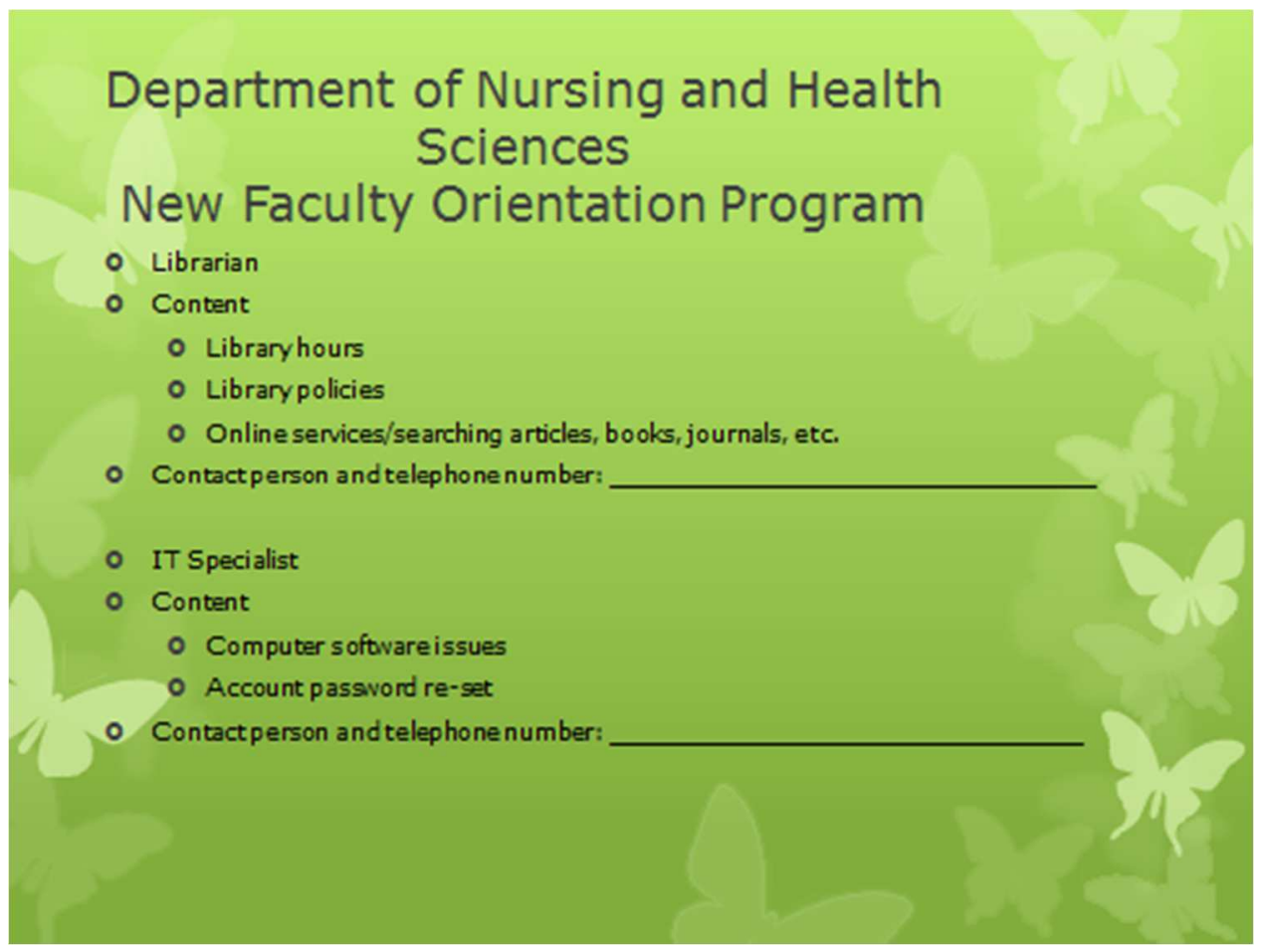

Here is a list of important departments located on campus. This information is also listed within your core concepts notebook. Please take a moment to familiarize yourself with each department and their services offered. As an educator, it is important to know your resources. 


\section{The Learning Modules Overview}

- This orientation/mentorship program is designed to provide novice educators (full and part time) the fundamental skills for teaching students.

- In order to understand the information, we ask all novice faculty to review the 4 learning modules. These learning modules are voiced over PowerPoint slides that last approximately 15 minutes. Each of the modules will end with a post-test that is required for the educator to take in order to advance to the next learning module. You can find the modules located under the "Teaching Resources" section within Moodle. 


\section{The Learning Modules}

- These 4 learning modules are based on the NLN core competencies. Although there are 8 competencies, this program will only focus on the 4 , we feel are critical to novice educators.

- Please complete all 4 of the learning modules within the first month of your hire date.

\section{The NLN Core Competencies}

- The eight core competencies are:

- Facilitate Learning

- Facilitate Learner Development and Socialization

- Use Assessment and Evaluation Strategies

- Participate in Curriculum Design and Evaluation of Program Outcomes

- Function as a Change Agent and Leader

- Pursue Continuous Quality Improvement

- Engage in Scholarship

- Function within the Educational Environment 


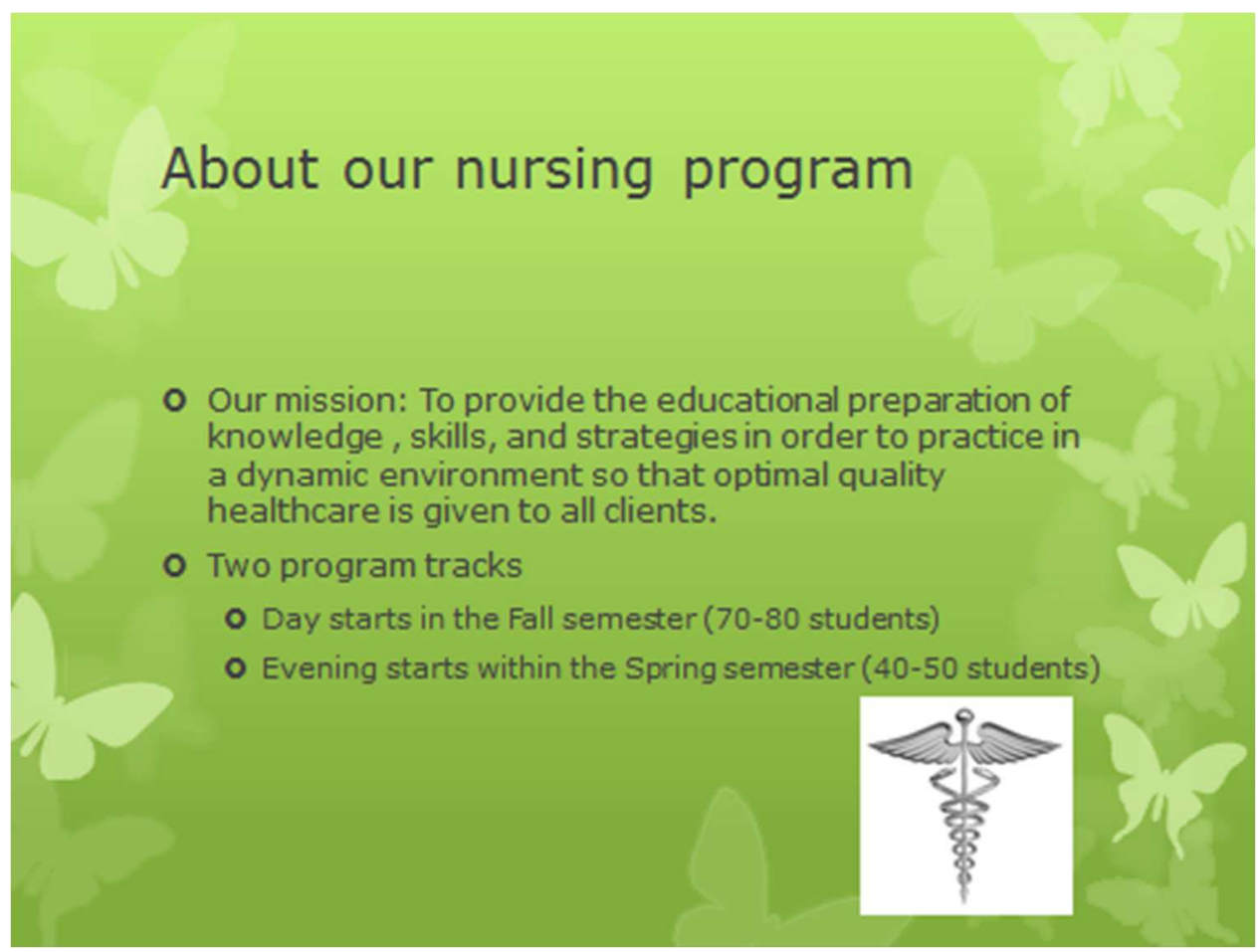

The associate degree in Nursing is a two-year curriculum that begins each fall or spring semester. It is a limited enrollment program in which applicants must meet minimum requirements by the specific deadline date to be considered for admission. Please note that meeting the minimum requirements does not guarantee admission to the program. General requirement for admission include: Three phases

Phase I

\section{Complete college admission process:}

Current nursing application, submit official high school, GED, or Adult High School, and college transcripts. (College transcripts will be reviewed for possible transfer credit.)

\section{Attend a mandatory nursing applicant information session:}

-No sign-up required. Attendance is taken at the conclusion of the session.

3. Meet minimum placement test scores:

Applicants must be eligible to register for college-level English and Math.

4. Meet biology competency

5. Completion of a North Carolina State Approved Nursing Assistant I course within the last ten years \& current active listing on NC Nurse Aide I Registry:

6. Complete Minimum Admissions Requirements

Phase II

Complete the Test of Essential Academic Skills (TEAS 5.0) with a minimum score of 62.

Phase III

Ranking review 


\section{About our nursing program}

- Nursing Courses

- NUR 111- Intro to health concepts

- NUR 112-Health/Illness conœpts

- NUR 113-Family health concepts

- NUR 114-Holistic concepts

- NUR 211-Healthcare concepts

- NUR 212-Health systems concepts

- NUR 213-Compex health concepts 
Module I

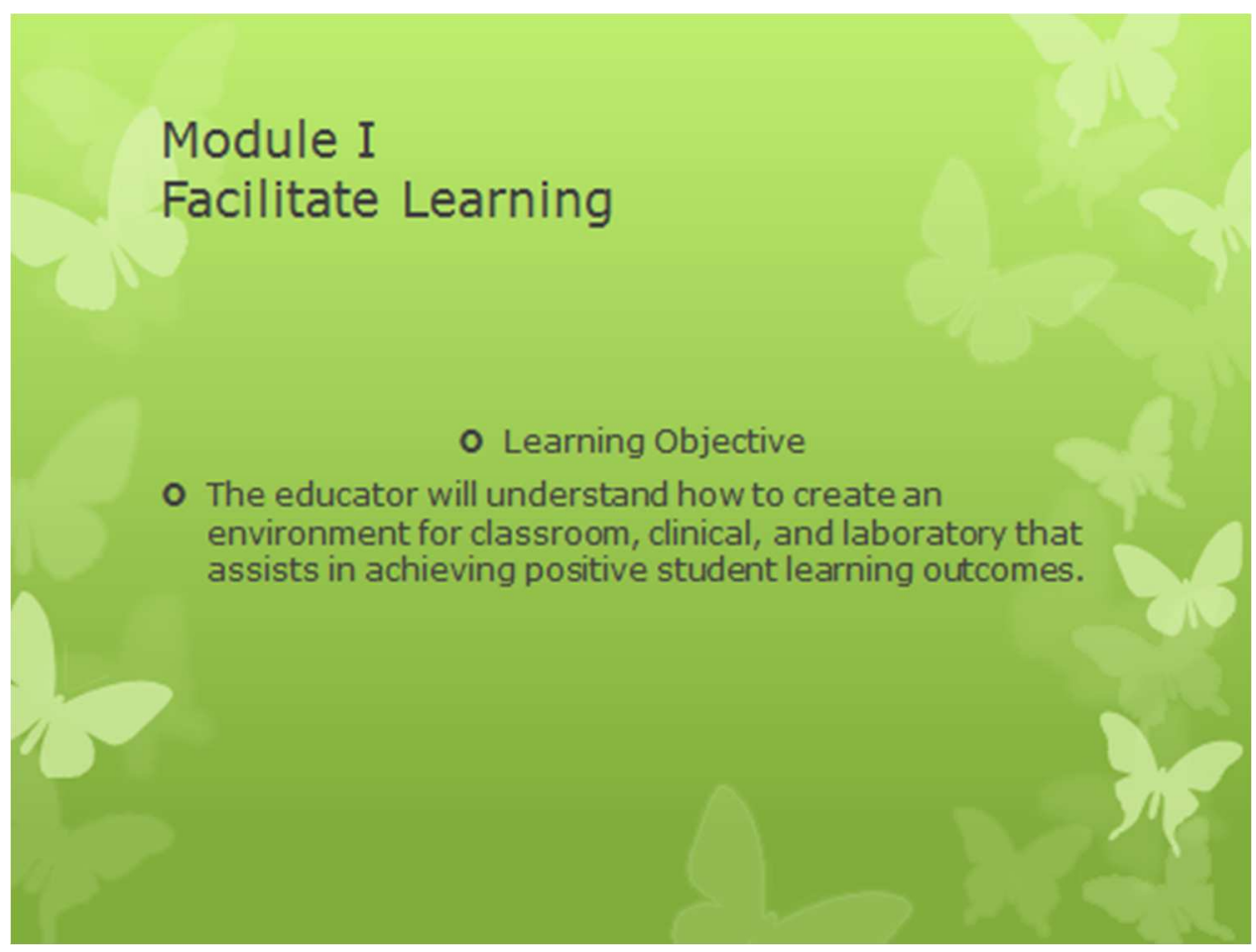

This learning module will discuss the NLN core competency Facilitating Learning. Please turn up your speakers, as this module is a voice over PowerPoint. Total run time for Module I is 15 minutes. 
Module I

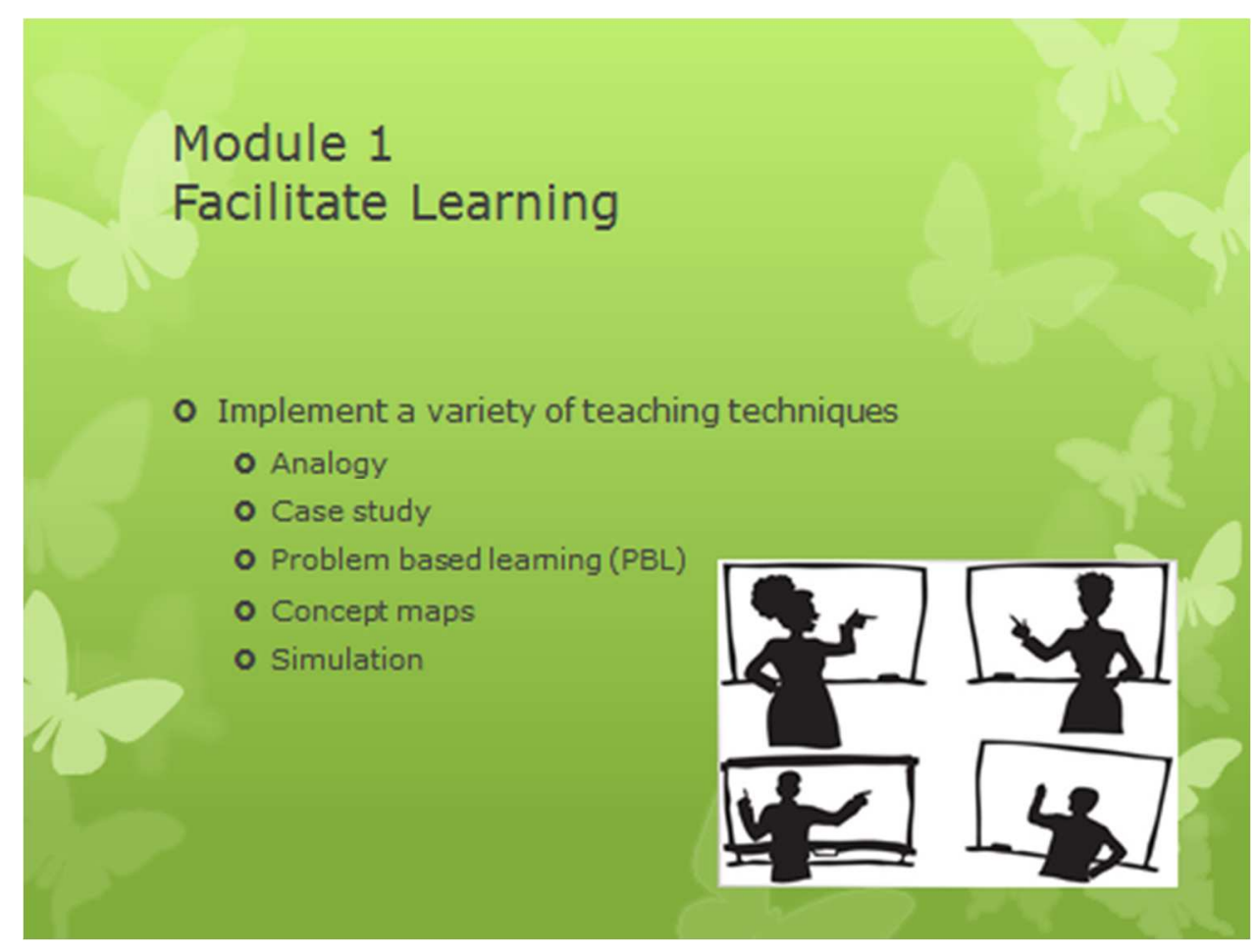

Analogy can be implemented to assist students in understanding unfamiliar content. Analogy enriches the comprehension of difficult conceptions by letting learners view the situation in another viewpoint. This technique can be implemented in different educational situations and can be applied to big or small groups, or used individually as a project.

Advantage: Is an effective learning approach, which can encourage critical thinking abilities.

Disadvantage: This technique won't interest every learner; several learners will be unwilling to take part and might think the technique a waste of their instructional time. Some learners struggle with creating the relationship in a significant manner.

Case study requires a breakdown of a clinical problem or situation. This teaching technique is primarily implemented to depict a realistic patient situation in the clinical setting. Therefore, it allows learners to understand theories and problem-solve within a clinical aspect. Case studies range from easy to difficult. Critical thinking happen when learners pose ideas that include problem solving rather than interpreting the information. The responsibility of the educator is to assist by integrating different possibilities presented by the learners' inquiries. 
Advantages: Encourages critical thinking skills through the breakdown and understanding the information. Exhibits nursing theories in a clinical manner so the learner can associate with them. When performed in a smaller group, case studies can create dialogue and students begin sharing ideas and thoughts among each other.

Disadvantages: Developing case studies require clinical experience and can be time consuming.

PBL is a learning technique that includes a group of student who work together to solve problems of realistic clinical scenarios. This technique also encourages critical thinking to occur. When PBL is implemented correctly, learners acquire the awareness of conceptions/information by collaborating during the scenario. Basically, the information is self-taught. PBL is preferably performed in smaller groups and take place over multiple learning sessions. Basic content is briefly discussed that helps set the tone for the scenario but the actual issue is not discussed. The learners among the group should recognize pertinent factors, and work together to figure out what other data will be necessary in the scenario. Throughout the PBL activity, the learners will achieve a solution to the clinical issue.

Advantages: Encourages learners to discover knowledge and critical thinking. Is also considered a learning technique that is active.

Disadvantages: For educators, gathering and organizing the necessary information and gaining the knowledge of teaching PBL is time consuming. Initially, learners may be displeased with the teaching technique; additionally, some might feel that all the work is being done by them with the expectation that this should be the responsibility of the educator. Educators may also feel concerned in regards to not lecturing or discussing the information.

Concept maps This teaching technique is a great way to promote critical thinking because it involves the learners to think, analyze several correlations, and consider various perceptions.

Advantages: This technique will display a cause and effect association to clinical problems. Leaners pay attention to several issues at once.

Disadvantages: Outline of map may be difficult to design and time intensive; multiple attempts of redrawing the map may occur so that appearance of concepts are optimized; may become jumbled that learners may have a hard time seeing the big picture.

Simulation allows the learner to become involved in the "real world" clinical scenarios without the threat of harm. The learner is expected to evaluate and make sense of the 
scenario, and implement judgments related to the facts that were given. Primarily takes place in a laboratory; simulation learning lets the learner perform a variation of skills which include physical assessments, psychomotor skills, and critical thinking.

Advantages: Encourages problem solving via assessing, analyzing, and deciding on interventions; rationales occur nonlinearly. Learners can run through scenarios as often as needed to gain experience, improve skills, and increase self-assurance.

Disadvantages: Developing scenarios can be time consuming. Setting up necessary equipment and material requires the assistance of several people, and asking additional educators to assist when several groups are concurrently engaging in the learning technique.

Implementing a variety of different teaching strategies can create opportunities for learners to develop their critical thinking and critical thinking skills.

** Reference: The University of New Mexico College of Nursing. (n.d.). Retrieved from http://nursing.unm.edu/resources/teaching-and-learning-strategies.html 
Module I

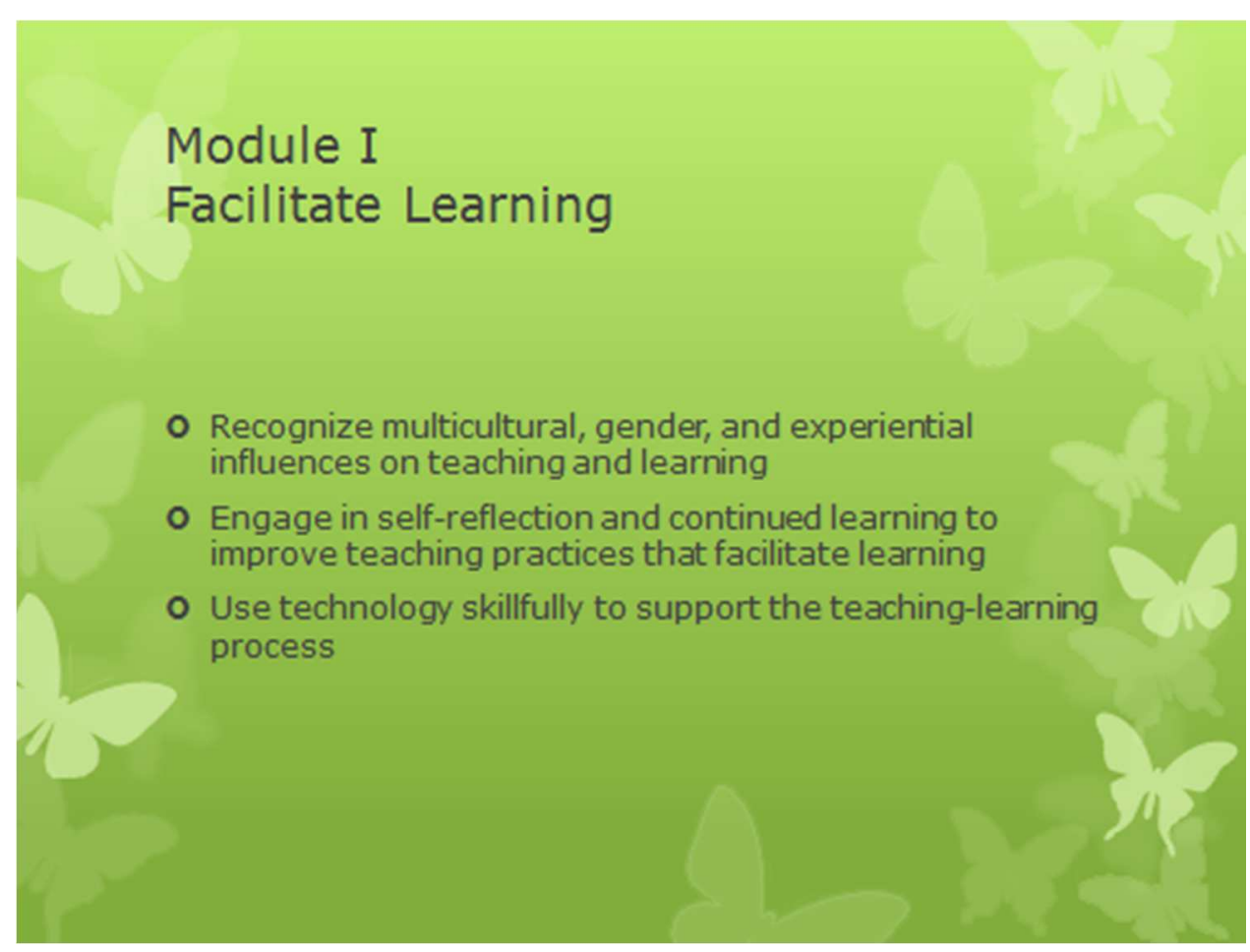

With the number of nontraditional students growing, many educators have discovered that adult learners are fundamentally different than their younger counterparts in many ways. Adult learners benefit from realistic examples of skills they can use in real life. Adult students have jobs, sometimes children and tons of responsibilities, so pack every class with information and useful activities. Consider balancing instructional time with lab time, giving students an opportunity to do modeling work or homework in class to give them a better chance of accomplishing all the requirements on time.

Reflective teaching means looking at what you do in the classroom, thinking about why you do it, and thinking about if it works - a process of self-observation and selfevaluation. By collecting information about what goes on in our classroom, and by analyzing and evaluating this information, we identify and explore our own practices and underlying beliefs. This may then lead to changes and improvements in our teaching. You may begin a process of reflection in response to a particular problem that has arisen with one or your classes, or simply as a way of finding out more about your teaching. You may decide to focus on a particular class of students, or to look at a feature of your teaching.

The purpose of using social media tools to facilitate such integration was to emphasize professional communication; better improve student comprehension and use of technology beyond electronic medical records (EMR) and personal computer word processing programs; and enhance student networking and collaboration with other 
nurses globally. The use of technology in education has removed educational boundaries, both students and instructors can collaborate in real time using advanced educational technologies. Technology is helping educators to expand beyond linear, text-based learning and to engage students who learn best in other ways.

** Reference: Doherty, B. (2012). Tips for teaching adult students. Retrieved from http://www.facultyfocus.com/articles/effective-teaching-strategies/tips-for-teaching-adult-students/ 
Module I

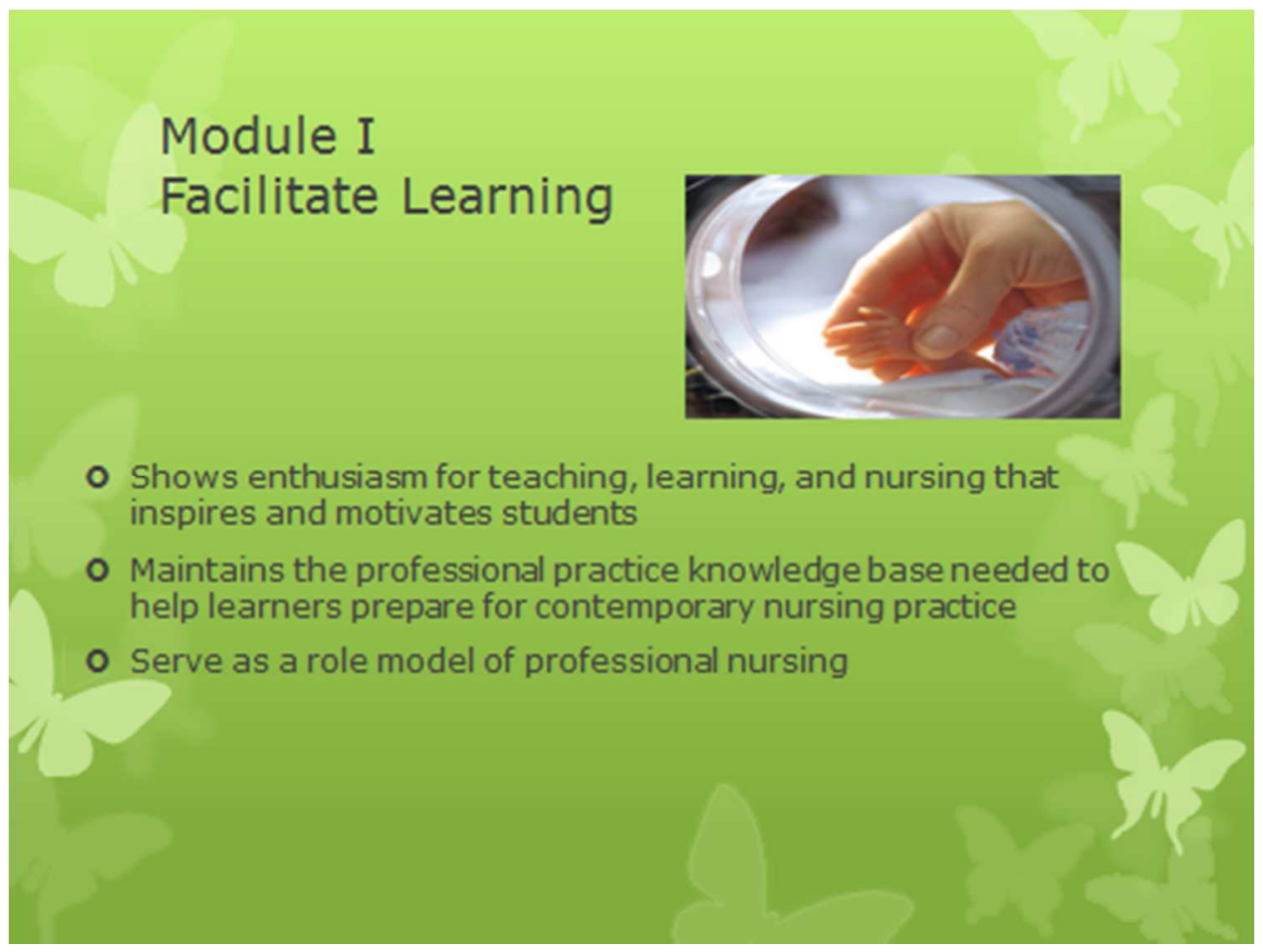

Nurse educators combine clinical expertise and a passion for teaching into rich and rewarding careers. These professionals, who work in the classroom and the practice setting, are responsible for preparing and mentoring current and future generations of nurses. Nurse educators play a pivotal role in strengthening the nursing workforce, serving as role models and providing the leadership needed to implement evidence-based practice. It is important we teach our students that true nursing is about one on one relationships nurse to nurse, nurse to doctor, and most importantly, nurse to patient. All relationships matter. You never know who or what will be the source of your first job but more importantly what you will learn from that person.

** Reference: Contributor, N. (2012). My nursing role model. Retrieved from http://www.nursetogether.com/my-nursing-role-model 


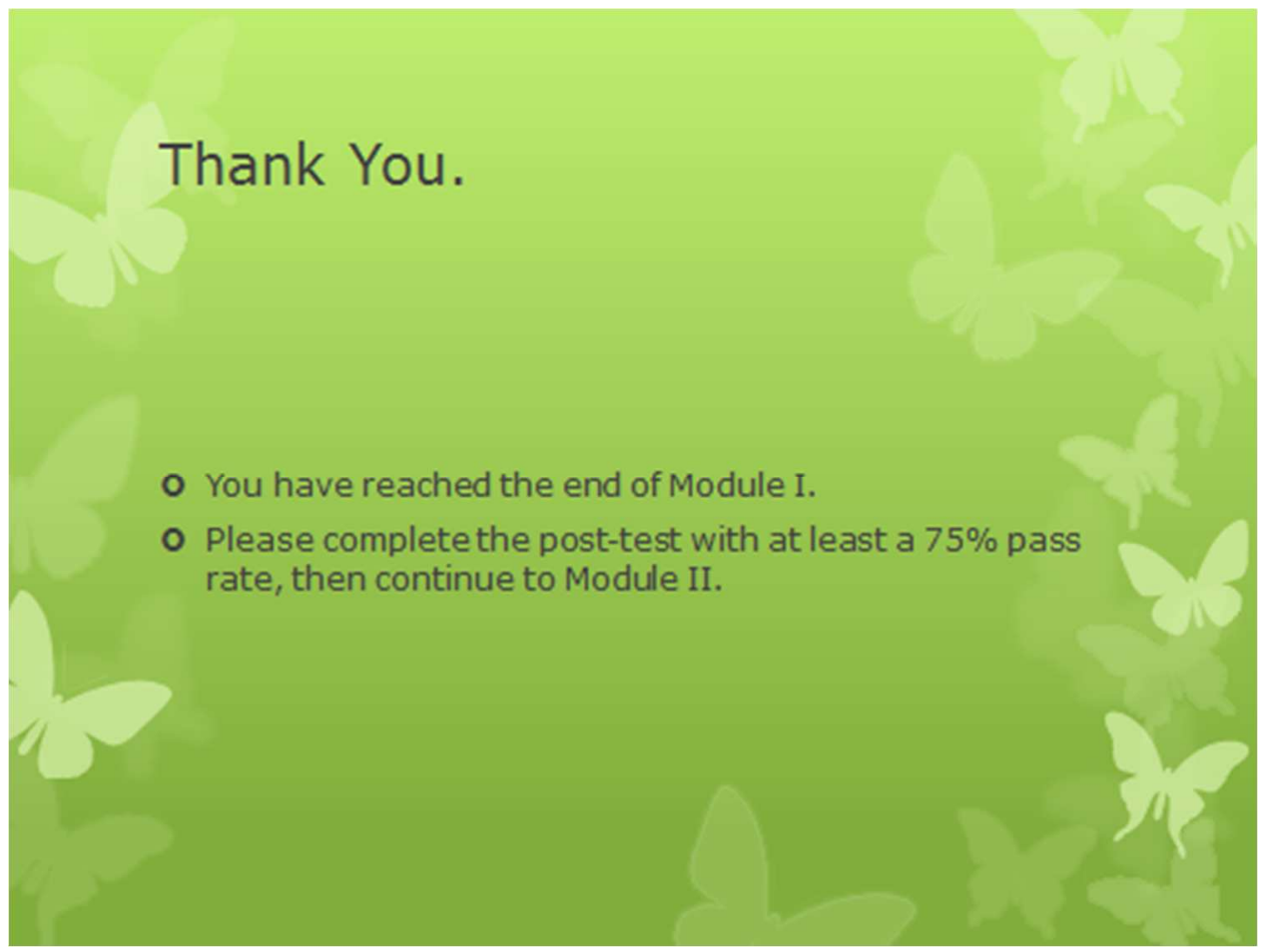




\section{Module I - Posttest}

1. Case studies are discouraged in academia because they do not stimulate critical thinking among students?

True or False

2. Which of the following teaching strategies demonstrates a cause and effect relationship to patient problems?
a. Concept maps
b. Case studies
c. Simulation
d. All the above

3. _ is utilized among educators to evaluate if their teaching skills are effective among all students?

Fill in the blank

4. Although nurse educators cannot teach students to be compassionate, it is our duty to demonstrate and model how a nurse's relationship with other nurses, doctors, and patients are supposed to be.

True or False 
Module I - Answer Key

1. False - Case studies do stimulate critical thinking

2. A. Concept maps - Shows cause effect and relationships to patient problem beyond what a traditional nursing care plan allows.

3. Reflective teaching - means looking at what you do in the classroom, thinking about why you do it, and thinking about if it works - a process of self-observation and self-evaluation.

4. True - It is important we teach our students that true nursing is about one on one relationships nurse to nurse, nurse to doctor, and most importantly, nurse to patient. All relationships matter. You never know who or what will be the source of your first job but more importantly what you will learn from that person. 
Module II

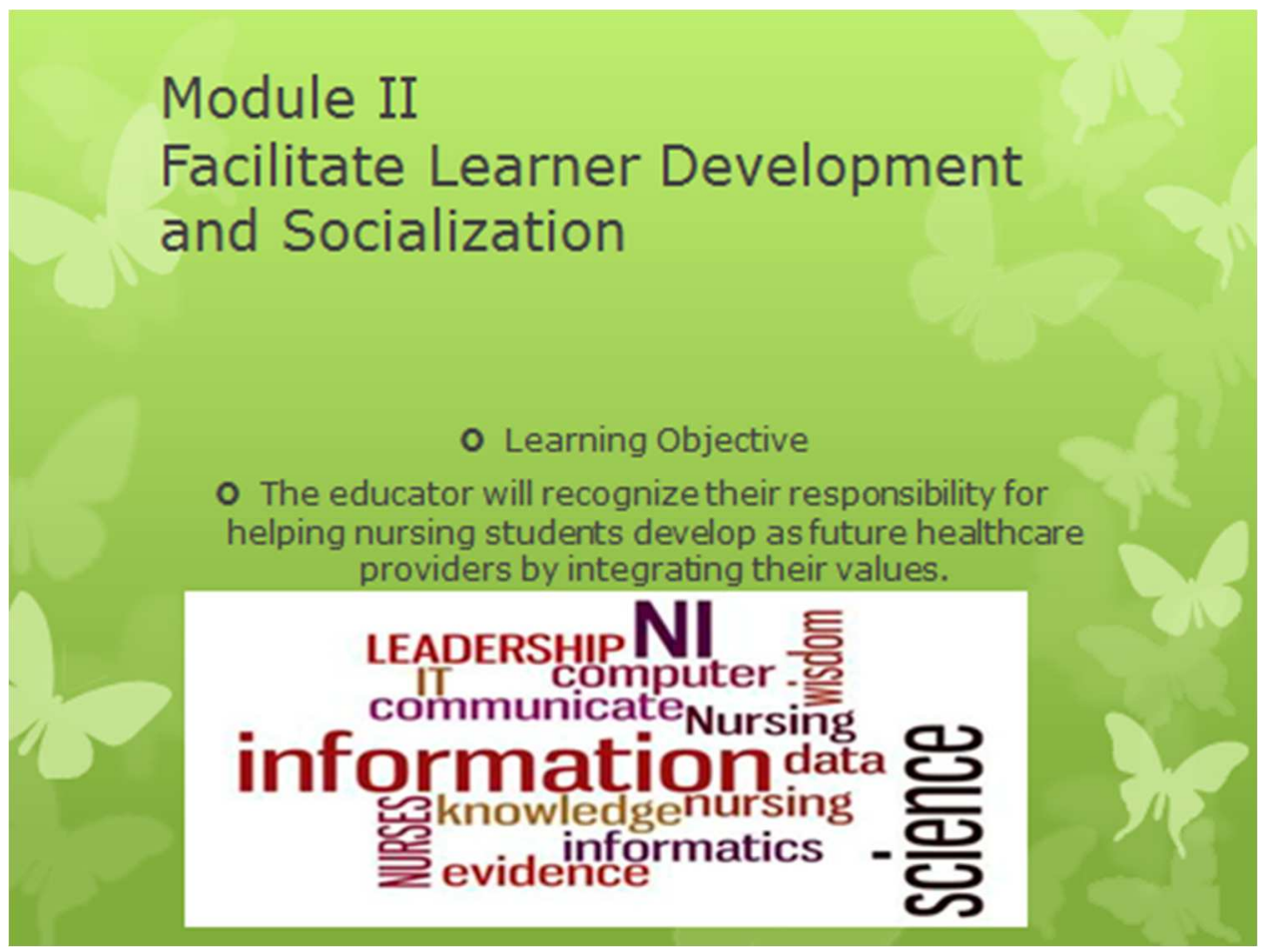

This learning module will discuss the NLN core competency Facilitate Learner Development and Socialization. Please turn up your speakers, as this module is a voice over PowerPoint. Total run time for Module II is 15 minutes. 


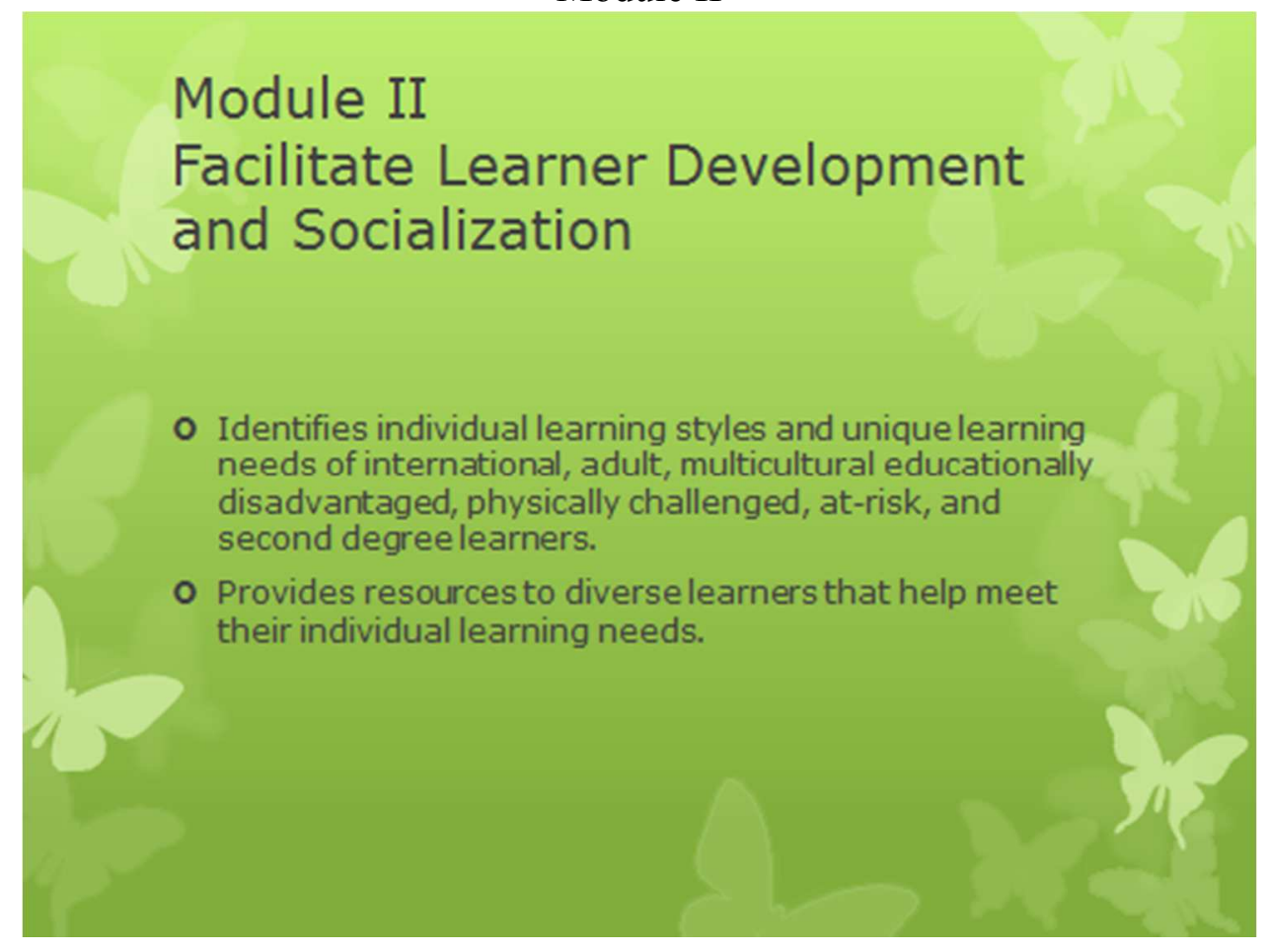

To help meet this criteria nurse educators can use class reflection. Class reflection can help educators determine which methods of teaching certain course material are effective. Nurse educator many have to implement a few different techniques within one class lecture to help each student understand the information. Additionally, it is pertinent that nurse educators identify the individual learning needs of each student and so that we can create a positive learning environments which will help to increase the knowledge skills and attitudes over time of each student so that students can meet their goals. Our nursing program admits a diverse variety of individuals. Each individual brings different life experiences and learning styles. Therefore, the nurse educator must utilize diverse teaching styles.

Nurse educators can also provide outside resources as a means of teaching to assist in a student's unique learning style. With technology being so advanced, there are many ways to help students understand the concepts in nursing.

**Reference: National League for Nursing. (2012). The scope of practice for academic nurse educators. New York, NY: National League for Nursing. 
Module II

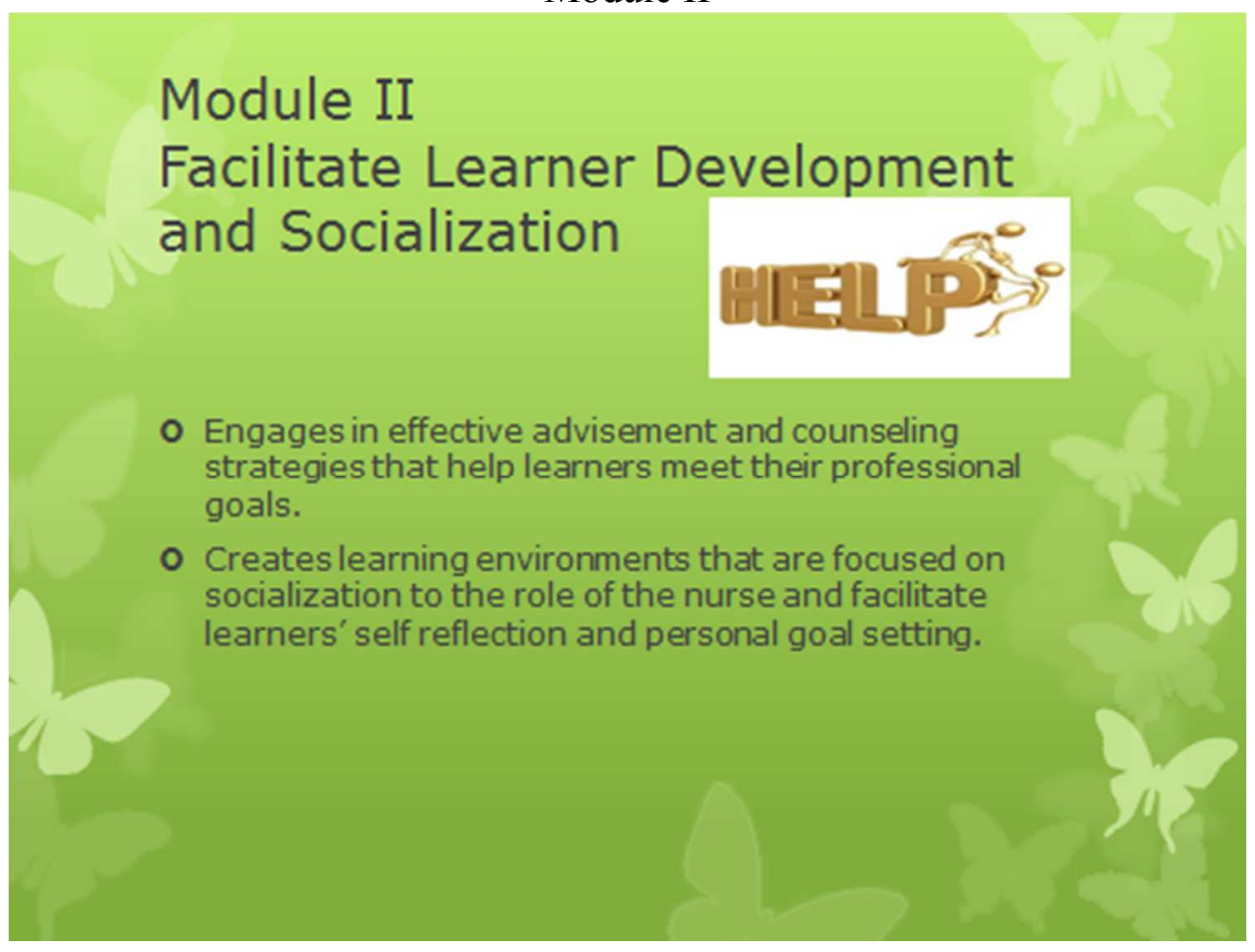

Nurse educators often time become mentors, coaches, and advisors to nursing students. Students seek assistance from instructors, especially if a rapport is already built. Student academic advising can be a time where educator and student connect to solve problems, determine goals, and gain clarity in nursing concepts.

Socialization to the role occurs during the entire nursing program. Socialization is a process of learning the norms, attitudes, behaviors, skills, roles, and values of the profession. There are two processes that help individuals learn their roles: first is the process of interacting with groups and significant others, and second is to learn from role playing, identification, modeling, instruction, observation, and trial and error. The outcome of professional socialization is to allow students to communicate effectively to patients, physicians, family, colleagues, and other multidisciplinary teams. By interacting with different groups of people, students have the opportunities to learn different experiences from each other and subsequently contribute to professional selfdevelopment. Socialization is a lifelong process beginning with the curriculum and faculty of the nursing program and is then extended into work setting. The development of professional values does not only begin with professional education in nursing but also continues along a continuum throughout the years of nursing practice.

\footnotetext{
**Reference: Lai, P. \& Kim, P. (2012). Concept of professional socialization in nursing. IeJSME, 6(1) 31-
} 35 . 
Module II

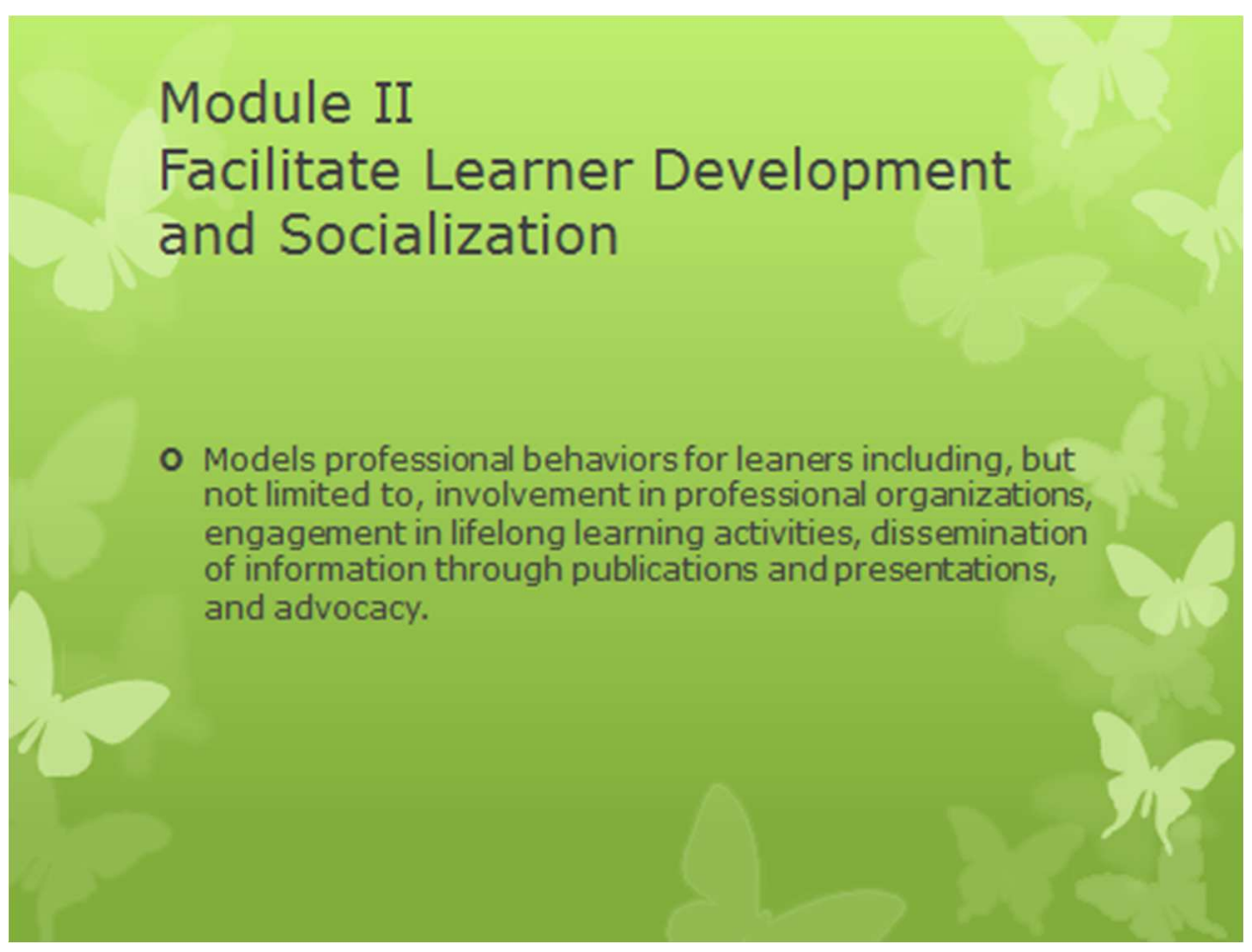

Inform and discuss the importance of the professional nursing organizations such as (but not limited to):

- American Academy of Ambulatory Care Nursing

- American Nurses Association

- International Council of Nurses

- National Organization for Associate Degree Nursing

Continuing education (CEs) is also another important aspect within the nursing profession. Each year nurses should complete at least $15 \mathrm{CEs}$ in order to maintain compliant with the NCBON requirements. This is an example of lifelong learning. 


\section{Thank you}

- You have reached the end of Module II.

- Please complete the post-test with at least a $75 \%$ pass rate, then continue to Module III. 
Module II - Posttest

1. It isn't necessary to implement several different teaching methods while teaching students because all students learn the same.

True or False

2. Socialization occurs when a person learns which aspects of the profession?
a. Norms
b. Attitudes
c. Behaviors
d. Skills
e. All of the above

3. such as YouTube.com and the internet are often integrated to help students understand the concepts of nursing.

Fill in the blank

4. Nurses are required to obtain continuing education each year to maintain compliance with the NCBON.

True or False 
Module II - Answer Key

1. False - It is pertinent that nurse educators identify the individual learning needs of each student and so that we can create a positive learning environments which will help to increase the knowledge skills and attitudes over time of each student so that students can meet their goals.

2. E. All the above - Socialization is a process of learning the norms, attitudes, behaviors, skills, roles, and values of the profession.

3. Technology - Nurse educators can also provide outside resources as a means of teaching to assist in a student's unique learning style. With technology being so advanced, there are many ways to help students understand the concepts in nursing.

4. True - Each year nurses should complete at least 15 CEs in order to maintain compliant with the NCBON requirements. 
Module III

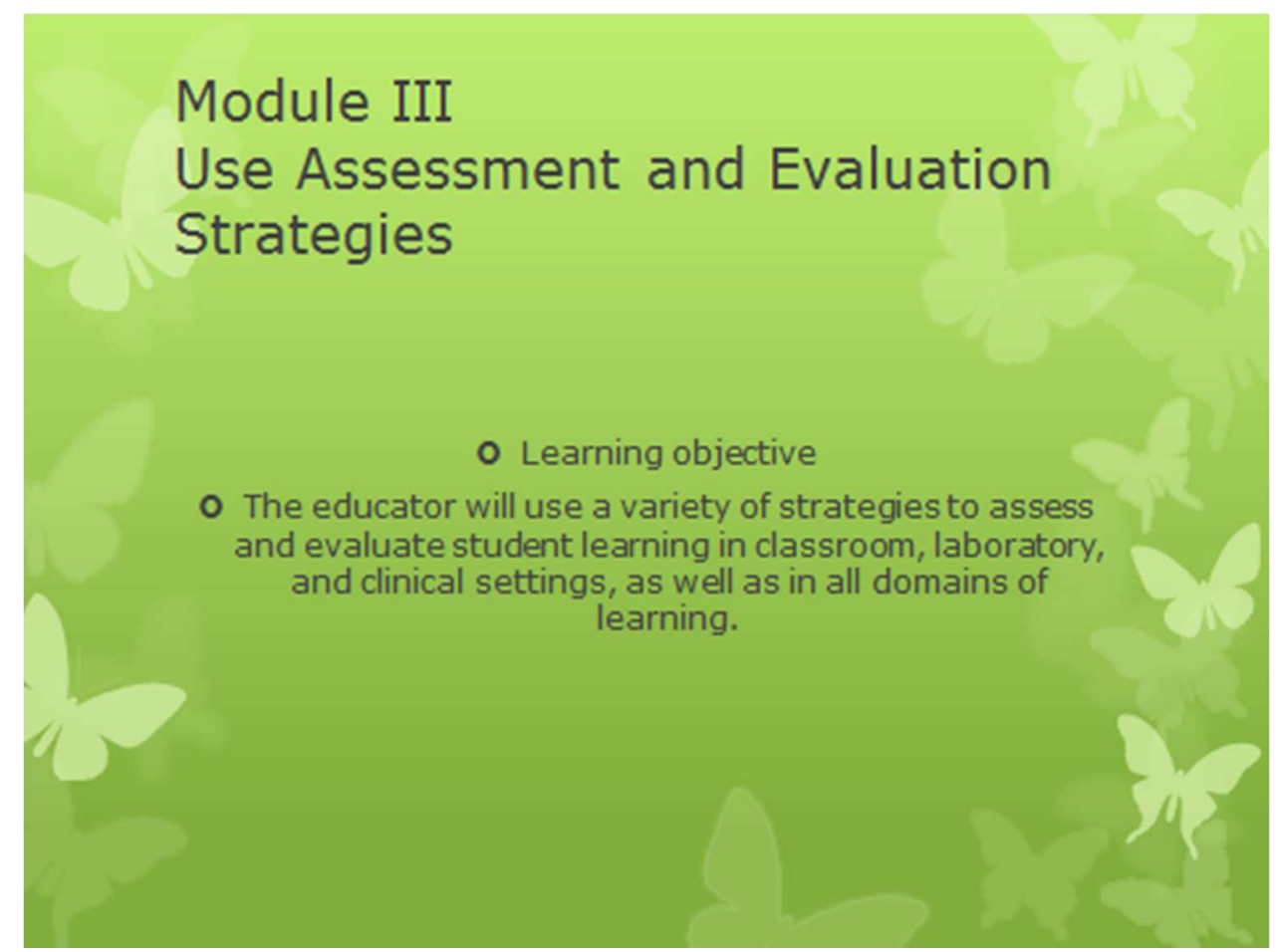

This learning module will discuss the NLN core competency Use Assessment and Evaluation Strategies. Please turn up your speakers, as this module is a voice over PowerPoint. Total run time for Module III is 15 minutes. 


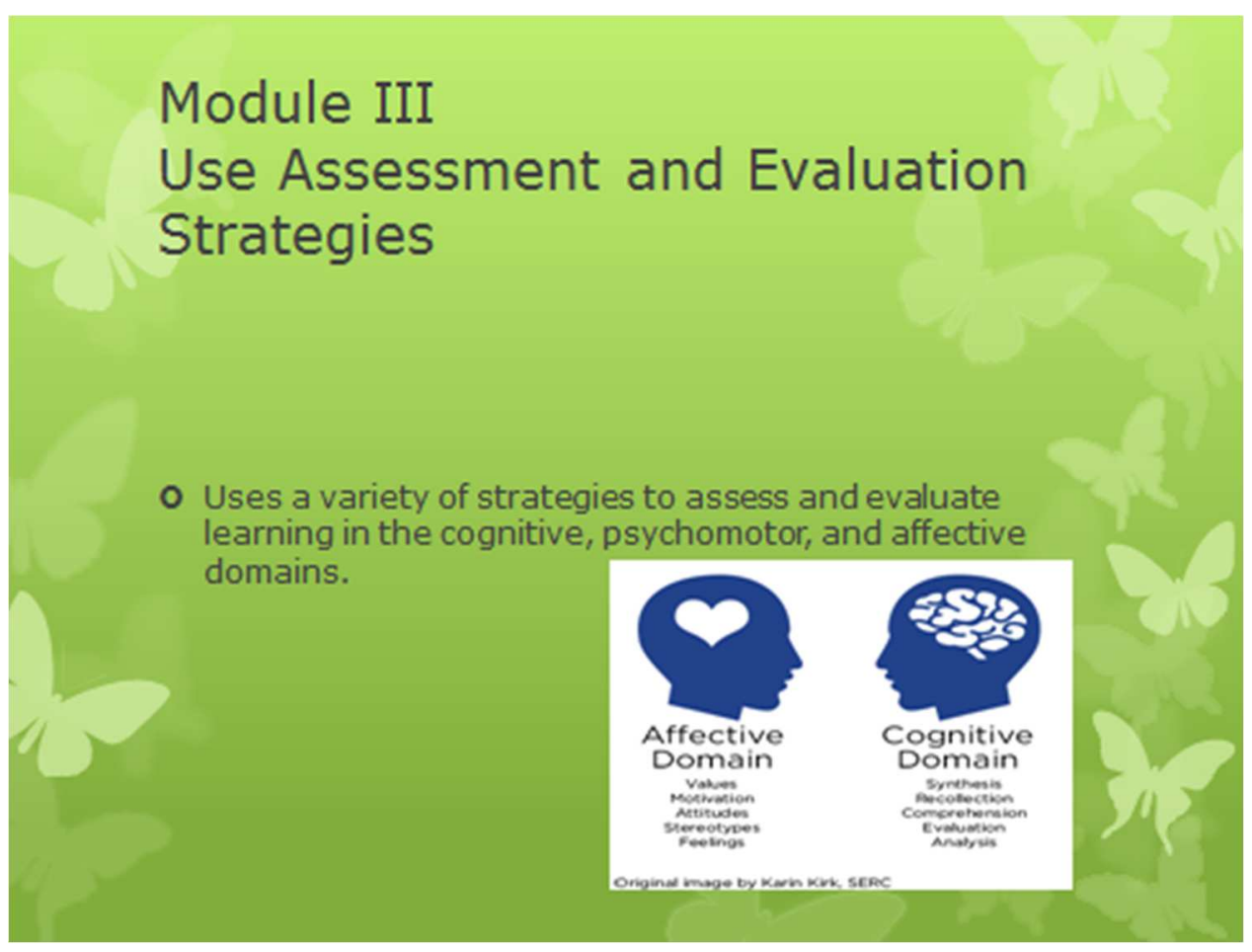

The three domains cognitive, psychomotor, and affective are all important in the profession of nursing. With each domain, the educator can implement different evaluation strategies to assess competency of the student.

For example, cognitive (mental) the nurse educator can uses tests, case studies, verbal reports, and critical thinking skills (clinical) to evaluate if the student has grown in that particular area.

Psychomotor (manual or physical skills) the use of laboratory check offs or skills in the clinical setting can be a means of evaluating the students competency of skills. In addition, educators can put a list of skills in a bag and allow each student to pull one skills and assess their competency. This method focuses on the recall of knowledge rather than memorization.

Affective (growth in feelings, attitude) can be assessed and evaluated through the use of therapeutic communication. In this technique, the students will partner together and pick a scenario. One student will be the patient and the other student will be the nurses. The goal of this technique is to ensure the student nurse is talking effectively in preparation for actual clinical setting situations. 
Module III

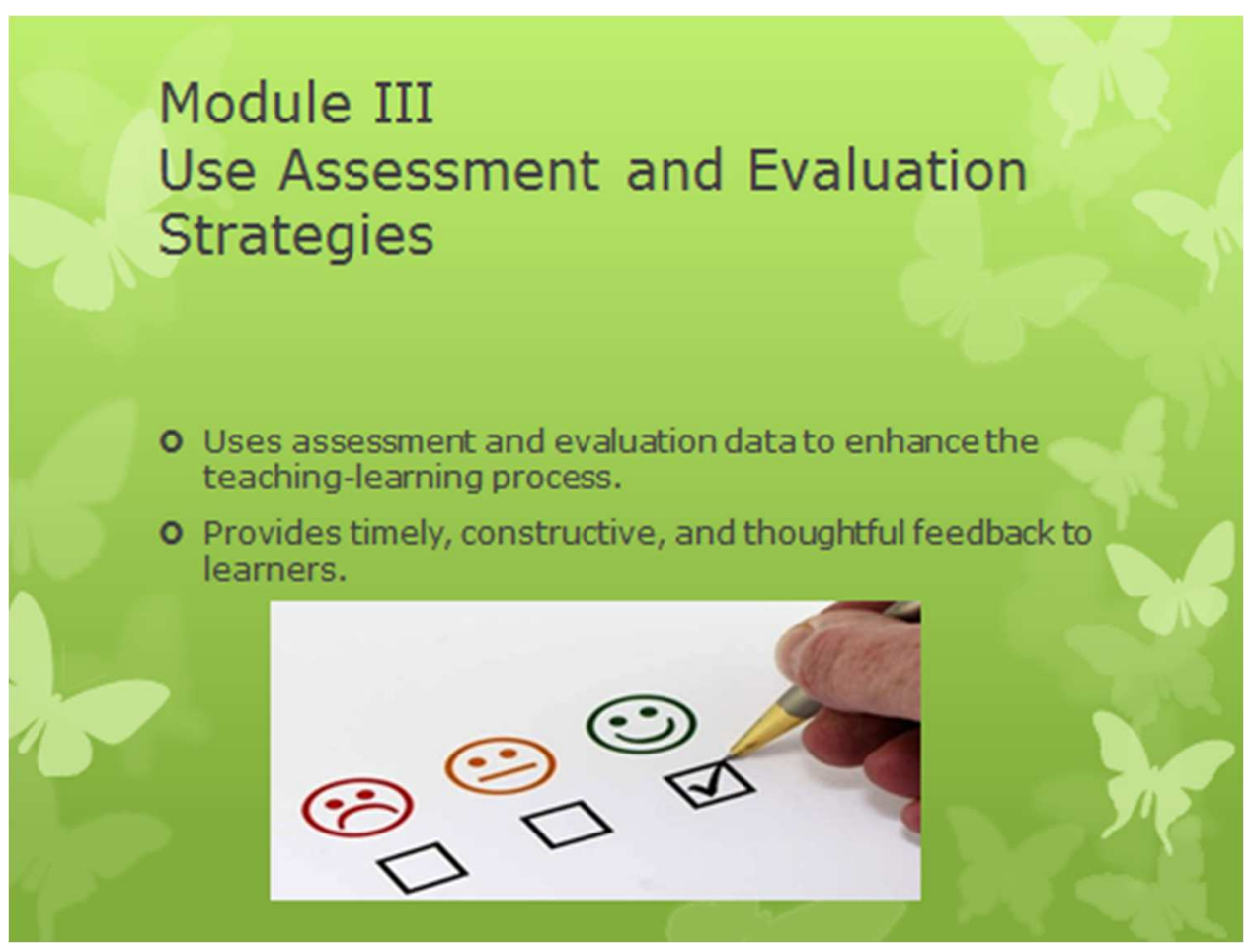

Assessment and evaluation are on-going processes so that the ultimate goal is to improve student learning outcomes. The more information we can gather, a more positive learning environment can be created. Formative and summative assessments can be implemented to gather the necessary data. Formative assessments can be quizzes, concept maps, flash cards or questions. Gathering this type of data can help the instructor to make changes if needed. Summative assessments can be in form of final exams or final projects. This information can help improve future teaching strategies if indicated.

Providing feedback is essential in any profession. Nurse educators must be honest with students. It is our duty to help each student succeed to their highest potential. Therefore, we must provide constructive and thoughtful feedback to that student so they can improve in their knowledge, skills, or thinking abilities in order to be a competent healthcare provider. However, it is equally important to give positive feedback to help build self-esteem. If possible, when having a conversation with a student about patient care, it is best to pull the student away from the patient and other classmates so that embarrassment does not set in or the student does not shut down.

\footnotetext{
** Reference Clynes, M. \& Raftery, S. (2008). Feedback: An essential element of student learning in clinical practice. Nurse Education in Practice. Retrieved from http://www.nurseeducationinpractice.com/article/S1471-5953(08)00020-6/references
} 


\section{Thank you}

- You have reached the end of Module III.

- Please complete the post-test with at least a $75 \%$ pass rate, then continue to Module IV. 
Module III - Posttest

1. Educators can use therapeutic communication to assess the psychomotor domain of students.

True or False

2. The cognitive domain can be assessed by which of the following:
a. Clinical skills
b. Medication administration
c. Case studies
d. Therapeutic communication

3. is an on-going process so that student outcomes can be improved.

Fill in the blank

4. Constructive feedback is discouraged because it can hurt the student's feelings. True or False 
Module III - Answer Key

1. False - Affective (growth in feelings, attitude) can be assessed and evaluated through the use of therapeutic communication.

2. A. Clinical skills - Cognitive (mental) the nurse educator can uses tests, case studies, verbal reports, and critical thinking skills (clinical) to evaluate if the student has grown in that particular area.

3. Assessment and Evaluation - Assessment and evaluation are on-going processes so that the ultimate goal is to improve student learning outcomes.

4. False - Nurse educators must be honest with students. It is our duty to help each student succeed to their highest potential. Therefore, we must provide constructive and thoughtful feedback to that student so they can improve in their knowledge, skills, or thinking abilities in order to be a competent healthcare provider. 
Module IV

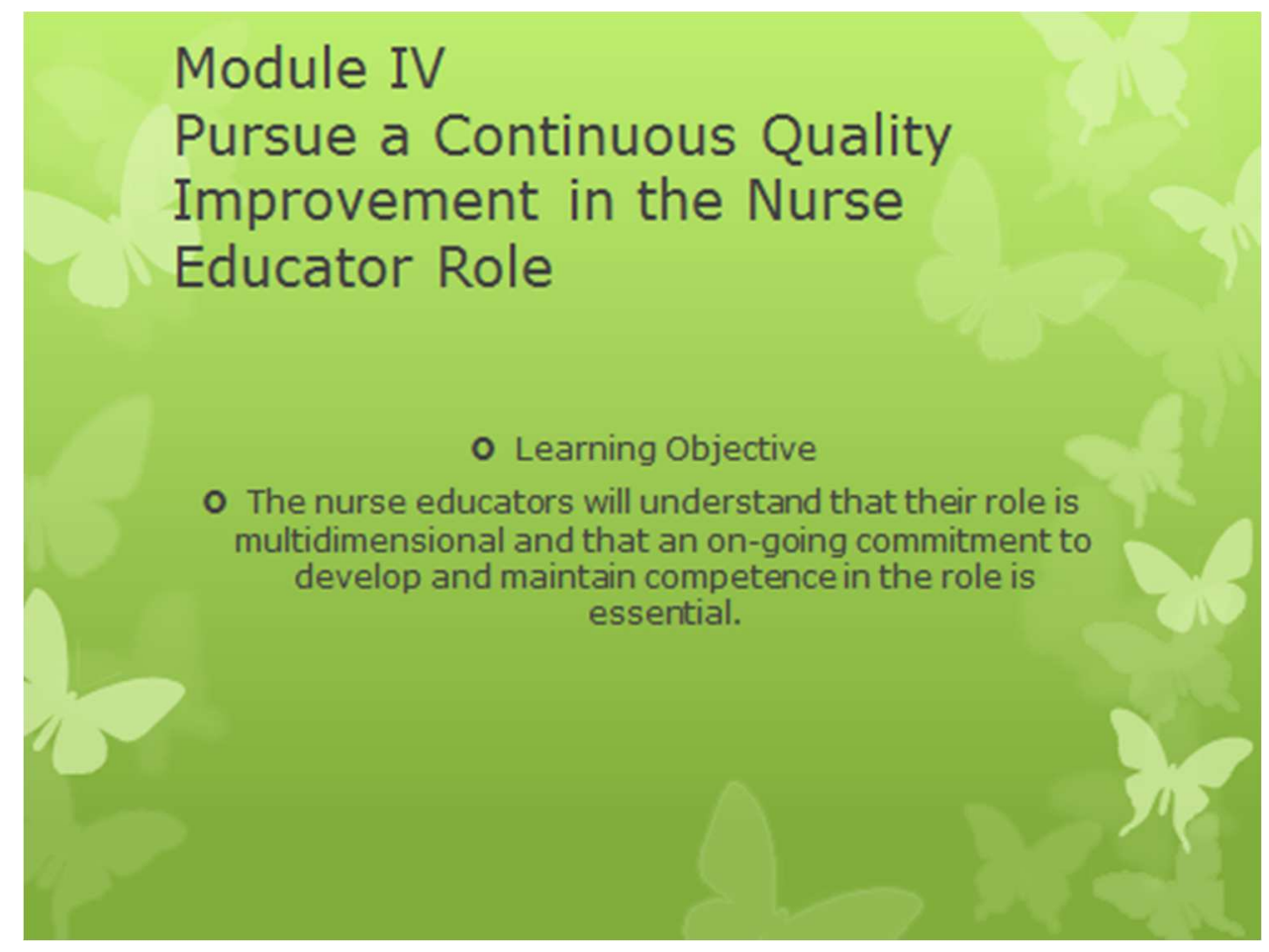

This learning module will discuss the NLN core competency Pursue a Continuous Quality Improvement in the Nurse Educator Role. Please turn up your speakers, as this module is a voice over PowerPoint. Total run time for Module IV is 15 minutes. 


\section{Module IV \\ Pursue Continuous Quality Improvement in the Nurse Educator Role}

- Demonstrates a commitment to life-long learning.

- Recognizes that career enhancement needs and activities change as experience is gained in the role.

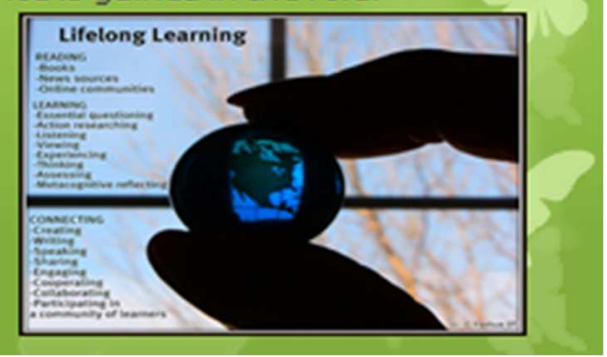

What is life-long learning? This term can be defined by reflecting on one's own practice and thereby determining the learning needs. Academic administrators require all faculty to participate in continuing professional development and to perform with cutting-edge competence in practice, teaching, and research. Professional development workshops, continuing education via the web, publications, and research are all options a nurse educator can choose from to engage in life-long learning.

Nursing is a fast-paced profession that is constantly changing. As a nurse educator, we must engage in life-long learning in order to maintain competency within the nursing profession.

** Reference: Mitchell, J., Clausen, J., Mueller, K., Wiley, N., and Nytes, P. (2008). Commitment to Lifelong Learning within the Nursing Profession as New Graduate Nurses. Retrieved from http:/www.slideserve.com/vitalis/commitment-to-lifelong-learning-within-the-nursing-profession-as-newgraduate-nurses 
Module IV

\section{Module IV}

Pursue Continuous Quality Improvement in the Nurse Educator Role

- Participates in professional development opportunities that increase one's effectiveness in the role.

- Supports and demonstrates the on-going competenœ of nurses who are currently practicing.
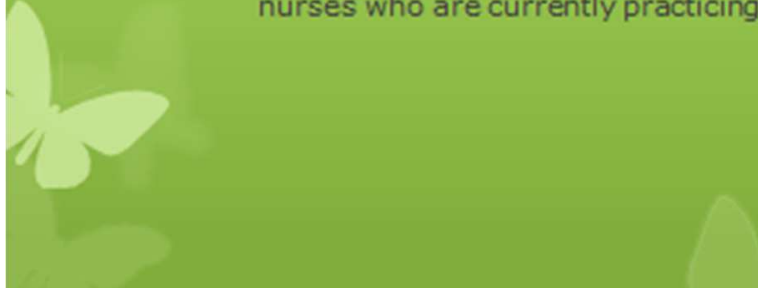

Professional development topics include:

- Teaching skills- It is essential to understand how adults learn and how educators

should facilitate the learning process. Effective instructors challenge adult learners to seek answers, find meaning, and apply new information rather than transmitting content.

- Curriculum/course development skills- This comes from your clinical experience and expertise and is tied to how you teach. It is important to create sound objectives and learning outcomes (the need to know content).

- Evaluation and testing skills- This area can be intimidating to novice faculty.

There are resources to help novice understand the process. However, it is 
important to use a variety of evaluations to determine the competency within the students.

- Personal attributes- Nurse educators must have communication skills. We are expected to work collaboratively with other faculty and interact positively with students. Nurse educators should be approachable, respectful, flexible, and maintain a sense of humor.

** Reference: Penn, B., Wilson., L., \& Rosseter, R. (2008). Transitioning from nursing practice to a teaching role. The Online Journal of Issues in Nursing, (13)3, 1-17. doi: 10.3912/OJIN.vol13No03Man03 


\section{Thank you for your time.}

o You have reached the end of the orientation modules. We hope that you found this information helpful as you begin your new career in nursing education. Please complete the last post-test for Module IV with at least a $75 \%$ pass rate.

- After the post-test, we ask if you could take a moment to evaluate the learning modules via the evaluation form.

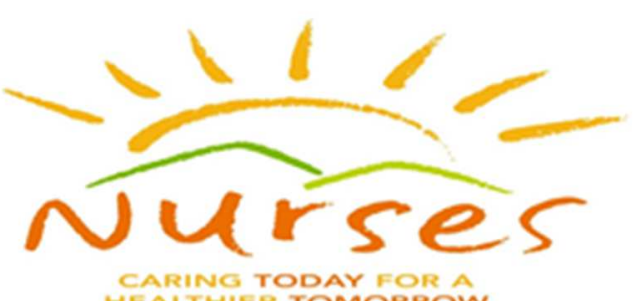

HEALTHIER TOMORROW 
Module IV-Posttest

1. Educators are encouraged to engage in life-long learning.

True or False

2. Life-long learning can be accomplished by:
a. Publications
b. Research
c. Professional development workshops
d. All of the above

3. can be an area of professional development that can be intimidating the novice nurse educators.

Fill in the blank

4. Nurse educators should have effective communication skills because we collaborate closely with other faculty members and students.

True or False 
Module IV - Answer Key

1. True - Academic administrators require all faculty to participate in continuing professional development and to perform with cutting-edge competence in practice, teaching, and research.

2. D. All the above - Professional development workshops, continuing education via the web, publications, and research are all options a nurse educator can choose from to engage in life-long learning.

3. Evaluation and testing skills - This area can be intimidating to novice faculty. There are resources to help novice understand the process. However, it is important to use a variety of evaluations to determine the competency within the students.

4. True - Nurse educators must have communication skills. We are expected to work collaboratively with other faculty and interact positively with students 
Learning Module Evaluation

Please complete this survey after you have completed the four learning modules. This survey will help us to strengthen our program and provide data to demonstrate the effectiveness of the core competency information as they relate to the growth of our nurse educators. Please use the scale below to rate the learning modules.

$$
\begin{aligned}
& \text { SD = Strongly Disagree } \\
& \text { D = Disagree } \\
& \text { A = Agree } \\
& \text { SA = Strongly Agree } \\
& \text { NA = Not Applicable }
\end{aligned}
$$

1. The information I received through the learning modules will enhance my teaching ability.

\section{SD D A SA NA}

2. I will implement this information throughout my teaching career.

\section{SD D A SA NA}

3. Being a novice nurse educator, the learning modules provided a pathway for me into the teaching role.

$$
\text { SD D A SA NA }
$$

4. The information from the learning modules was easy to understand.

SD D A SA NA 
Additional comments:

Date of completion:

Please return this evaluation form into the nursing administration office. Thank you! 
Method A Formative and Summative Evaluation

Novice Educator Competency Survey

As a part of the mentorship program, all novice nurse educators will be asked to rank themselves in the following questions. Please complete this survey prior to the mentorship program so that this program can be tailored to your needs. You will be asked to complete the survey again after the mentorship program is complete. Additional comments are encouraged. Please return this document to the nursing administration office.

1. Developing a syllabus
A. Not Competent
B. Somewhat competent
C. Competent
D. Very competent

Comments:

2. Creating lectures and learning outcomes that are associated to the curriculum
A. Not Competent
B. Somewhat competent
C. Competent
D. Very competent

Comments:

3. Integrating the use of technology into the lecture
A. Not Competent 

B. Somewhat competent
C. Competent
D. Very competent

Comments:

4. Creating appropriate tests and analyzing the scores
A. Not Competent
B. Somewhat competent
C. Competent
D. Very competent

Comments:

5. Verbalizing appropriate methods in handling student situations
A. Not Competent
B. Somewhat competent
C. Competent
D. Very competent

Comments: 
Method B

Formative and Summative Evaluations

These questions will be asked to the nursing faculty who served as mentors.

1. What are your feelings toward novice educator's competency levels?

2. What were some challenges and positive aspects of the mentorship/ orientation program?

3. Do you feel novice nurse educators should be supported by the seasoned faculty during their first year of teaching, why or why not?

These questions will be asked to the novice nurse educators.

1. Describe your competency levels now compared to month one regarding curriculum development, learning objectives, lectures/ planning, and testing procedures.

2. What is your perception related to being involved in a mentorship/orientation program? 
Mentor Evaluation Form

Name of Mentor:

Thank for your participation in the mentoring program. The nursing administration asks all novice nurse educators who have completed the mentorship program, to answer the following statements. This survey will help us to strengthen our program and provide data to demonstrate the effects of mentoring on mentors and mentees. All the individual data from this survey will be kept anonymous. Please use the scale below to rate the faculty that served as your mentor.

$\mathrm{SD}=$ Strongly Disagree

$\mathrm{D}=$ Disagree

$\mathrm{A}=$ Agree

$\mathrm{SA}=$ Strongly Agree

NA $=$ Not Applicable

1. My mentor was accessible to me:

\section{SD D A SA NA}

2. My mentor demonstrated professional integrity:

\section{SD D A SA NA}

3. My mentor demonstrated content expertise in my area of need:

\section{SD D A SA NA}

4. My mentor was approachable:

\section{SD D A SA NA}

5. My mentor was supportive and encouraging:

SD D A SA NA 
6. My mentor provided constructive and useful critiques of my work:

\section{SD D A SA NA}

7. My mentor motivated me to improve my work product:

\section{SD D A SA NA}

8. My mentor was helpful in providing direction and guidance on professional issues (e.g., networking):

\section{SD D A SA NA}

9. My mentor answered my questions satisfactorily (e.g., timely response, clear, comprehensive):

\section{SD D A SA NA}

Additional comments:

Date of completion:

Please return to the nursing administration department. Thank you 
Helpful References for Development and Implementation of Program

Caffarella, R. (2002). Planning programs for adult learners: A practical guide for educators, trainers, and staff developers (2nd ed.). San Francisco, CA: JosseyBass.

Clynes, M., \& Raftery, S. (2008). Feedback: An essential element of student learning in clinical practice. Nurse Education in Practice. Retrieved from http://www.nurseeducationinpractice.com/article/S1471-5953(08)000206/references

Contributor, N. (2012). My nursing role model. Retrieved from http://www.nursetogether.com/my-nursing-role-model

Eddy, P. (2010). New faculty issues: Fitting in and figuring it out. New Directions for Community Colleges, 152, 15-24. doi:10.1002/cc.423

Galbraith, M. (2004). Adult learning methods: A guide for effective instruction ( $3^{\text {rd }}$ ed.). Malabar, FL: Krieger Publishing.

Hadidi, N., Lindquist, R., \& Buckwalter, K. (2013). Lighting the fire with mentoring relationships. Nurse Educator, 38(4), 17-163. doi:10.1097/NNE.0b013e318296dccc

Handwerker, S. (2012). Transforming nursing education: A review of current curricular practices in relation to Benner's last work. International Journal of Nursing Education Scholarship, 9(1), 1-16. doi:10.1515/1548-923X.2510 
Jacobson, S., \& Sherrod, D. (2012). Transformational mentorship models for nurse educators. Nursing Science Quarterly, 25(3), 279-284. doi: $10.1177 / 0894318412447565$

Lai, P., \& Kim, P. (2012). Concept of professional socialization in nursing. International e-Journal of Science, Medicine \& Education, 6(1) 31-35. Retrieved from http://imu.org.my/ejournal/approved/7.Research_Lai_p31-35.pdf

Mitchell, J., Clausen, J., Mueller, K., Wiley, N., \& Nytes, P. (2008). Commitment to lifelong learning within the nursing profession as new graduate nurses. Retrieved from http://www.slideserve.com/vitalis/commitment-to-lifelong-learning-withinthe-nursing-profession-as-new-graduate-nurses

National League for Nursing. (2012). The scope of practice for academic nurse educators. New York, NY: National League for Nursing.

Penn, B., Wilson., L., \& Rosseter, R. (2008). Transitioning from nursing practice to a teaching role. Online Journal of Issues in Nursing, 13(3), 1-17. doi: 10.3912/OJIN.vol13No03Man03

The University of New Mexico College of Nursing. (n.d.). Teaching and learning strategies. Retrieved from http://nursing.unm.edu/resources/teaching-andlearning-strategies.html

Schoening, A. (2013). From bedside to classroom: The nurse educator transition model. Nursing Education Perspectives, 34(3), 167-172. http://dx.doi.org/10.5480/1536$5026-34.3 .167$ 
Suplee, P. \& Gardner, M. (2009). Fostering a smooth transition to the faculty role.

Journal of Continuing Education in Nursing, 40(11), 514-520.

doi:10.3928/00220124-20091023-09 


\section{Appendix B: Informed Consent Form}

Title of study: Challenges of a Novice Nurse Educator's Transition from Practice to Classroom

Researcher: Tori Brown, MSN, RN

Institute: Walden University: Higher Education and Adult Learning Program

\section{Purpose of this research study:}

I am Tori Brown, a doctoral candidate from Walden University. I am conducting research on novice nurse educators. I want to understand their perceptions and thoughts in regards to transitioning from bedside nursing into academia. Since you meet the criteria for a novice nurse educator, I would like to invite you to join this research study.

\section{Procedures}

If you agree to participate, we will set up a mutually convenient time and place to meet for the interview. I will ask a set of interview questions about your experiences as a nurse educator, resources that you used, and what motivated you to become a nurse educator. I will also ask you to complete a demographic form with such information as age and educational experience. The interview will last approximately 30-60 minutes and will take place in a private room on the campus of Guilford Technical Community College. I will audio-record the interview for accuracy of the data gathered. A general summary of the interview will be sent to you at a later time for review. At that time, I would like your opinion of my initial findings and interpretations. This process is called member checking.

\section{Possible risks or benefits}

Participation in this study involves no foreseeable risks. . Your decision whether or not to participate is confidential and will not affect your current or future relationship with the school of nursing. There is no direct benefit to you. However, the results of the study may help me to formulate interventions that could help ease the transition process of nurse educators as they transition from the clinical area into academia.

\section{Right of refusal to participate and withdrawal}

You are free to choose to participate in the study. You also have the right to withdraw your participation at any time without any penalty. You may also refuse to answer some or all the questions if you don't feel comfortable with those questions.

Payment: No payment will be provided for participation in this study.

\section{Confidentiality}

The information provided by you will remain confidential. Nobody except the principal investigator will have access to it. A code number will be associated with your data so that no personally identifiable data will be on the audio-recording or transcript. Data will be maintained in a secure password-protected computer at the researcher's home. Your name and identity will also not be disclosed at any time. However, the data may be seen by the University Research Committee and may be published without giving your name or disclosing your identity.

\section{Available Sources of Information}


If you have any further questions you may contact Tori Brown, Walden University at on following phone number . In addition, you may contact a Walden University representative if questions arise about your right as a participant at (612) 3121210. Walden University's approval number for this study is 08-20-14-0285351 and it expires on August 19, 2015.

\section{AUTHORIZATION}

I have read and understand this consent form, and by signing this letter of consent, I signify my participation in this research study. I understand that I will receive a copy of this form. I voluntarily choose to participate, but I understand I can withdraw from this study at any time.

Participant's Name (Printed):

Date:

Participant's Signature:

Date:

Researcher's Signature:

Date: 
Appendix C: Demographic Sheet for Participants

Age:

Gender:

Nursing background:

a. Number of years as an RN:

b. Areas employed as an RN/length of time spent in each area (e.g. hospital, community agency, etc.):

c. What population of nursing did you provide care for (pediatrics, adult medical -surgical, intensive care, oncology, cardiology, etc.) and length of time:

Education background:

a. Highest level of education/type of degree: -

b. Year you received your

degree:

Teaching background:

a. Have you had prior teaching experiences (full or part time) before your employment at this nursing program, if so, what was the length of time: 
b. Year you first began teaching nursing students:

Perceived career level in Benner's framework as nurse clinician:

Novice; Advanced beginner; Competent; Proficient; Expert

Perceived career level in Benner's framework as nurse educator:

Novice; Advanced beginner; Competent; Proficient; Expert 
Appendix D: Permission Letter to Gain Access to Participants

To:

As you are aware, I am pursuing a Doctor of Education degree from Walden University. As a partial fulfillment of my requirements, I must complete a doctoral project study entitled "Challenges of a Novice Nurse Educator's Transition from Practice to Classroom." My research is a qualitative research design, in which my participants will be asked to participate in a confidential individual based interview session with myself. In recent conversations, I have expressed my interest in completing my research project within the nursing program at . I am writing this letter to request permission and assistance in gaining access to the 2012 Self-Study and employee database in which I can select potential participants based upon the inclusion criteria that have been established.

After reviewing the database, the selected individuals will be sent a letter of invitation asking for their participation. An informed consent and Interview Protocol will also be sent to provide information about the nature of the study, methodology/design, participation role/expectations, risks and benefits of participants, how the results will be used, privacy of the participants, and participants' rights during the duration of the study. When interviews are conducted, I am asking for administration to assist me in locating a small private room that can be locked from inside the room.

I appreciate your time and efforts in assisting me to satisfy the requirements for my degree. I look forward to hearing back from you.

Sincerely,

Tori Brown, MSN, RN 


\section{Appendix E: Self-Study Information}

1. Number of Full Time Novice Educators:

2. Number of Part Time Novice Educators:

3. Number of Full Time Seasoned Educators:

4. Number of Part Time Seasoned Educators:

5. Nursing background of Novice Educators:

a. Number of years as an RN:
a. 0-5 years
b. 6-10 years
c. 11-15 years
d. Over 16 years

6. Nursing background of Seasoned Educators:

a. Number of years as an $\mathrm{RN}$ :
a. 0-5 years
b. 6-10 years
c. 11-15 years
d. Over 16 years

7. Education background of Novice Educators:
a. BSN
b. MSN
c. Doctorate 
8. Education background of Seasoned Educators:
a. BSN
b. MSN
c. Doctorate

Description of the composite information related to novice faculty 
Appendix F: Invitation Letter

My name is Tori Brown. Nursing is my background; however, I am pursing a Doctor of Education degree from Walden University. As a partial fulfillment of my requirements, I must complete a doctoral project study. This letter is an invitation to participate in my study entitled "Understanding the Challenges of a Novice Nurse Educator's Transition from Practice to Classroom."

The purpose of this study is to explore the thoughts, perceptions, and feelings of novice nurse educator and their transition into academia. Nurse educators are an essential factor in educating the future healthcare providers. Although these nurses are considered expert nurse clinicians, obtaining a new role as an educator can make them a novice.

My study is considered a qualitative case study. This means that the participants will be asked to engage in an interview session for an hour or less. Questions are based around the perceptions of being a novice nurse educator. The only criteria to be involved in this research project are:

- $\quad$ Novice nurse educator with less than three years of teaching experience

- $\quad$ Nurse educators teaching a variety of courses both in academic and clinical settings

Your participation is voluntary and your consent may be withdrawn at any time. No payment or compensation will be provided for this study. The results of this study may be presented in reports, presentations, or publications; however, your identity will not be disclosed for any reason. There are no foreseeable risks involved in this study. The benefit of this study is to identify effective strategies that may assist in the transition process of novice nurse educators from clinical practice to academia.

Thank you for your time in reviewing this invitation letter. I have also attached the Informed Consent and Interview Protocol for your review. If you are interested in participating in this study or have additional questions or concerns, please email me at this secured email address:

Sincerely,

Tori Brown, MSN, RN

Walden University Doctoral Student (EdD) 
Appendix G: Interview Protocol

1. I'm interested in what motivated you to want to teach. Think back on a specific instance in which you thought, "I would really like to teach in a nursing program." Tell me about the incident with as much detail as you can? (RQ 1)

2. Think back on the challenges you have faced in transitioning from clinical practice to teaching. I'd like you to tell me about an incident that stands out in your mind when you wondered whether you had made the right decision to move into teaching instead of clinical practice. Have you had any experiences like that? (RQ 2)

3. Now I'd like you to tell me about an experience during your transition to teaching that stands out as a really special, positive experience. (RQ 3)

4. What types of support or guidance were especially important to you in transitioning to a teaching role? (RQ 4) (Probing question if necessary)What resources did you use to help you transition into academia?

(Probing question if necessary) Upon entering into academia, do you feel you were properly educated? Why or why not? 
Appendix H: Interview Analysis

1. How do novice educators describe their motives in wanting to become a nurse educator?

\begin{tabular}{|c|c|c|c|}
\hline Quote & Location & Category & Tentative Theme \\
\hline $\begin{array}{l}\text { It is that teaching mentoring that I love } \\
\text { so...I'm pretty faith driven and I felt } \\
\text { and perhaps this is where I should be } \\
\text { and that I was going back to my roots } \\
\text { and I was going back to what I loved -- } \\
\text { I'd be teaching again and the other } \\
\text { would get me out of management and } \\
\text { maybe this is what I was supposed to } \\
\text { do, so I kind of came back to what I } \\
\text { originally thought I wanted to do back } \\
\text { in the } 90 \mathrm{~s} . .\end{array}$ & 3, p. 2 & Giving back & $\begin{array}{l}\text { Wanting to give } \\
\text { back by helping } \\
\text { others }\end{array}$ \\
\hline $\begin{array}{l}\text { At the end of that year (local research } \\
\text { setting) invited me to be a full-time } \\
\text { faculty member I love the students and I } \\
\text { really realized it I loved clinical and I } \\
\text { loved the students so I actually went } \\
\text { through the process of interview and } \\
\text { was offered the position; however the } \\
\text { pay was about a } \$ 15,000 \text { pay cut and I } \\
\text { could not afford to take the position.... I } \\
\text { loved clinical so I decided I would stay } \\
\text { in the clinical arena. }\end{array}$ & 3, p. 1 & Giving back & $\begin{array}{l}\text { Wanting to give } \\
\text { back by helping } \\
\text { others }\end{array}$ \\
\hline
\end{tabular}


2. What are novice nurse educators' perceptions of challenges they faced in transition from clinician to nurse educator?

\begin{tabular}{|c|c|c|c|}
\hline Quote & Location & Category & Tentative Theme \\
\hline $\begin{array}{l}\text { As far as a challenge, I think it's always challenging in } \\
\text { a generic way, this is broad, to be new because you } \\
\text { don't, you're not, you don't have that that kind of } \\
\text { background with the people you are working with, so } \\
\text { that's challenging because everybody else knows you }\end{array}$ & 3, p. 3 & $\begin{array}{l}\text { Feeling } \\
\text { unprepare } \\
\text { d }\end{array}$ & $\begin{array}{l}\text { New kid on the } \\
\text { block }\end{array}$ \\
\hline $\begin{array}{l}\text { I was in a my first experience here in the } 213 \text { course to } \\
\text { be honest and some people here are aware of it, I was } \\
\text { left out on a lot of the decisions, a lot of the } \\
\text { communication and to be honest it was on purpose, and } \\
\text { it was not very pleasant. }\end{array}$ & 3, p. 3 & Left out & $\begin{array}{l}\text { New kid on the } \\
\text { block }\end{array}$ \\
\hline $\begin{array}{l}\text { I think there was some on purpose lack of inclusion.... } \\
\text { So I really had to learn on my own that first semester I } \\
\text { really didn't get much assistance.... I just said okay be } \\
\text { quiet and figure out on your own. So I've did a lot of } \\
\text { figuring it out on my own }\end{array}$ & 3, p. 4 & Left out & $\begin{array}{l}\text { New kid on the } \\
\text { block }\end{array}$ \\
\hline $\begin{array}{l}\text { it was kind of like a bullying, to be honest eat your } \\
\text { young, I mean I can tell you some examples it was not } \\
\text { pretty }\end{array}$ & 3, p. 4 & $\begin{array}{l}\text { Eat your } \\
\text { young }\end{array}$ & $\begin{array}{l}\text { New kid on the } \\
\text { block }\end{array}$ \\
\hline $\begin{array}{l}\text { As far as teaching in the classroom....I didn't..... I was } \\
\text { not really taught, I was given some things and said here } \\
\text { look at this and here's the textbooks you can read } \\
\text { them....but I wasn't taught, taught things about how } \\
\text { things went together so really kind of taught myself } \\
\text { those things }\end{array}$ & 3, p. 7 & $\begin{array}{l}\text { The } \\
\text { unknown }\end{array}$ & $\begin{array}{l}\text { Teaching } \\
\text { adjustments }\end{array}$ \\
\hline $\begin{array}{l}\text { I was presenting in the dark and the lead teacher came } \\
\text { to me and said you presented things that were not in } \\
\text { their curriculum. Well I had the concepts but I do not } \\
\text { have access to anything but a textbook.... which I'd } \\
\text { have to read all those pages so that was very very } \\
\text { difficult. }\end{array}$ & 3, p. 7 & $\begin{array}{l}\text { Teaching } \\
\text { in the dark }\end{array}$ & $\begin{array}{l}\text { More Structure/ } \\
\text { Teaching } \\
\text { adjustments }\end{array}$ \\
\hline I spent a lot of time grading (whispering) papers & 3, p. 7 & $\begin{array}{l}\text { Time } \\
\text { investment }\end{array}$ & $\begin{array}{l}\text { Work is always } \\
\text { with you }\end{array}$ \\
\hline $\begin{array}{l}\text { what needs to be in place in a pathway, that when } \\
\text { someone new comes you have an organization... as to } \\
\text { how to train them, and you say okay they need to know } \\
\text { this this and this and this is how we are going to } \\
\text { structure }\end{array}$ & 3, p. 10 & $\begin{array}{l}\text { Being } \\
\text { prepared }\end{array}$ & More mentoring \\
\hline
\end{tabular}


3. How do novice nurse educators describe positive experiences that they encountered in their first year of teaching?

\begin{tabular}{|c|c|c|c|}
\hline Quote & Location & Category & Tentative Theme \\
\hline $\begin{array}{l}\text { So, I was the new kid, I was the one in their senior } \\
\text { class who they had never met, I came at the end of } \\
\text { October and they met me in January for the first time. } \\
\text { The senior group, the } 59 \text { students chose me to be the } \\
\text { person to pin them so I think that stunned the group, } \\
\text { but I think it was....it stunned me....because I felt that } \\
\text { we had a good relationship and I could see that I was } \\
\text { reaching them they were coming to me with issues, and } \\
\text { I felt that I was making a difference }\end{array}$ & 3, p. 5 & $\begin{array}{l}\text { Precious } \\
\text { moments }\end{array}$ & Making a difference \\
\hline $\begin{array}{l}\text { I relate to students very well because I relate to nurses } \\
\text { very well. So quickly I had a rapport with the students. }\end{array}$ & 3, p. 5 & $\begin{array}{l}\text { Building } \\
\text { relations } \\
\text { hips }\end{array}$ & Making a difference \\
\hline
\end{tabular}

4. What are novice nurse educators' perceptions of support offered by the nursing department in their first year of teaching that helped them overcome challenges in the transition process?

\begin{tabular}{|l|l|l|l|}
\hline Quote & Location & Category & Tentative Theme \\
\hline $\begin{array}{l}\text { one of the teachers (name) and said you need a mentor } \\
\text { because I was basically just figuring it out on my own } \\
\text { and she started helping me figure out what was } \\
\text { happening because I didn't know anything. }\end{array}$ & $3, \mathrm{p} .4$ & Support & Just figure it out \\
\hline $\begin{array}{l}\text { So basically this person told me I'll help you figure } \\
\text { out, what's going on, and I'll show you this, and we'll } \\
\text { get you that, we'll make sure you know what you're } \\
\text { doing. }\end{array}$ & 3, p. 5 & Support & A shoulder to lean on \\
\hline $\begin{array}{l}\text { we kind of synergized where I can help her little bit, } \\
\text { but she mainly 90\% helped me.... and just...I think it } \\
\text { was just general logistics and understanding how things } \\
\text { worked }\end{array}$ & 3, p. 6 & Support & A shoulder to lean on \\
\hline
\end{tabular}




\section{Appendix I: Research Site IRB Approval}

Date: $\quad 8 / 13 / 2014$

IRB File NUM: $\quad 2014-02$

Title: Challenges of a Novice Nurse Educator's Transition from Practice to Classroom Principal Investigator: Tori Brown

Institution/

Department: Walden University: Higher Education and Adult Learning Program

Insurance Coverage: In Place $\mathrm{X}$ Not necessary

Action Taken:

Exempt from Full Review

$\mathrm{X}$ Expedited Review

Full IRB Review

Modifications and Comments:

No modifications necessary.

\section{Disposition of Application:}

$$
\begin{array}{r}
\mathrm{X} \text { Approved } \\
\hline \text { Disapproved }
\end{array}
$$

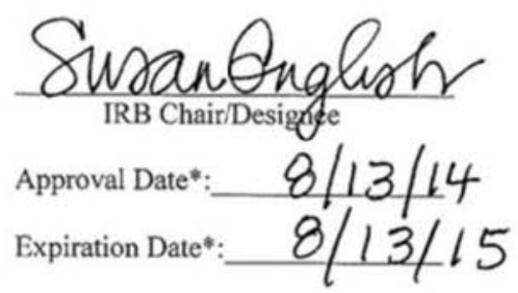

*Approval of Research is for up to ONE year only. If your research extends beyond one year, the project must be reviewed before the expiration date prior to continuation. 
Appendix J: National Institute of Health Certificate of Completion

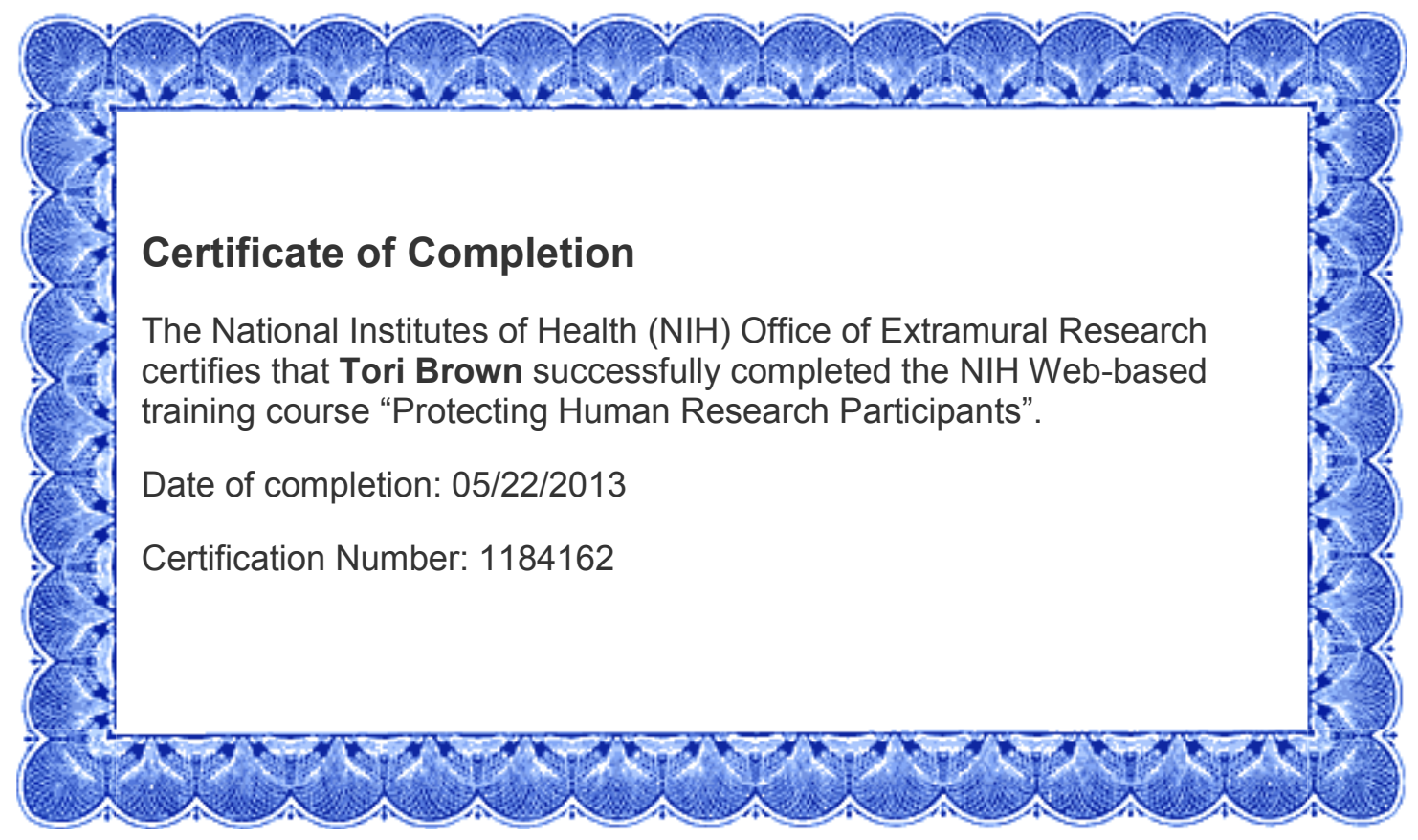

